\title{
The Poiesis of
}

Systems

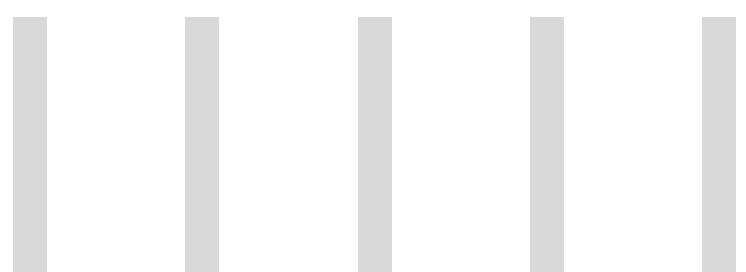

A 120-point thesis

By Jessica Janine Smith

A thesis

submitted to the Victoria University of Wellington in fulfilment of the requirements for the degree of Master of Landscape Architecture

Victoria University of Wellington

2017 


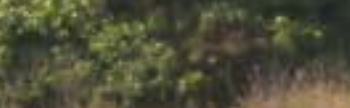

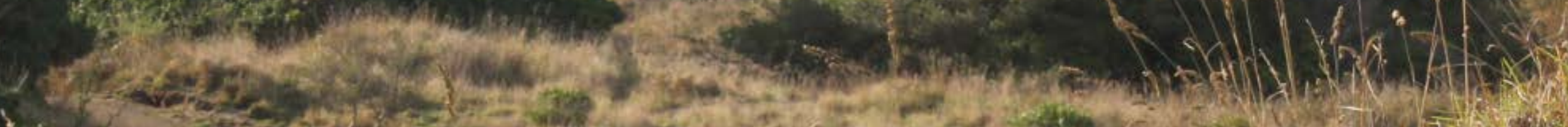
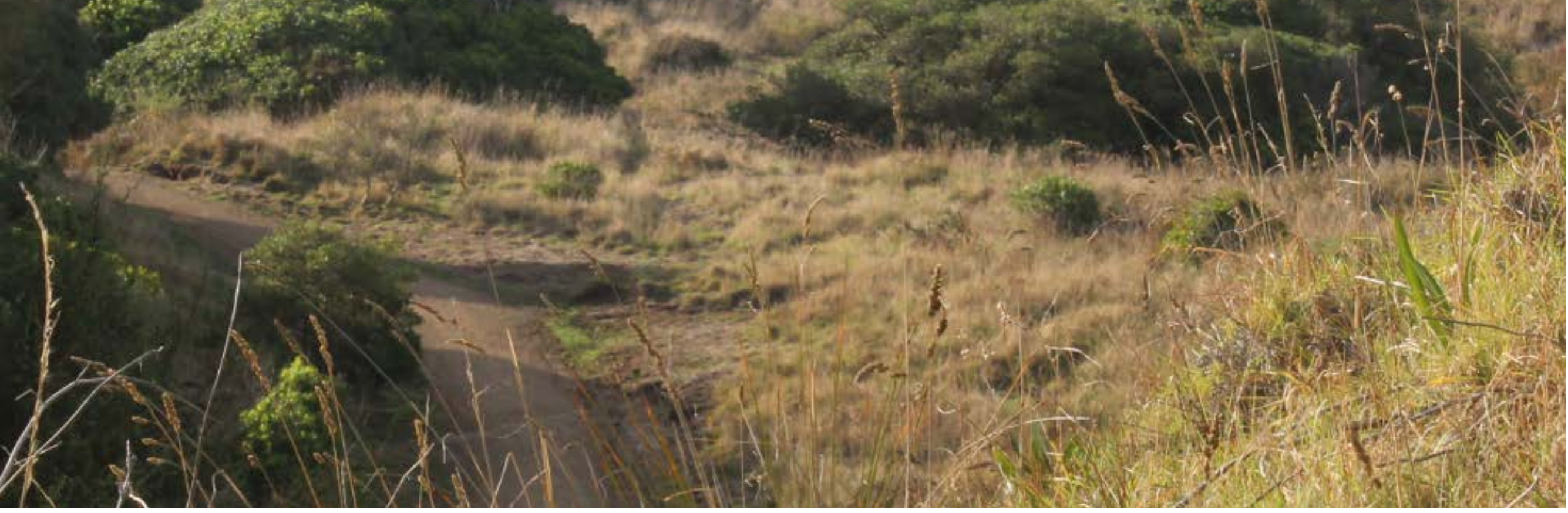
“Whatungarongaro te tāngata toitū te whenua

As man disappears from sight, the land remains"

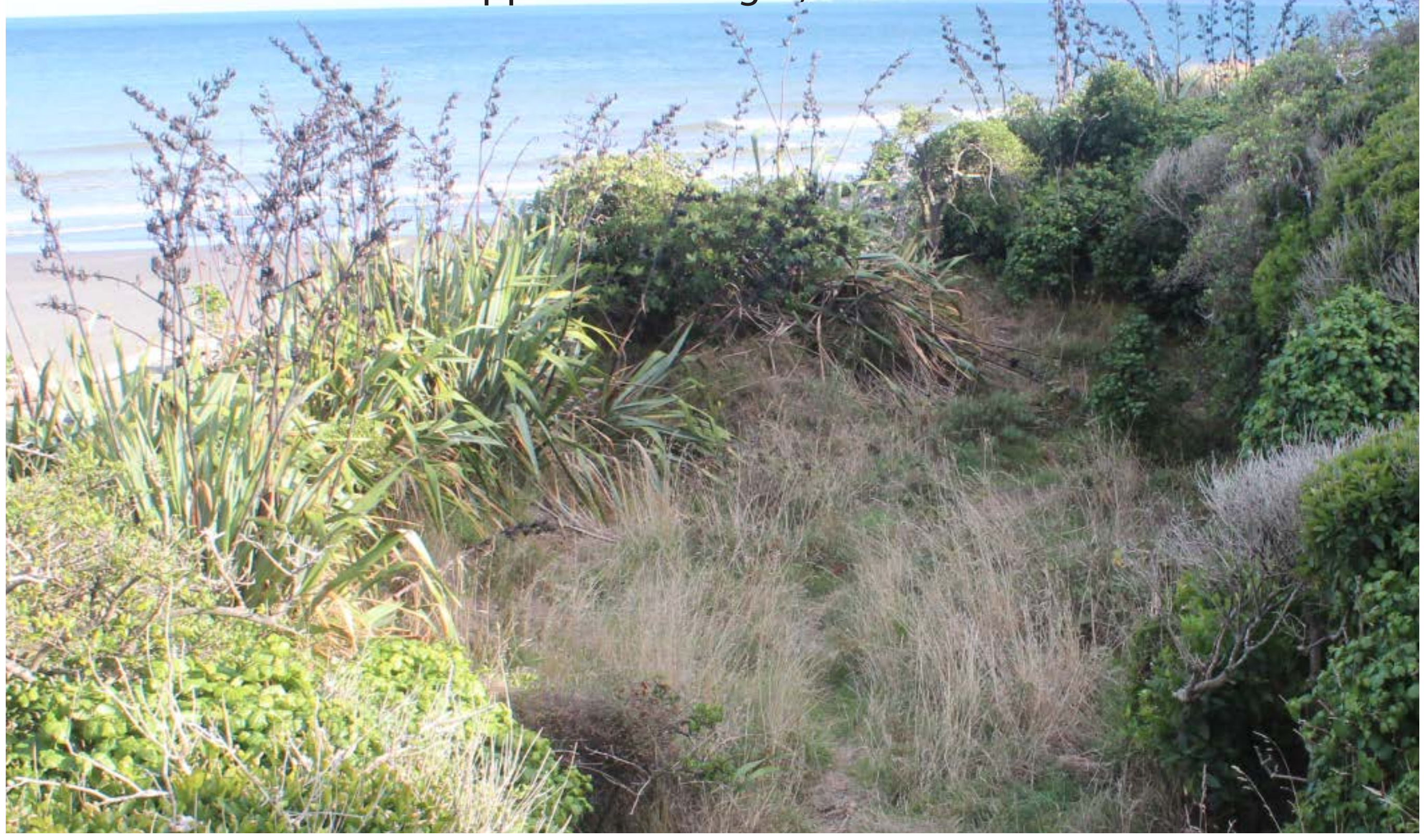





\section{Acknowledgements}

My time at university has been a thunderstorm of knowledge, friendship and self-discovery

Thank you to my mentors; Penny Allan, Martin Bryant and the landscape architecture faculty for helping me discover what I am capable of

Thank you to my friends and family for being by my side

And a special thanks to Alexander for indulging me in armchair philosophy and cafe drawing sessions for the past 5 years 



\section{Abstract}

This thesis looks at how to engage with the existing 'poiesis' of the Kapiti region north of Wellington, to reveal the large scale ecological systems operating in this coastal landscape, making them legible at the human scale. The research has also developed into an exploration of how sites should produce their own boundaries, and how simplistic structures can bring together the large-scale systems down to an engaging human scale.

Kapiti is a region undergoing fast development and change. Since the days of early European settlement the natural processes once found in there have been altered or depleted to allow for human infrastructure. This has left it with degraded dune and wetland ecosystems. Through the lens of different 'Acts / Catalysts' this research uses a variety of design approaches to privilege the human perspective of experiencing space. The design outcome of this research is a series of wooden catalyst structures arranged along a transect starting in Kapiti Island and ending at the foot of the Tararua Ranges. 



\section{Contents}

ACKNOWLEDGMENTS

ABSTRACT

1 INTRODUCTION

- The Problem

- Aims and Objectives

- Site Analysis

-Initial Hunch

-Question

-Methodology

2 THEORETICAL CONTEXT

- Kapiti Coast Coastal Hazards

- Wetland Types in New Zealand

- Sand Engine

- Fog Catchers

- Drawing and Making in the Landscape Medium

- Notation

- Expression
3 THEMES

- What is Poiesis

- How can Reading the Landscape be Generative

52

- How to Negotiate a Site

4 PRELIMINARY DESIGN

- Design Reflection

70

5 FINAL DESIGN : Poles to Build and Connect Ecosystems 77

- Birds

- Sand

- Wetland

98

6 DISCUSSION 103

36

- The Notion of Site

105

38

40

- Reading the Landscape

106

- Design Techniques

107

- Further Research

108

7 CONCLUSION

111

REFERENCES AND INDEX 


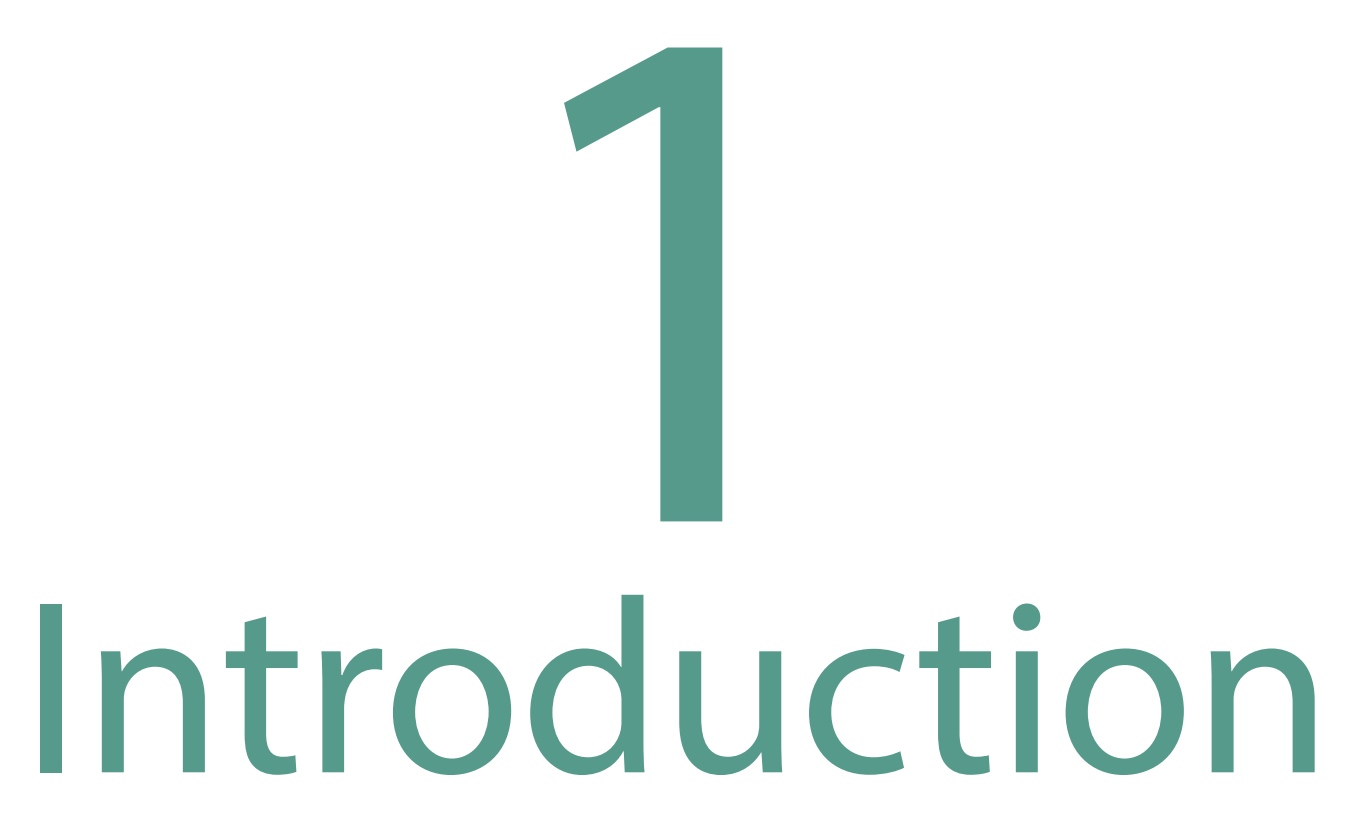




\section{The Problem}

Initially I set out to find a problem to solve in Kapiti. As the research developed the design became more about opportunity, and how small interventions could open up new ways to experience the landscape.

Kapiti Coast was once home to sprawling dunes and swampy wetlands, but the turn of the last century saw the area transform into pasture and urbanised, depleting the dunes and in-filling the wetlands. Currently work is underway for Transmission Gully, a new highway that cuts through Kapiti. The space between the Tararua Ranges, Transmission gully, and Kapiti Island has the potential to become parkland that privileges growing ecologies and intensifies people's ability to read the landscape.

On this premise this thesis will address the faltering ecological systems of Kapiti by reading the landscape in a way that can be generative in design as well as in producing stronger ecosystems. 


\section{A Way In}

The word 'Poiesis' is an ancient Greek verb meaning 'to make'. The idea of describing design interventions in the landscape as an action strongly resonated with me. Poiesis became a word which opened up new ideas and ways of thinking about how we intervene or treat landscape ecological processes. Instead of placing something static in the landscape such as a sea wall to prevent erosion, Poiesis has allowed me to explore interventions that evolve and change with the landscape and its natural systems. I came across the word Poiesis while exploring ways to meaningfully combine the restoration of ecological systems along the Kapiti Coast, and trying to reveal the existing narratives and timeline of the land. I first encountered this word in an essay by James Corner titled Drawing and Making in the Landscape Medium, which I discuss in detail in Chapter 2. Chapter 2 and 3 of this thesis go into more detail of what this word means and how it can be used as a tool for designing within the realm of landscape architecture. 


\section{Aims and Objectives}

Aims

- Engage with drawing and design techniques to reveal the large scale systems operating in coastal landscapes so they are legible at the human scale.
Objectives

-Explore expressions of of large scale coastal landscapes, e.g. Tidal currents and sand entering the dune system

-Develop interventions in the landscape which will over time show the processes operating while allowing people a participative role in activating this growth, i.e Designs that not only engage with the larger scale systems, but also tell their story

-Reflect on how a landscape can be designed and understood through poetic interventions and how to develop a deeper understanding of the story the systems are trying to tell 


\section{What is this \\ design for?}

This thesis has developed into an exploration of how sites should produce their own boundaries, and how simplistic structures can bring together the large-scale systems down to an engaging human scale.

This design for Kapiti is about revealing the ecological systems that once made-up the regions natural environment pre-settlement. Once the ecological systems (shifting sand dunes and wetlands) have been identified this design research experiments with ways to intercept and recharge these systems allowing them to re-emerge in a way which responds to the surrounding community and landscape on an environmental level and an intimate human level.

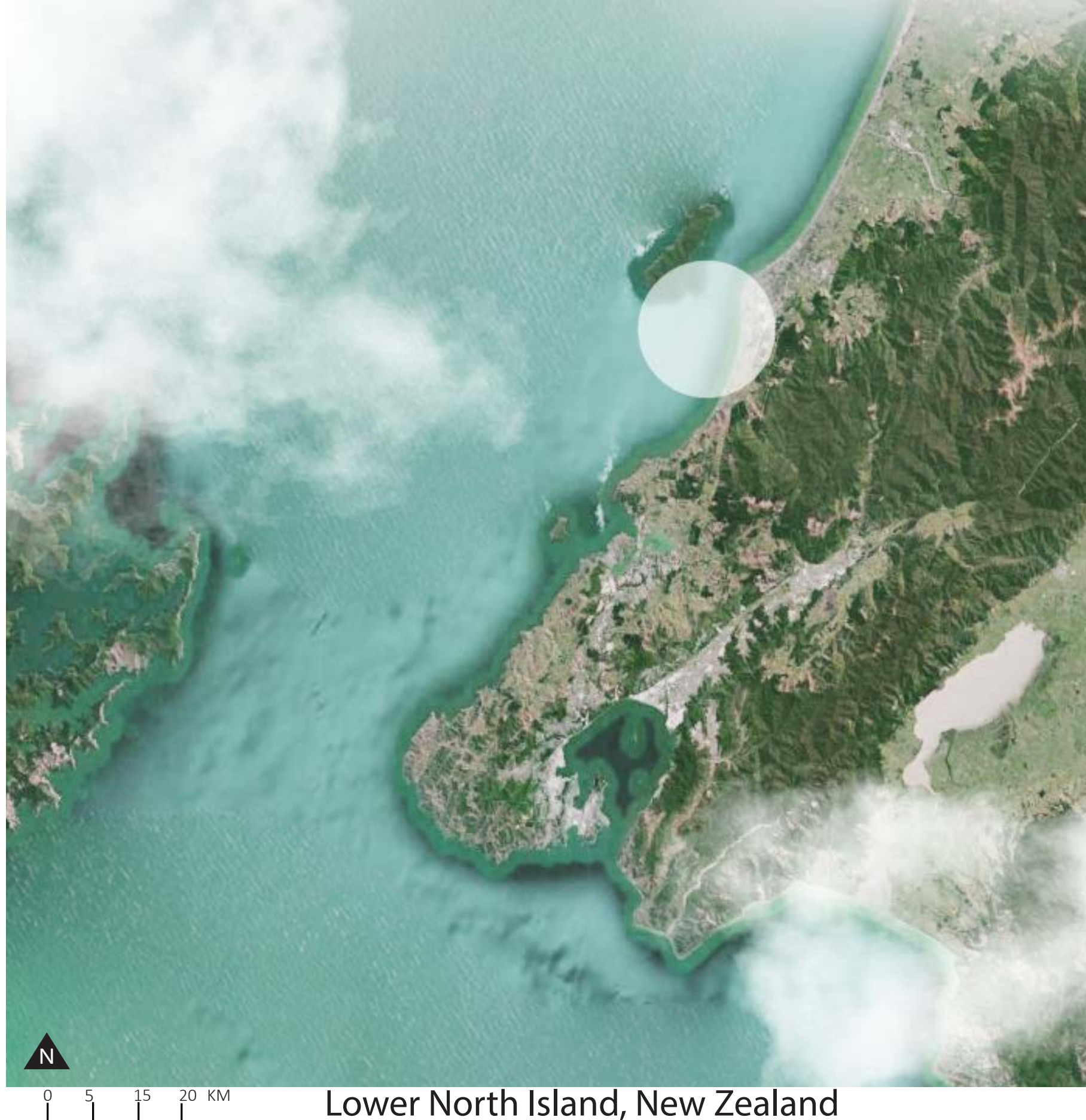

16 



\section{Removal of Kapiti ecosystems}

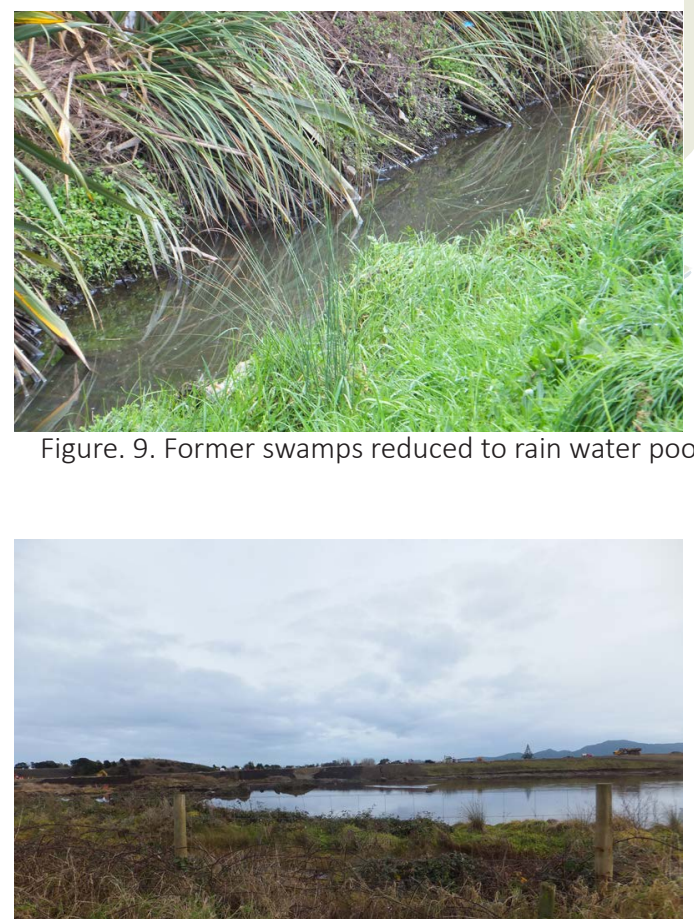

Figure. 10. Site of Transmission Gully Earthworks, water table is high so pooling happens when the earth surface is moved

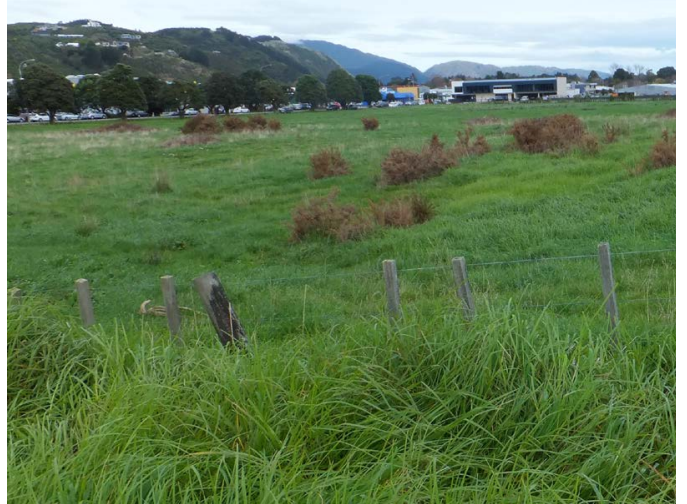

Figure. 11. This former swamp was allegedly once deep enough to navigate a waka through

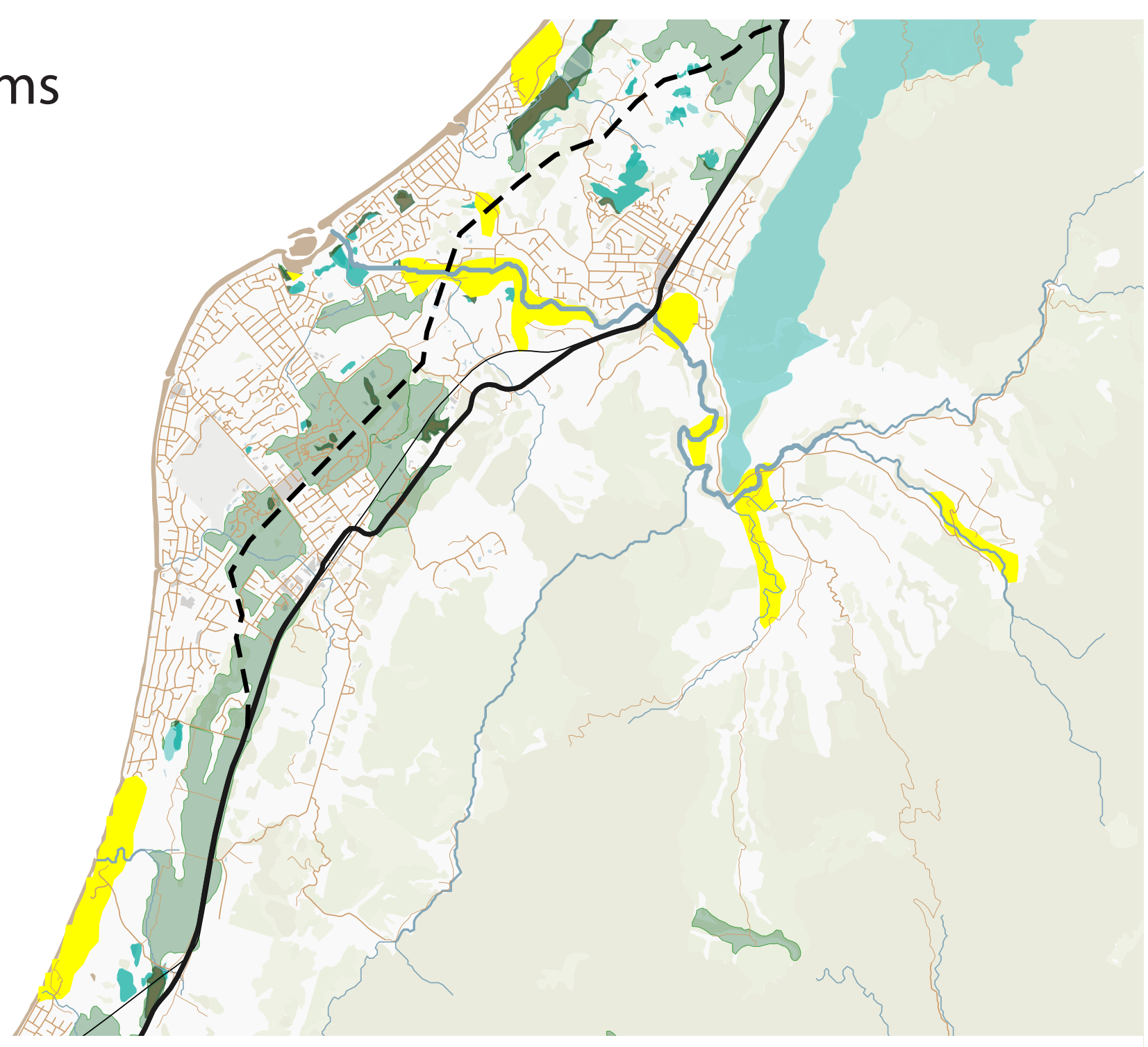

Scale: $1: 100,000$

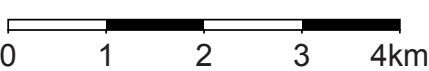

Legend:

Post-Settlement wetlands

Pre-Settlement wetlands

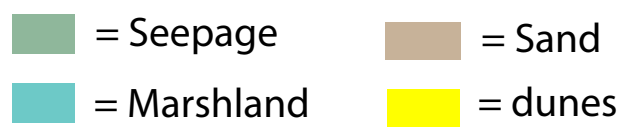




\section{Kapiti Tendencies}

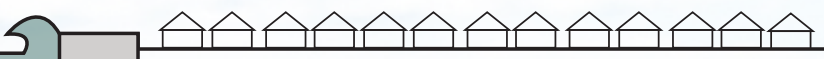

Figure. 14. Section diagram of the current land use of Kapiti

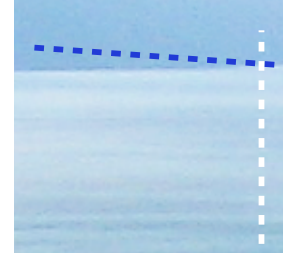

Kapiti Island

\section{Design theory}




\section{Coastlands}
Raumati
Queen Elizabeth Park
Pastural Land (former migrating dunes)
dunes

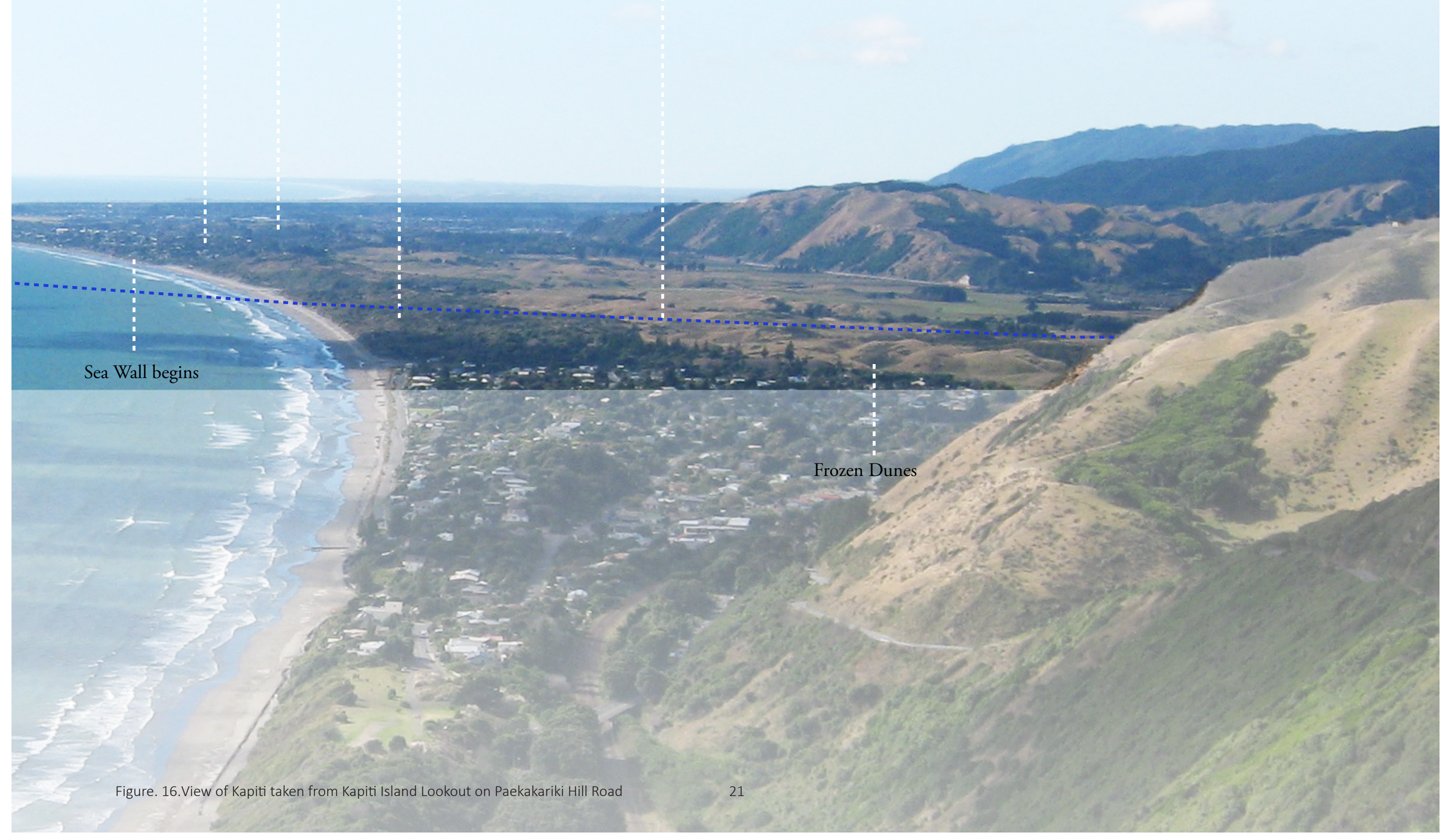




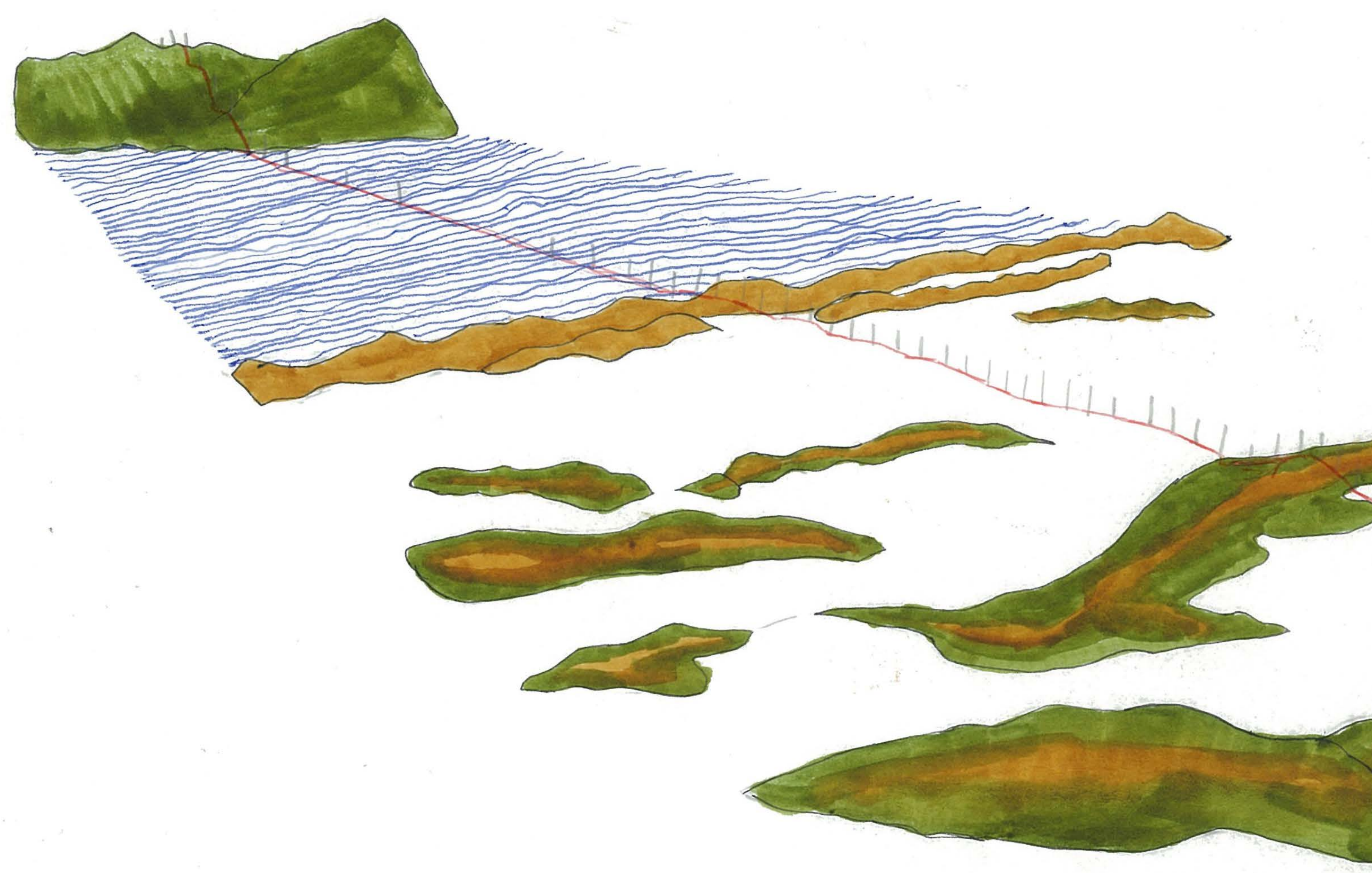

Figure. 17.Site transect that crosses over dunes, wetlands, hills, suburbs, ocean and sand from 22 Kapiti Island to the mainland 


\section{The Preferred Site}

The research addresses the site as a transect, cutting through all the ecosystems (including suburbia) from Kapiti Island to the mountains. This decision has helped to restrict the scope.

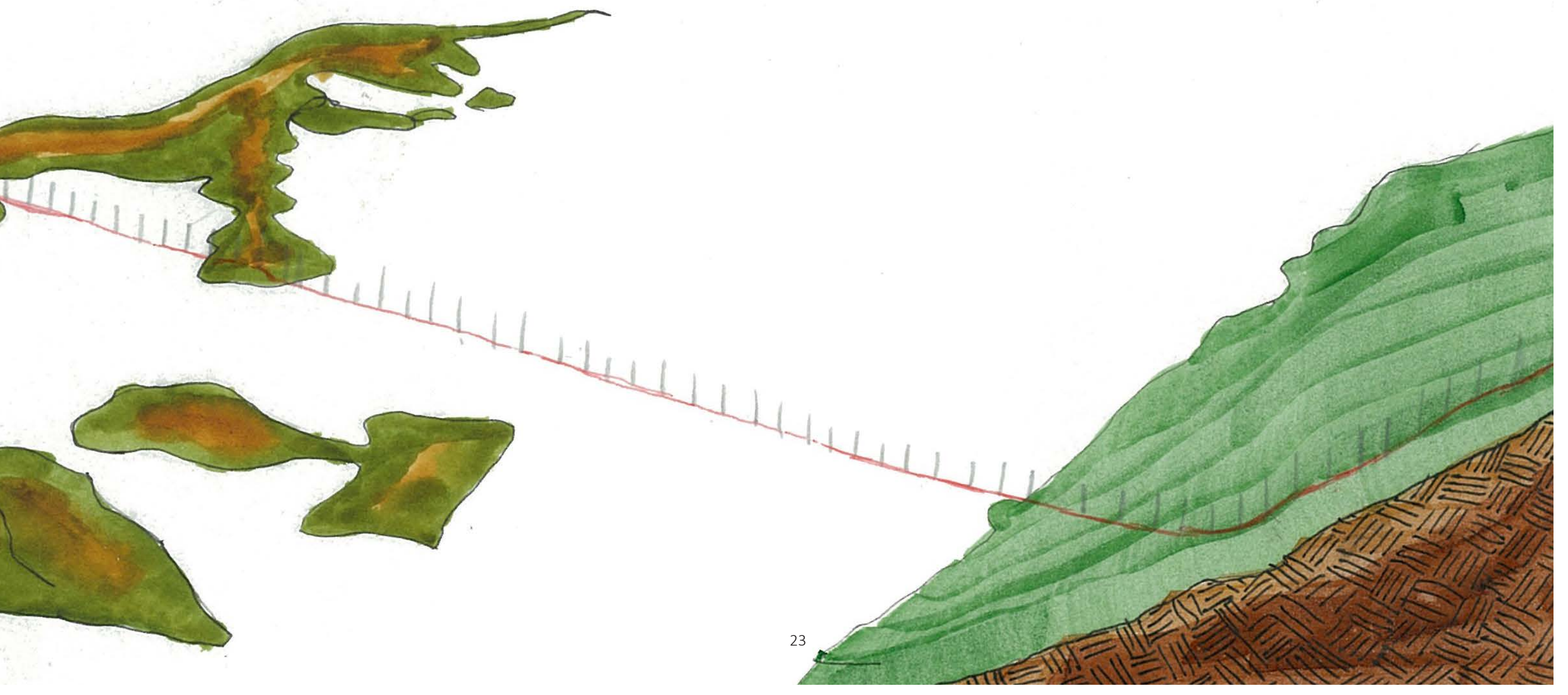




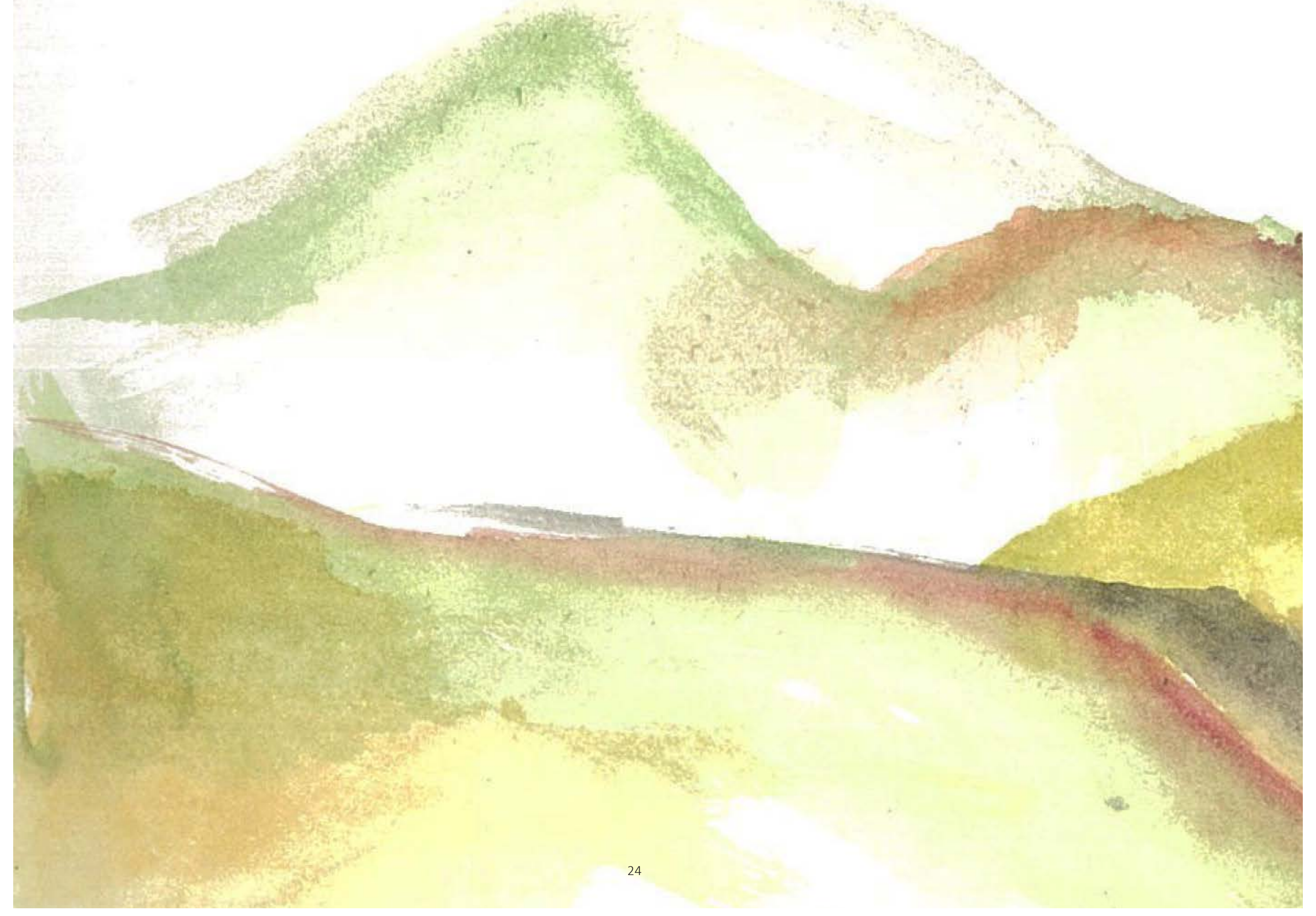




\section{Initial Hunch and Design Ideas}

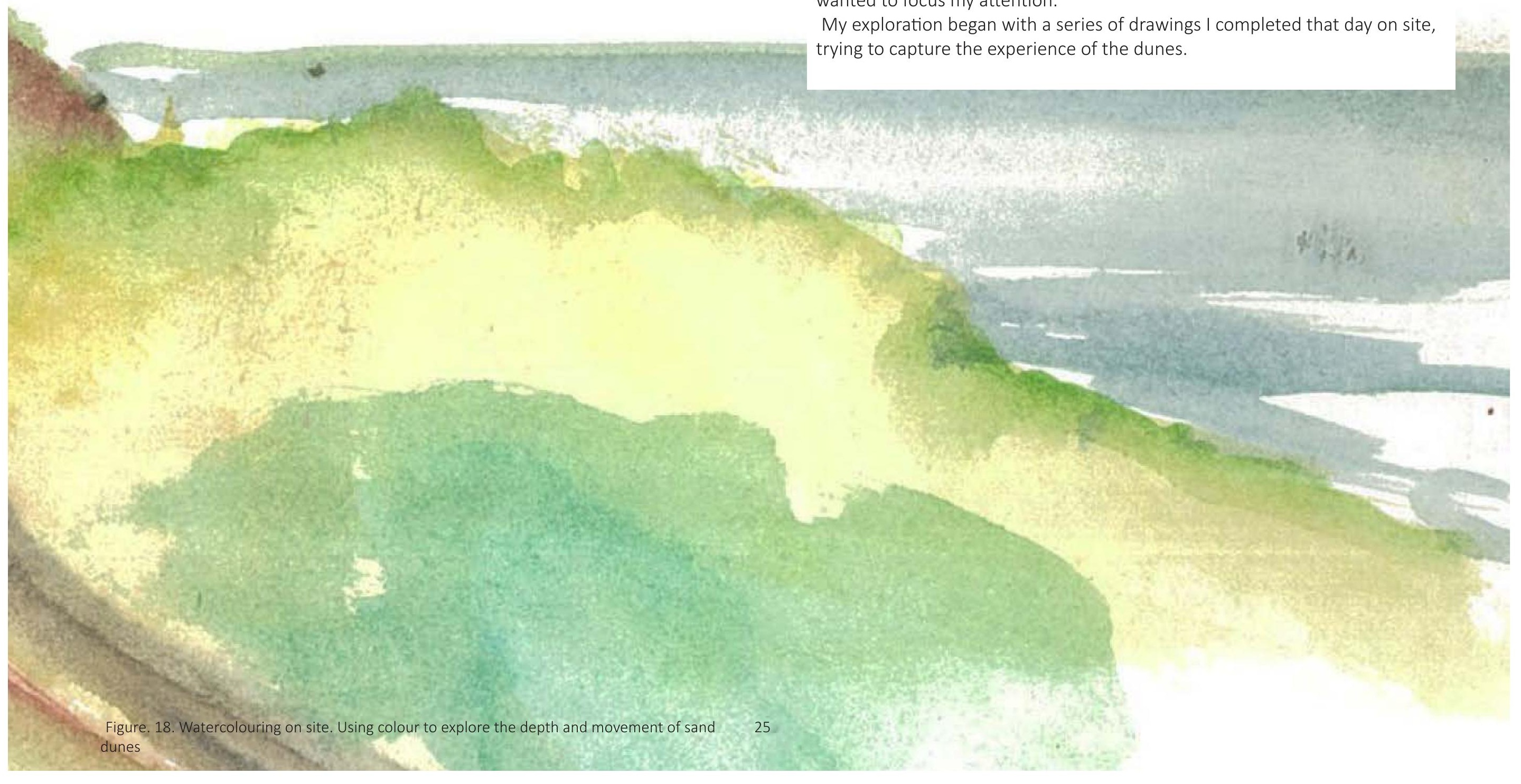

Upon my initial site visit to Kapiti, I became enthralled with the sand dunes of Queen Elizabeth Park and Raumati South. These dunes have a vibration to them. You become fully enveloped by their form and it feels like sand is shifting all around you. Sound bounces around dunes, you can hear the ocean at one point, and move one metre to the side and the sound is gone. The whole place is filled with echoes, buzzing and the sound of birds. I knew this was where I wanted to focus my attention.

My exploration began with a series of drawings I completed that day on site, trying to capture the experience of the dunes. 
The initial problem I set out to explore was the eroding coast and failing seawalls. I knew I wanted to marry the idea of re-building the eroding coast with structural elements, as I've always been fascinated with the way Peter Zumthor would place his buildings in the land and I wanted to align my experiments with his, namely his unbuilt project Poetic Landscapes. In this project he collaborated with a literature group in from 1998 to 1999. It began with the idea of Author and Council Woman Brigitte Labs-Ehlert who invited him to design a set of buildings to house poems about a certain piece of countryside written by notable poets of the area. (Zumthor)
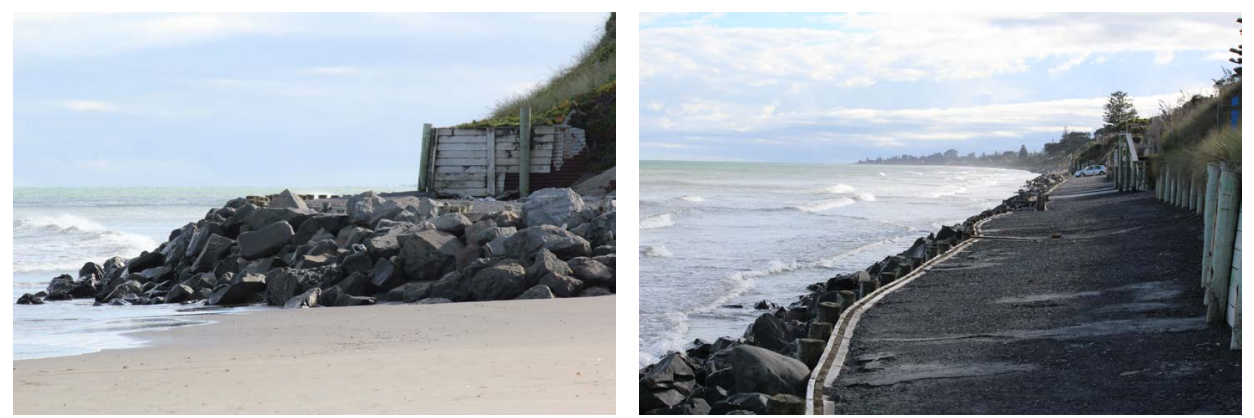

Figure. 20. Figure. 21. The end of the sea wall in Raumati South. This wall constantly needs rebuilding in order to respond to erosion

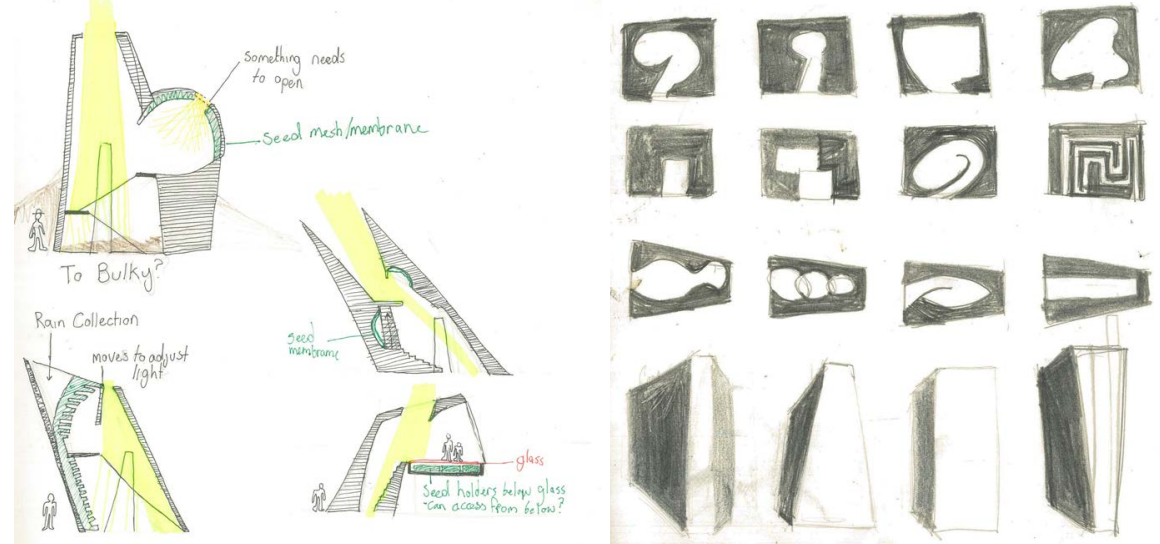

Figure. 19. Following Zumthor's ideas on exterior and interior form I began exploring how light and shadow could work on structures with a dunal landscape.

The designs and images produced in this series led me to consider how structures can become an atmospheric part of the landscape, and even aid in allowing them expand.

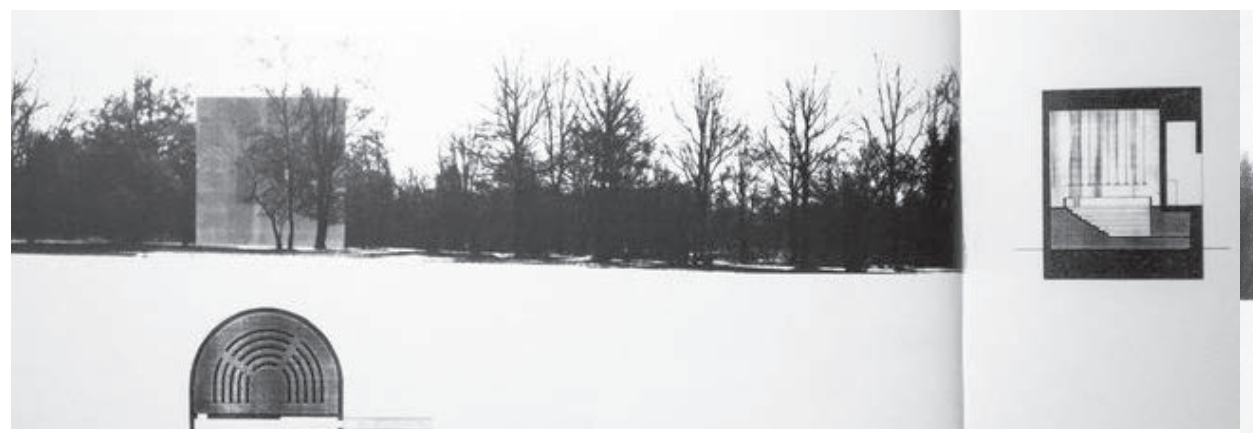

Figure. 22.Sections with plans produced by Zumthor to illustrate his poetry reading buildings within the landscape. The outer shell of the building disguises the inner form. This effect

produces a sense of secrecy about the building's interior. This ambiguity could be useful for the research conducted in this thesis.

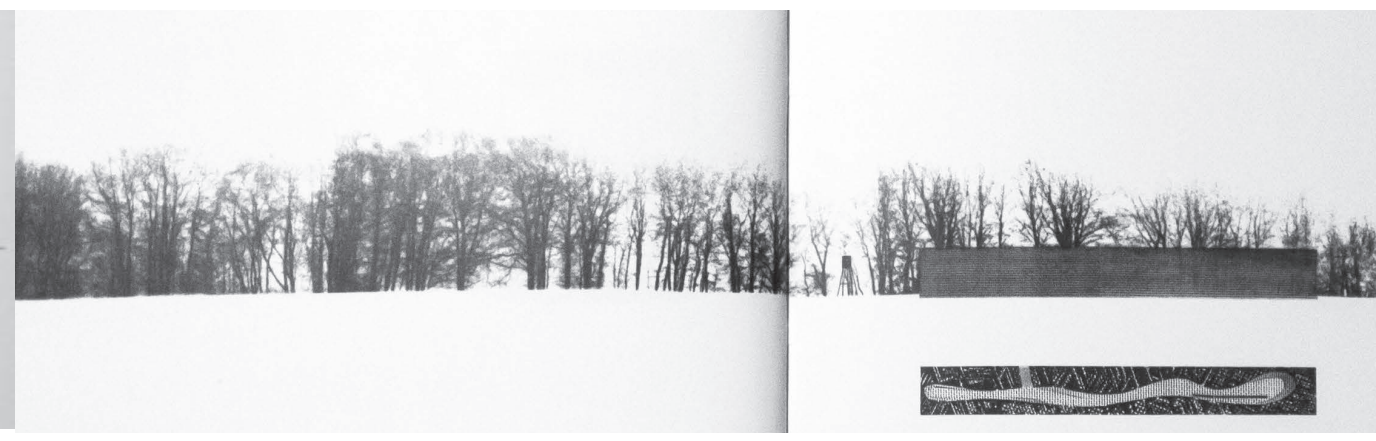

Images from Peter Zumthor work from 1998- 2001, project 1- Poetic Landscapes 
These designs progressed to become inhabitable spaces and possess functions such as water collection. The problem with these is they are just objects with no context or no relationship to the landscape. The next step was to define how these implementations could work as catalysts in the landscape and become places where changes to the landscape systems can begin to happen.
These structures evolved to not only prop the sand dunes up, but to also function as seed banks for marram grass and spinifex to further stabilize the dunes.

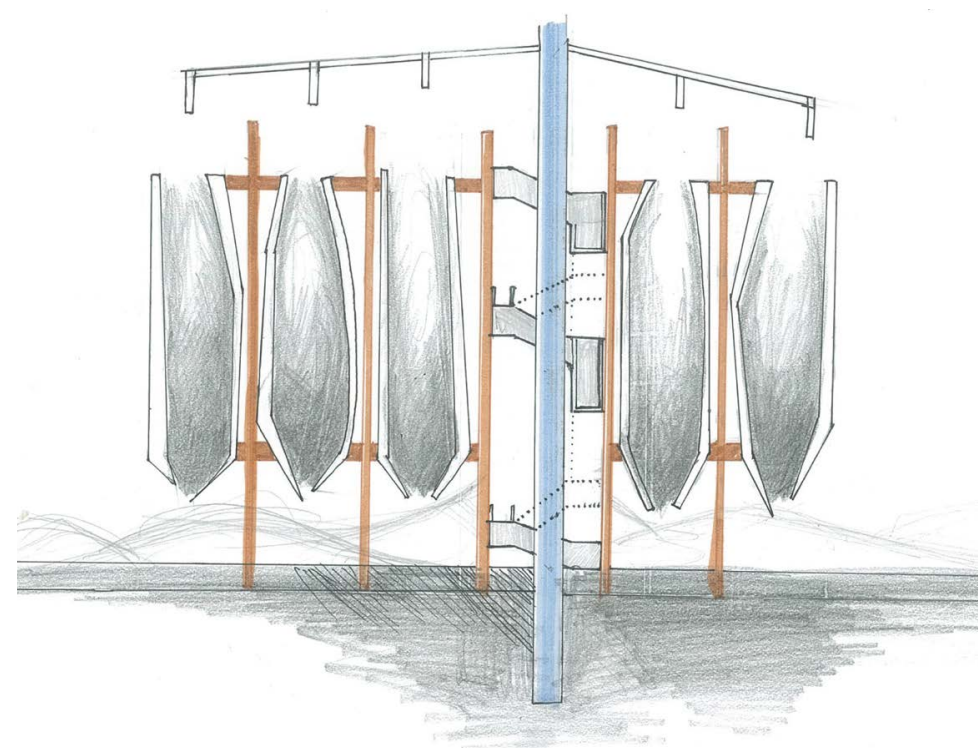

Figure. 23. If we treated the space as industrious and stored the seeds in giant silos and irrigation systems, how would people interact with them?

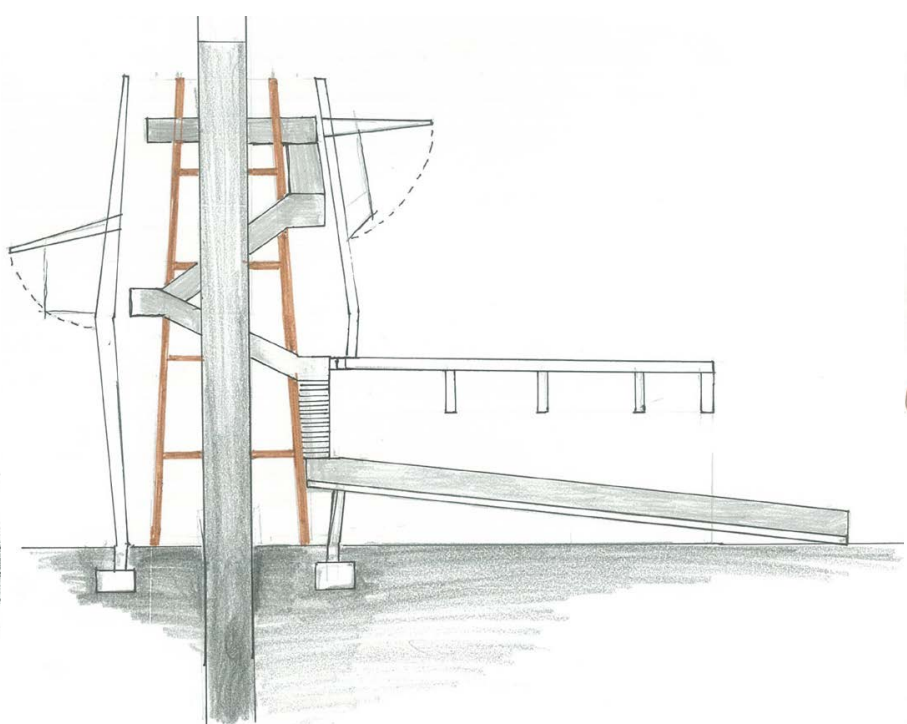

Figure. 25.

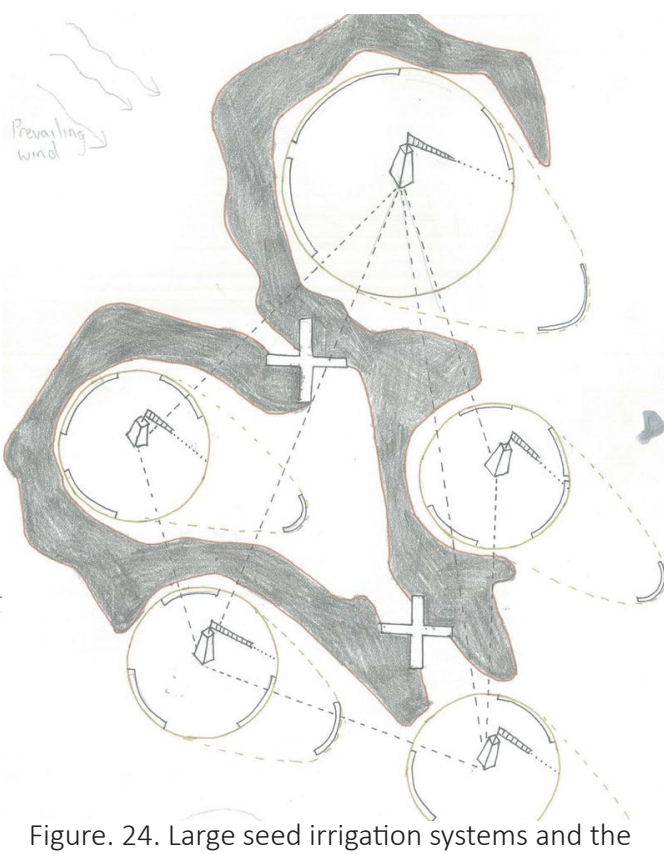
potential space around them. 


\section{Seed Dispersal}

From a lecture given by Tim Park - a plant and dune expert- for the 400 level students at Victoria University of Wellington it became clear that this site has seed dispersal issues. Seed dispersal can be both a blessing and a menace. The 1930s saw the New Zealand government put resources towards solving the problem of sensitive and eroding dunes, which came in the form of planting Marram grass and pine. These species are too efficient at stabilizing dunes and actually prevent the natural process of dunes building up to a 25-degree slope and then being blown out by storm surges only to begin the process again. Instead these plants hold the dunes in place, at much steeper angles for a very long time, allowing the land to become too stable and halting the movement and blowouts of the dunes (a natural part of their cycle). These plants disperse their seeds via wind, therefore preventing them from being an issue is difficult.

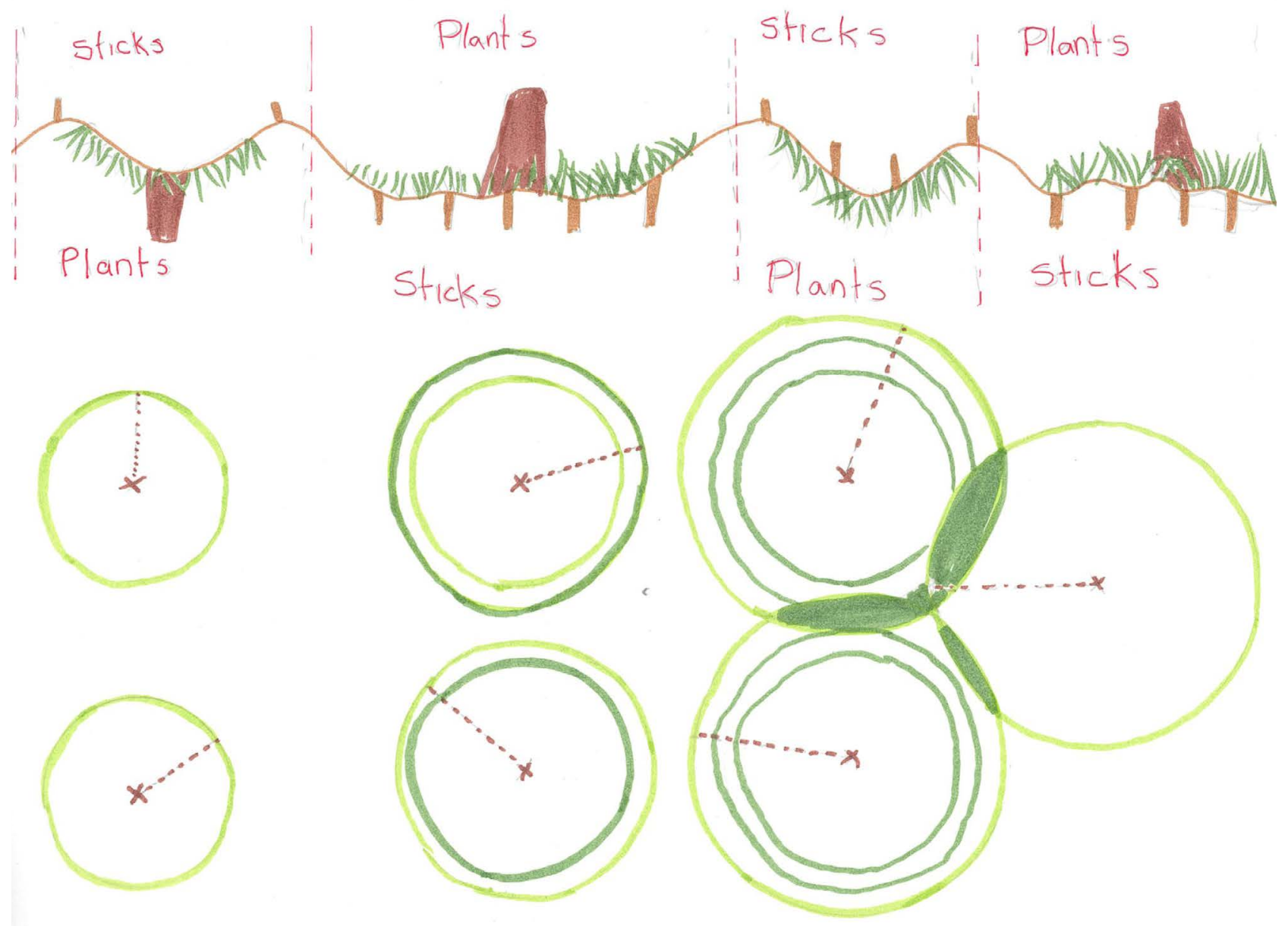

Figure. 27. Circular seed dispersal patterns and how they may overlap 

'An action to transform and continue the

world' has become a mantra, which allows

me to engage with and process all the

information Kapiti has to offer.

\section{What does \\ Poiesis look like in the Landscape?}

Primary thesis question 

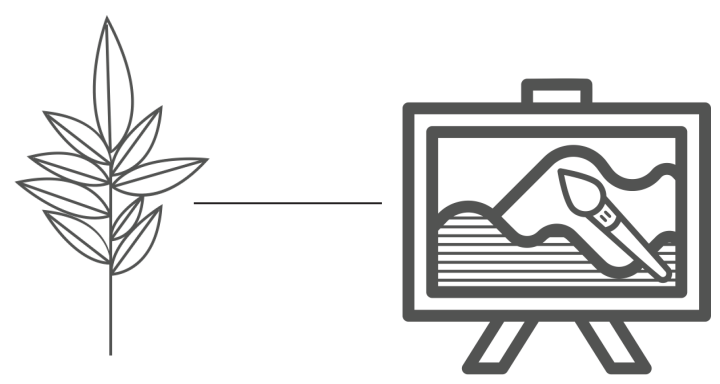

Science $\because \mid 0=$

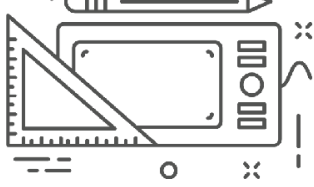

Design

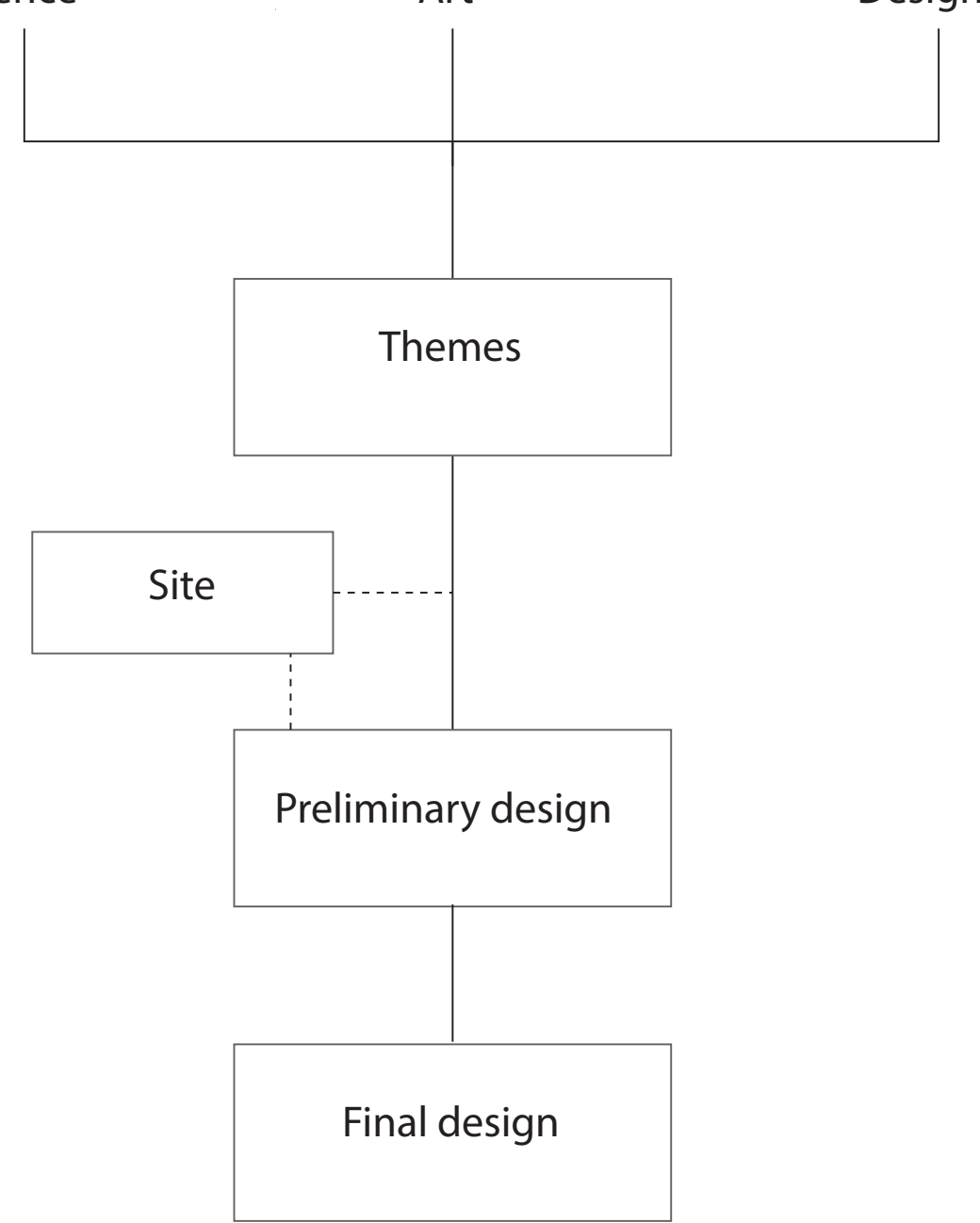

\section{Methodology}

Using a site in Kapiti:

Understand where the systems overlap and use these as places to express the performance of systems

Design a set of structures (Catalysts) that actively engage in furthering the growth of the landscape

Determine how these structures interfere with the landscape and how they can slowly become less prominent as the landscape develops and reaches a stage of Autopoeisis

Use design for multiple benefits, meaning structures that serve more than one purpose, such as bird watching towers that are also seed banks / dispensaries

Develop a deep understanding of what poiesis and poetics are and how 3-D spaces can become poetic

Develop strategies for representing a series of landscape 'poems / acts'. These should address: time, cultural narrative, natural processes, and play (human engagement). E.g. storyboarding and film. 


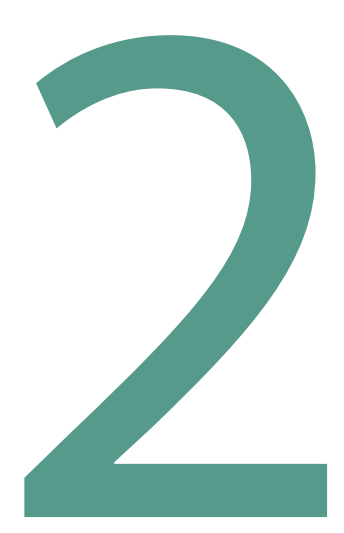

\section{Theorectical Context}

Who this research aligns with 
One of the principal objectives of this design research investigation is to explore expressions of patterns of large-scale coastal landscapes and to build a deeper understanding of the story the systems tell. The systems at play tell stories and there is the potential to explore where these systems overlap and draw out a participative role for people, through story telling? in which the landscape begins to not only grow and change, but also visually document these changes over-time.

The first portion of this chapter considers two research papers that explore dune systems in Kapiti and how wetlands can be resurrected or revived in Kapiti. The role of this review is to understand what systems are at play and analyse them with precision in order to draw out each system's stories and determine how they can be 'tapped into' as a design tool. The latter part of this chapter looks at how these systems can be visually represented at the larger scale as well as how they connect with the human scale. This portion of the chapter looks at the literature and theories behind representation and drawing in the landscape. The theories explored here address how these systems can be drawn upon to aid a growing landscape and how they can best be understood by people on the site . 


\section{Kapiti Coast Coastal}

\section{Hazard Assessment}

\section{Dr. Willem de Lange}

Dr. Willem de Lange, an expert in coastal science, states in the Kapiti Coast Coastal Hazard Assessment (reference) that most coastal erosion in Kapiti happens in Raumati and Paekakariki. Raumati is the focal point for dune stabilizing and rebuilding for this research. The dunes here take a parabolic form due to inconsistent wind directions. The dunes have greatly diminished and destabilised through the residential and pastoral developments of this site, creating the need for sea walls (Cockayne).

All of the sediment that make up the Kapiti coastline comes from the major rivers up north - approximately 170 kt.y - and local rivers - 28 kt.y. It takes sand 50 to 60 years to travel from these bodies of water down the Kapiti coast and is greatly affected by wind oscillations and influencing precipitation (Lange). Due to the already destabilised system, this is no longer enough sediment to maintain a healthy dunescape. Lange also states there is a reduced capacity for waves transporting sediment to Raumati due to the cuspate foreland caused by Kapiti Island. The oceans currents are dictated by tides and winds prevailing from the north-west. This is how sediment is pushed onshore from the north in a north-west direction (Lange, 2012). However, this cuspate foreland interrupts the primary wave transportation of the deep waters of the Rauoterangi Channel. The natural systems at play here are still completely functional, but in need of intervention if the dunes are to be rebuilt to protect the eroding coastline of Kapiti. This information allows us to engineer structures to help rebuild the beach where erosion has occurred and helps us to understand with more precision how systems are at play when it comes to sand movement.

It is clear from this research that the site's dunescape is made up of the following systems: Sedimentation movement, water currents, wind, precipitation, and seed dispersals. With this information it is possible to start formulating where these processes occur on site, which systems work in conjunction with or against each other and what they mean at the human scale.

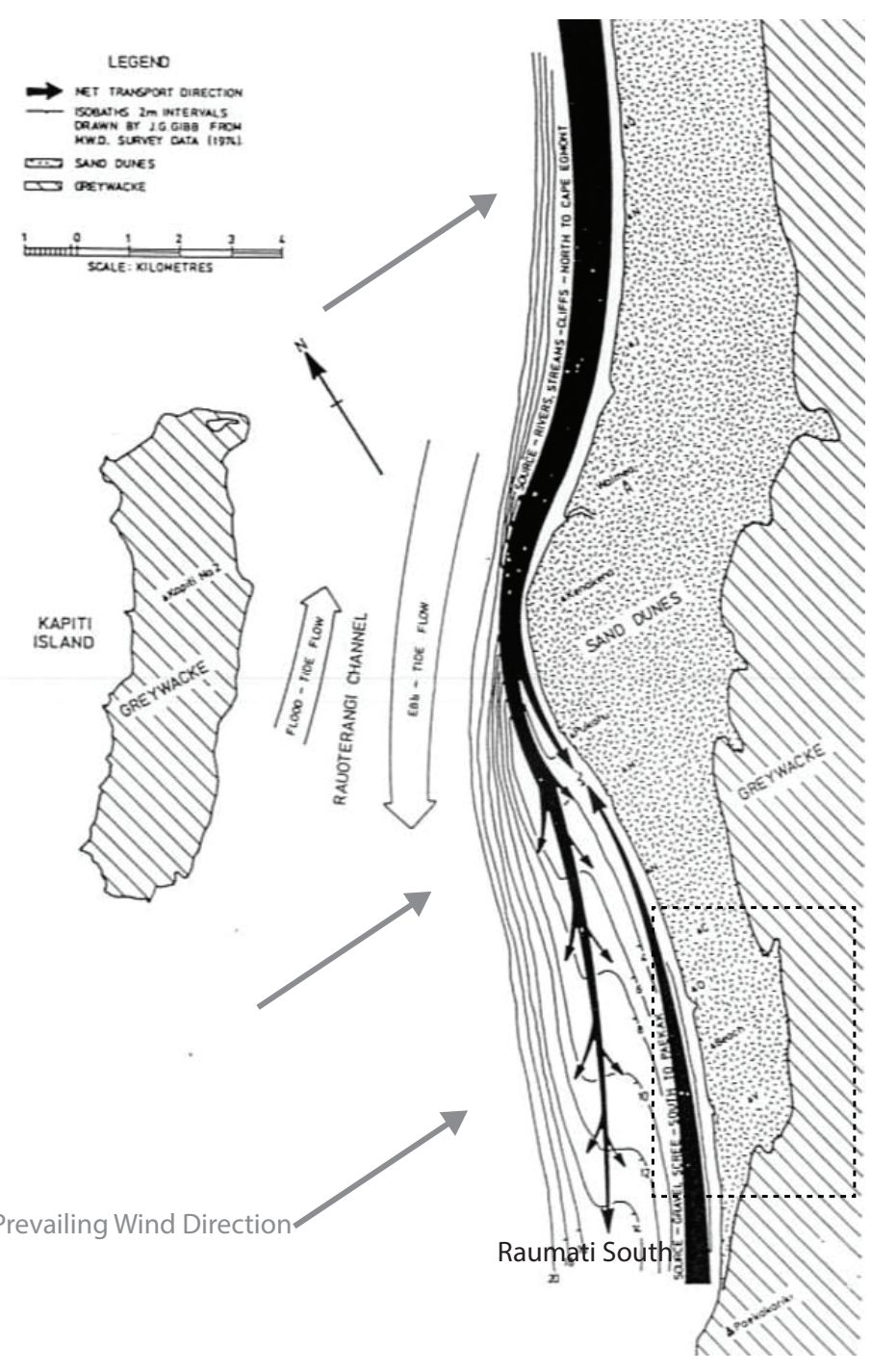

Figure. 30. Base image- Proposed Sediment Transport Pathways for the Southern Section of the Kapiti Coast imaged sourced from Gibb and used by de Lange Kapiti Coast Coastal Hazard Assessment pg. 7 


\title{
Wetland Types in New Zealand
}

\author{
Peter Johnson, Philippe Gerbeaux
}

According to Peter Johnson and Philippe Gerbeaux there are three types of wetland typologies in the research site of Kapiti . These are (a) ephemeral wetlands, (b) marshlands and (c) seepages.

(a) Kapiti was once the home of numerous wetlands. One of these was located at the back of dunes within the dune-slacks. This is due to water becoming trapped as the dunes rise, which results in a tidal-influenced wetland. These ephemeral wetlands are classified as rare ecosystems and are temporary environments that thrive during the wetter periods of the year (Yukhnevich) Ephemeral wetlands should be explored in a site like Kapiti because of the abundance of Dune land s. Ephemeral wetlands are one of the most temperamental lowland ecosystems and once naturally occurred behind the Raumati south dunes.

(b) As visible on fig 31 the research site currently has a number of marshlands retained from the pre-settlement days. These are due to much of this land being peat (Peter Johnson), although these have diminished greatly. According to Peter Johnson and Philippe Gerbeaux (ecologists and the authors of Wetland Types in New Zealand) marshlands consist of "usually shallow water, often seasonal, mineral substrate and herbaceous vegetation. (c) There is also vast areas of seepage throughout the entire site. This is due to the site receiving water and nutrients from up slope off of the Tararua Ranges (Peter Johnson). "Seepages and flushes form where groundwater emerges on hillsides to form soils that are mostly permanently saturated with relatively nutrient and oxygen rich water. Seepages tend to be wetter for longer periods than flushes, which are often formed by a periodic pulse of water following rain. The high water table excludes the woodiest plants from these habitats and herbaceous species dominate. They may be extensive in some circumstances, but they are often relatively small, covering no more than a few dozen square metres" (Peter Johnson).

The challenge when designing for large scale systems is how to construct space in which these wetlands can thrive. In order to get these wetlands to function the systems that must be acknowledged are: rainwater runoff, precipitation, soil type, topography and planting. 


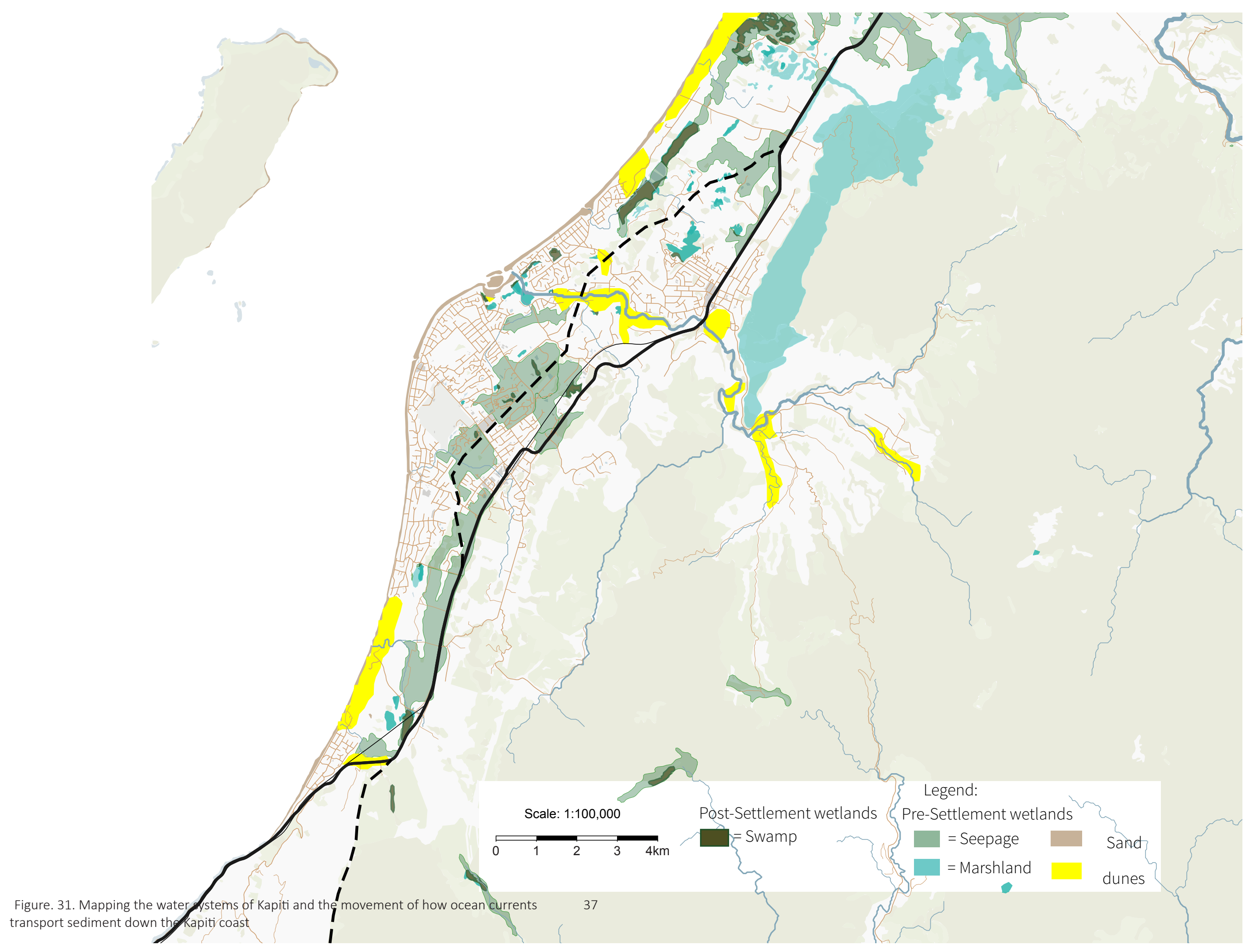




\section{Sand Engine}

\section{Fastcoexist - Michael J Coren}

Zandmotor (also known as Sand Engine) a large ecological sand intervention whose invention is largly credited to Professor Marcel Stive. This is a project from the Netherlands, where, like New Zealand they face a lot of erosion and sea level rise issues. Sand engine consists of 22 cubic metres of sand being strategically placed in the coastal shallows and allowing nature to redeposit the sand naturally to rebuild broken dunes. This method is more stable than the current methods of replenishing the dunes on land every 5 years which is the typical course of action globally as the sand engine process takes 20 years to complete its cycle and uses less sand than traditional sand dump methods. (Coren).

Through exploring how the sand engine technology could work in Kapiti, it became clear that of the speed of currents caused by the cuspate foredune would prevent most sediment from staying in that space. I began to explore non-invasive structures that would trap sediment along the shore, eventually deciding on a system of thin poles.

Poles can work like plants and rocks in the sense that sand will cling to them and gather to form mounds and eventually dunes.

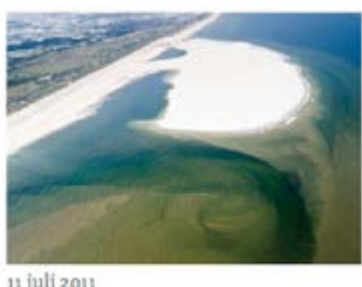

"11 juli 2011

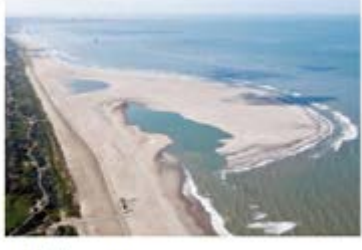

3oktober 2011

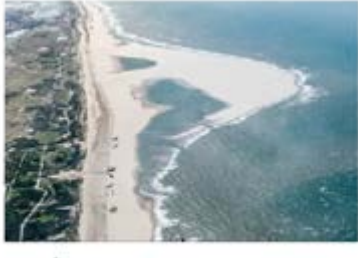

14 mei 2012

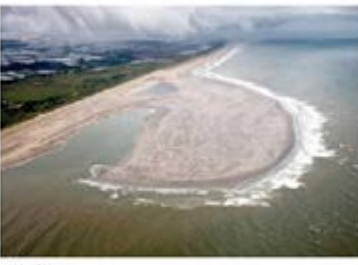

18 juli 2011

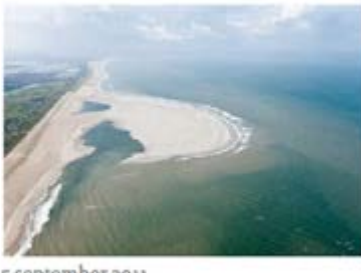

5 september 2011

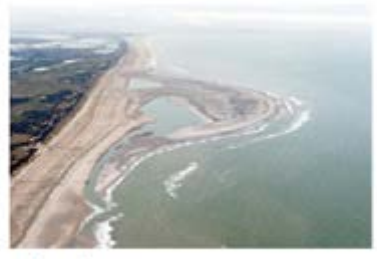

10 januari 2012

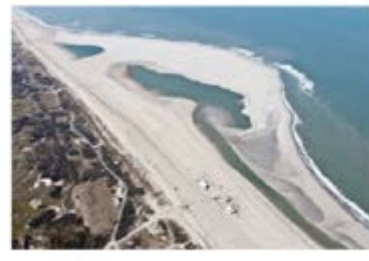

20 marr 2012
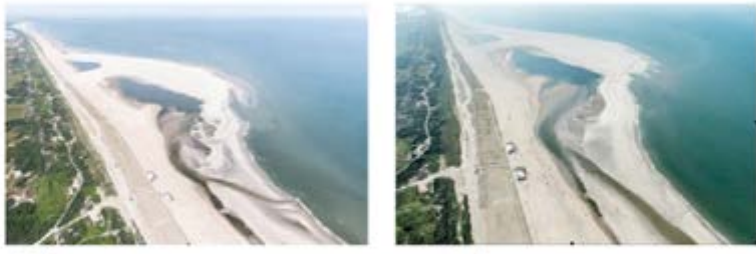

with 2012

seprember 2012

Figure. 32. The movement of sand from when Zandmotor was implemented to the following year sourced from The Sand Engine : A solution for vulnerable Deltas in the 21st Century
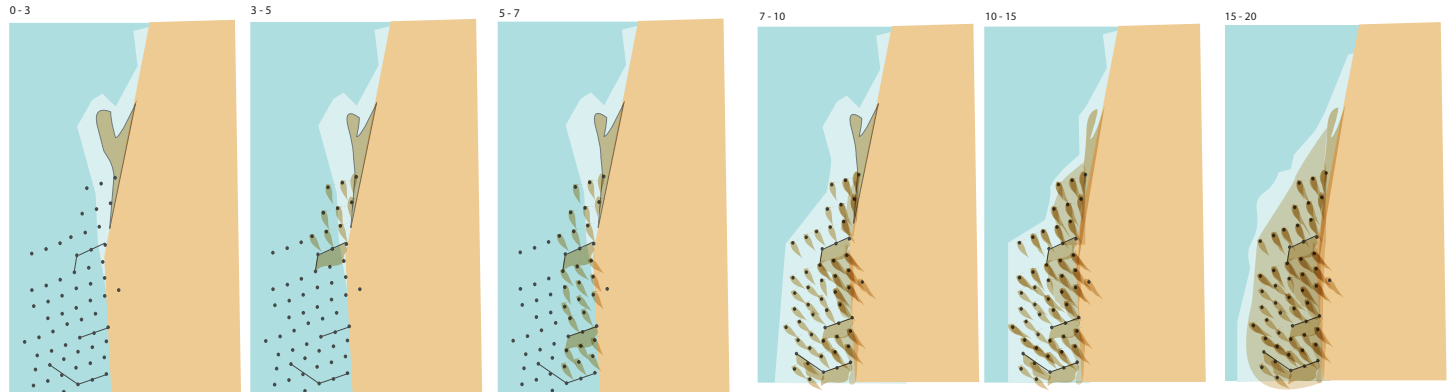

Figure. 33. Drawing to understand how the sand would build up with a sand motor and pole intervention 


\section{Parabolic Dune Formation}

Geomorphology processes over time have produced parabolic dunes along Kapiti Coast, stretching from the Wanganui River in the north to Paekakariki in the south. Parabolic dunes span kilometres inland from the coast and are crisscrossed by old streams, rivers and wetlands (Dewhurst).

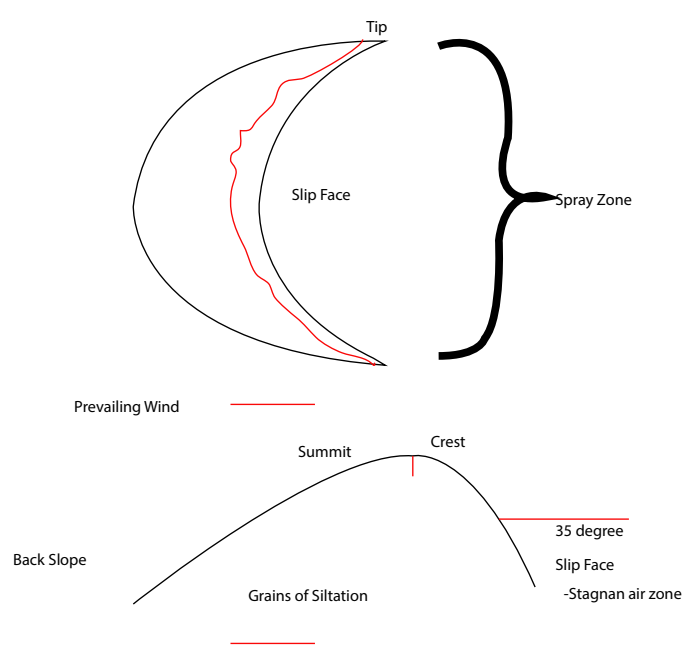

Figure. 34. Diagram of parabolic dune formation

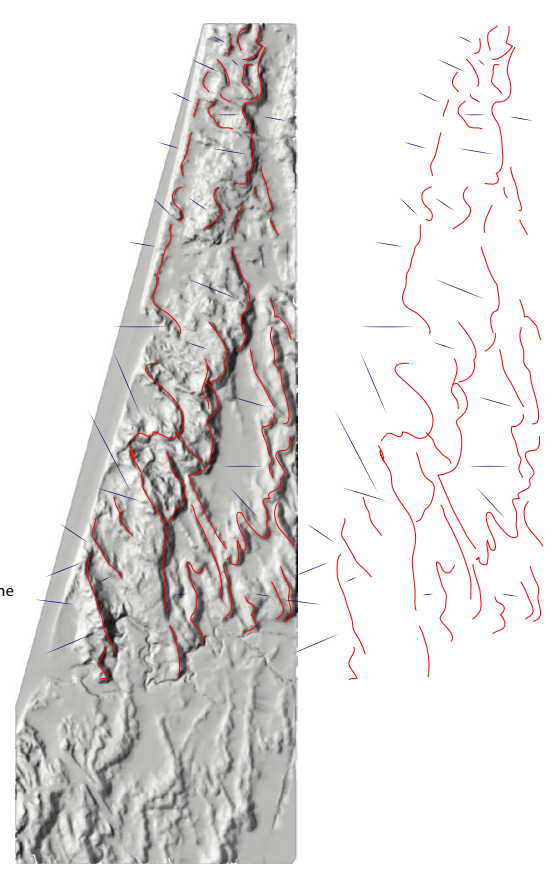

Figure. 35. Ridgelines of existing

Paekakariki dunes and sediment migration pattern

\section{Flora behind the Dunes}

The types of flora planted help to indicate the areas in which the dunes are 'frozen'. Much of this exotic planting is pine forest and deeply rooted, which prevents the natural migration of sand.

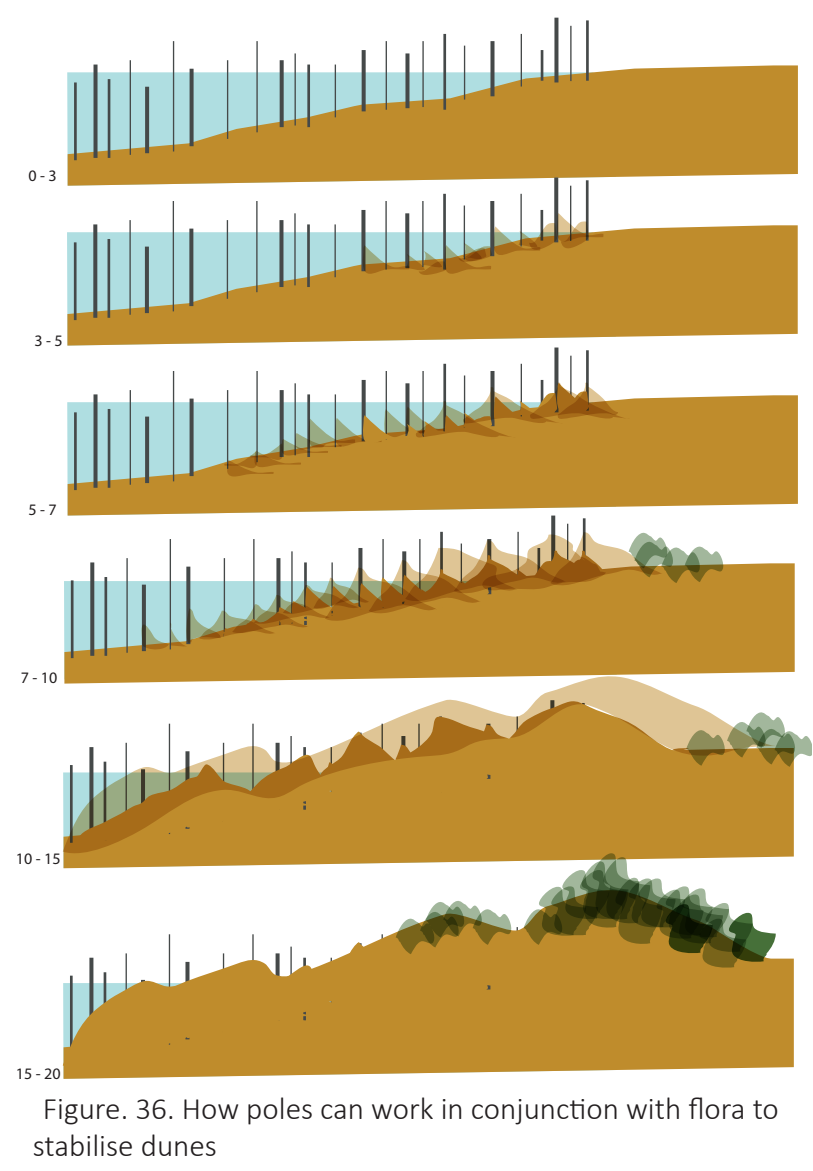




\section{Fog Catchers}

Fog Catchers, like the ones found in Peru, are an incredibly simple technology that requires very few materials for set up. Fog catchers consist of single or double layer mesh netting supported by two posts rising from the ground. The collectors are positioned on ridge lines perpendicular to prevailing wind (North-West of Kapiti) and capture moisture as fog sweeps through. The number and size of meshes chosen will depend on the local topography and demand for water. Fog catchers are typically used in arid places with a low level of drinking water because they are able to harvest enough water for small coastal townships (Alicia Quezada).

Fog catchers can be useful in Kapiti in the initial stages of wetland building. As these won't be needed to provide drinking water (unless there is an emergency) the technology can be put to use as a sort of concentrated irrigation systems to allow the pooling of water and the implementation of wetland plants.

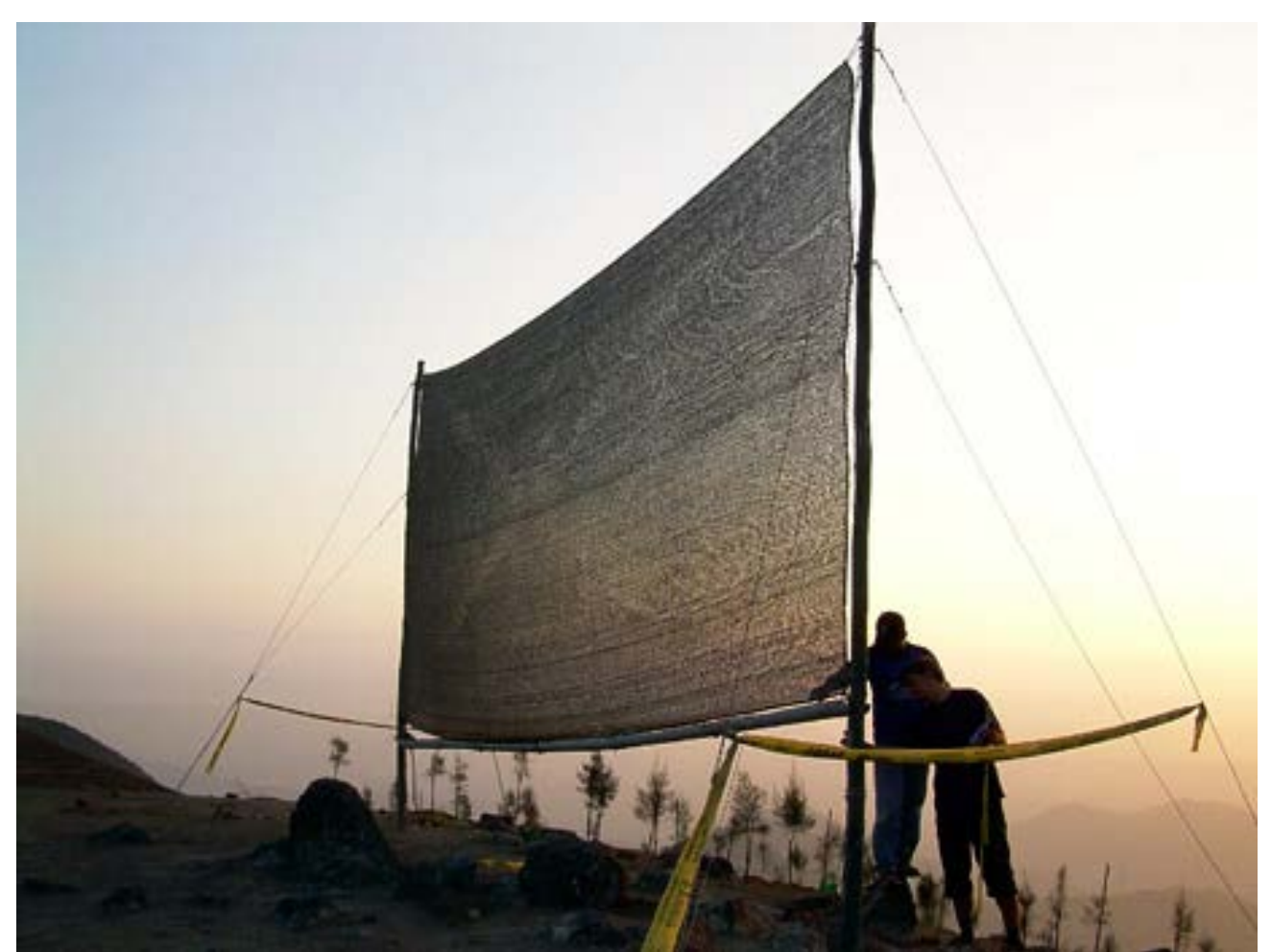

Figure. 37. Fog Catcher being assembled in Peru, source poleshift 


\section{Representing Science Through Art}

The purpose of this section is to review and understand how landscape systems can be represented on paper. This is an obscure relationship as landscape systems are intangible, often non-visible phenomena that we experience in many

ways other than visually and at many different scales. Therefore it is important to understand the relationship between drawing and the production of built landscapes. 


\section{Drawing and Making in the}

\section{Landscape Medium}

\section{James Corner}

James Corner writes in his essay Drawing and Making in the Landscape Medium: "A central characteristic of the often ambiguous 'landscape' is that it is at first a schema, a representation, a way of seeing the external world and, based on one's point of view, such schemata vary significantly" (Corner). This brings up the question of how one represents and draws out the poetics of landscape systems if they are so ambiguous and so based on one's own perception. The act of drawing in landscape design takes one of at least three directions: either it is an analysis of what exists on site (Documentation), a drawing of what is not there yet, a picture of what may one day be there in a manner that is comprehensible to those who will be building or using the space (Representation) or a combination of these. This process is very removed from the process of making a landscape. The act of representation of what is not there yet typically involves having preconceived notions of what you need to draw and with precision. These drawings are not the end result as they are removed from the landscape itself. This is different to the process undertaken by artists of other mediums, as they have the privilege of working with the medium that will be the end result from the beginning. So their work continuously 'unfolds' as the artist is personally engaged with the medium and the possibilities that emerge (Corner).
It is important to see the making of a drawing as a "dialogue, a perceptive conversation between the medium and the imagination that cannot be intellectualised or thought of external to experience" (Corner). This is something the ancient Greeks understood quite well: understanding 'making' as an explorative process and a dialogue is the backbone of 'Poiesis . "Only through the sentient perception of tactile and creative activity - the actual work of making - can discovery and revelation occur" this is the basis of human agency (Corner). Therefore, I think the discrepancy between what is drawn and what is landscape is not necessarily disadvantageous, drawing and the landscape are merely different modes of experience. 


\section{Notation}

\section{Lawrence Halprin}

Lawrence Halprin, an American Landscape Architect, devised a notational score of sorts to read the landscape. The scores he designed are not dissimilar to the theories put forward by theorist and choreographer Rudolf Laban. Laban developed a method of scoring for ballet called Labanotation. This scoring method choreographs the body moving through space and time, in a way which dancers can follow. This is done with a series of abstract symbols and encodings that follow a very precise key. Inspired by his wife's dancing career and choreography Halprin began forming this new way of documenting people and systems navigating through space. He named this 'Motations' (Movement Notations) (Prudence). According to Paul Prudence "His Motations were guides for the intended motion of people through space as well as scores for actual moving parts of the architecture itself - such as water in fountains". In effect Halprin devised a way of documenting narrative through a landscape, similar to how one would choreograph a dance. Although these drawings are beautiful and accurate, they are not highly evocative nor do they give the reader any sort of connection to the space. A notational drawing should be read with precision like the Halprin drawings, but should also represent factors of the landscape that one feels without necessarily seeing or actively engaging.

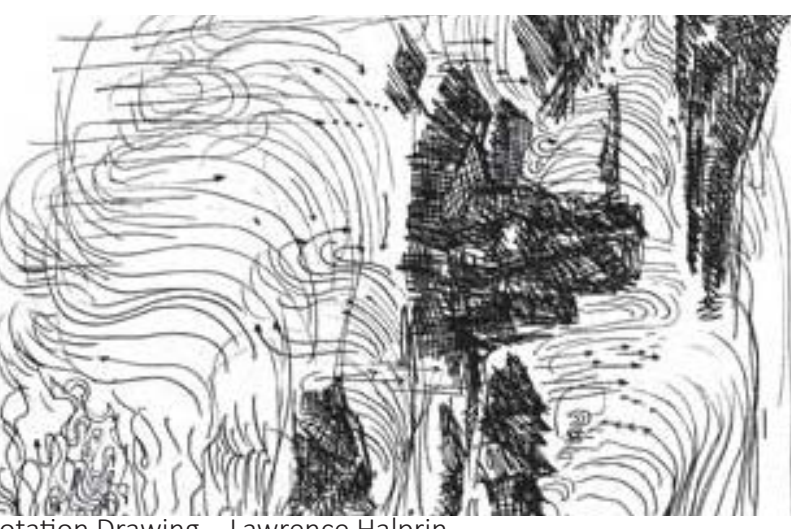

Figure. 38. Motation Drawing - Lawrence Halprin

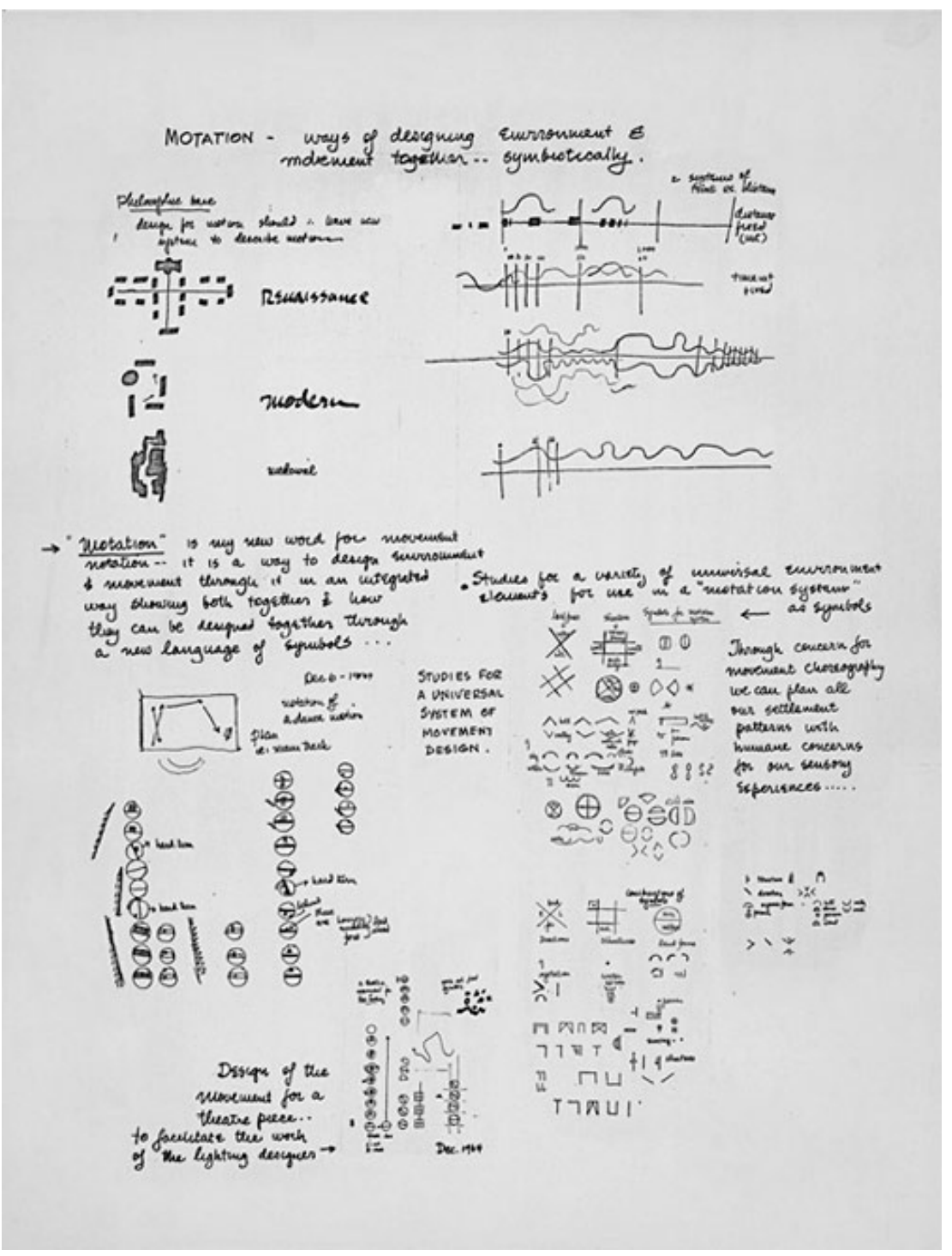

Figure. 39. Halprin explores drawing and examining sites in two dual ways. He is either abstractly analytic, or he does rough sketches of what he observes. 


\section{Expression}

\section{John Wolseley}

John Wolseley is a highly expressive artist who explores the way in which we dwell and move through the landscape. The aim of his works is to explore the intricacies of nature and relate them "to the abstract dimensions of the earth's dynamic systems" (Wolsley). Wolsley paints with watercolour, collage, printing, using leaves and birds as brushes and other emotive, tactile process that connect the work of art with the landscape they were painted in. These works of art are a beautiful combination of scientific documentation and emotional responses. However, although his drawings of things in nature at the naturalistic scale are very precise, they lack the obvious and quickly readable precision displayed in the works by Halprin .

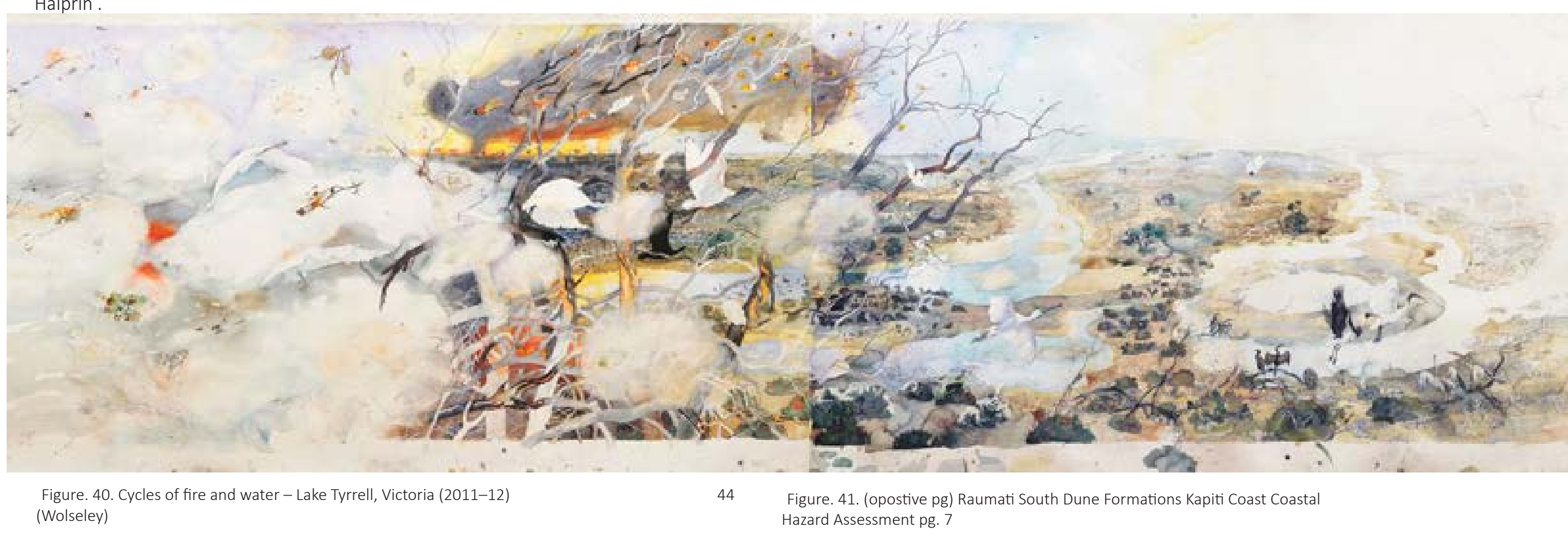




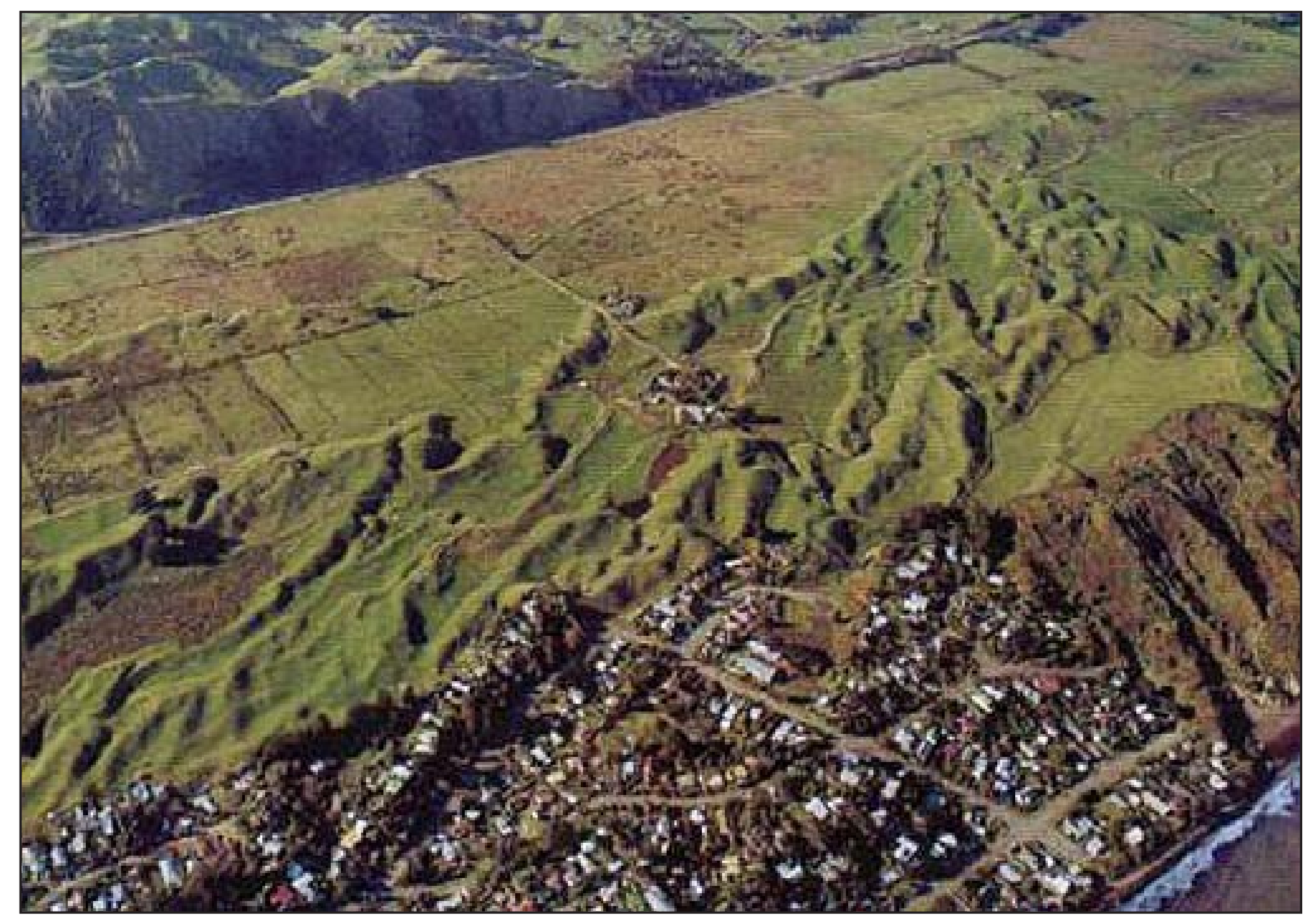




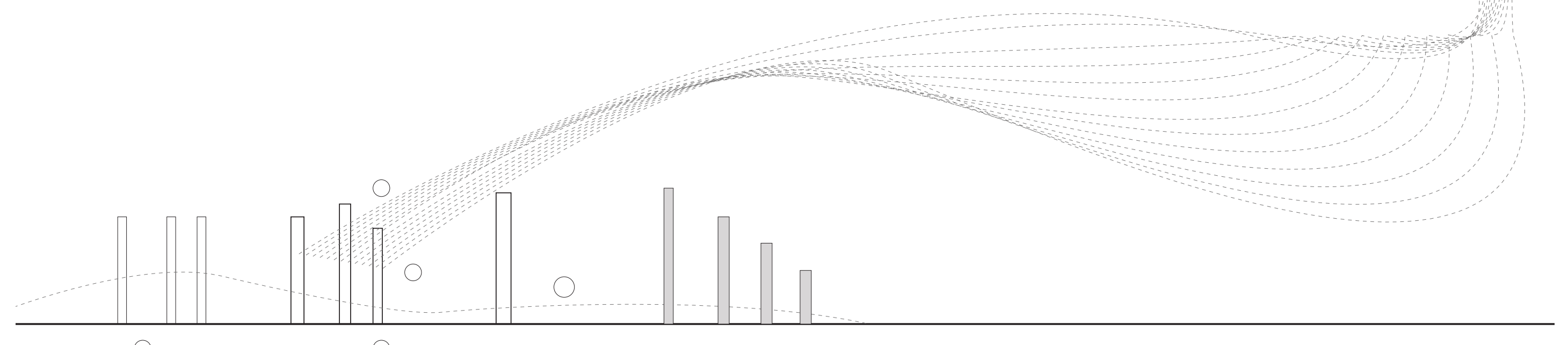
0 


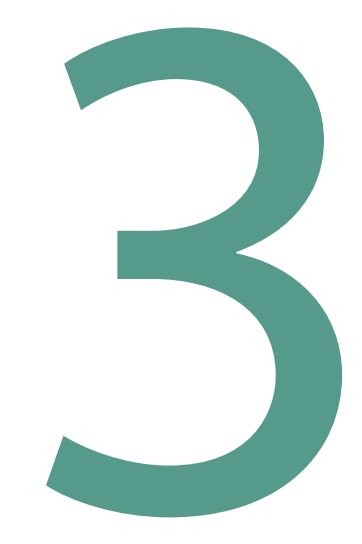

Themes 
This thesis asks the question 'What does Autopoeisis look like in the landscape?' I have been exploring this through design iterations,

experimenting with new site analysis techniques and through mixed media.

While reviewing the above literature, a few themes have begun to emerge.

These are: Poiesis, How reading a site can be generative, and How to negotiate a site. These themes keep looping me back to my aims and objectives.

The overarching aim of this thesis is to engage with Poiesis to reveal largescale systems operating in coastal landscapes so that they are legible at the human scale. The word Poiesis has become a portal through which I am able to comprehend the world around me in a way that may bring something new to how we interpret landscape architecture

\section{Poiesis means an action that}

\section{transforms and continues the}

world. 


\section{What is Poiesis?}

Poiesis is the origin of the word poetic. In this sense, poetic is the reconciliation of thought with matter and time, and person with the world. This is the definition of poetic I am referring to in the discussion below.

This idea was brought about when reading James Corner's essays. Poiesis has become the cornerstone of my research. There are two texts that shaped my understanding of Poiesis and what it meant to me These are; James Corner's Drawing and Making in the Landscape Medium and Praxis and Poiesis in Aristotle's practical philosophy by Oded Balaban.

In his essay Drawing and Making in the Landscape Medium James Corner refers to how the people of Ancient Greece understood the connection between the medium and what you are creating with it by stating:

"An important connotation of Poiesis, meaning to create or make, is that only through sentient perception of tactile and creative activity - the actual work of making - can discovery and revelation occur, the longed- for "moment" of disclosure" (Corner)

Through the physical and sensational process of making- be that a person constructing something, or the wind forming a sand dune- we begin to understand and comprehend what is happening around us.
This connection between the landscape and Poiesis is reinforced in Praxis and Poiesis in Aristotle's practical philosophy by Oded Balaban. Aristotle states that Physis (the Greek philosophical idea of nature) is the ultimate form of Poiesis, and Poiesis can be seen as the imitation or continuation of physis. Aristotle's definition of Poiesis is restricted to making or producing that has as its aim something beyond itself, i.e. There is an outcome to the process (BALABAN). These ideas suggest how human acts of Poiesis (an action that transforms and continues the world) might affect or improve the autopoeisis (the healthy functions of ecological systems) of the natural systems occurring in Kapiti.

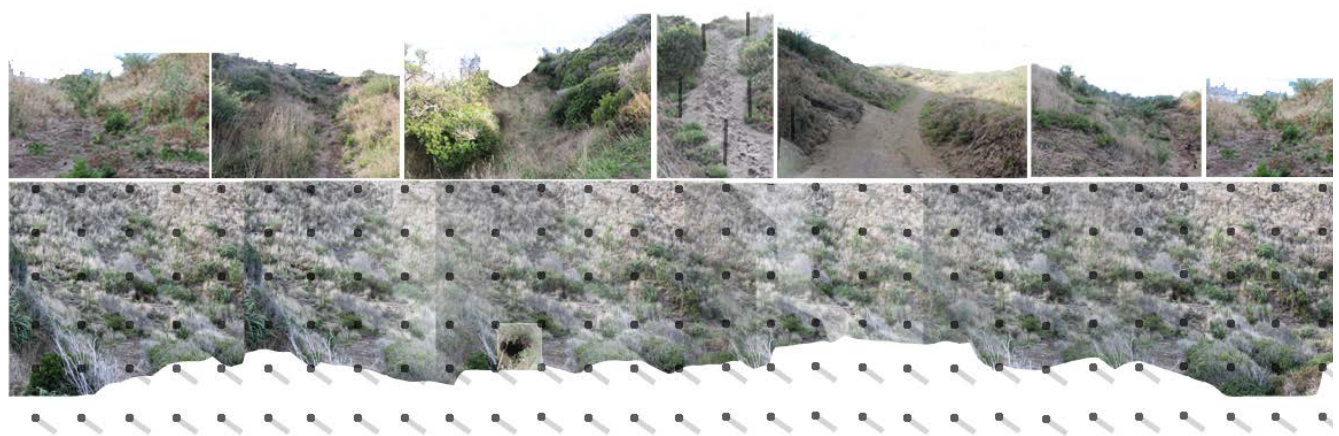

Figure. 42. Drawing experiment linking pole in the landscape to future land formation and public space

The above definitions of Poiesis have led to a definition of Poiesis for this thesis. For this research and design I will be exploring what I refer to as 'Small Poiesis' which is a small intervention or structures that can be designed and placed in the landscape. These are less invasive than the typical interventions we make to change a natural system. The other form of Poiesis defined in this thesis is Autopoeisis: The healthy functioning and processes of the systems in place that make up Kapiti's landscape. 


\section{How we currently tap into systems}

This research is exploring Kapiti's ecological systems, their autopoeisis and how one might intervene in a productive and positive way. In order to explore this, it is important to first examine how we are already engaging and manipulating ecological systems. There are ways in which we engage with systems that are effective and work with nature, and there are ways in which we control nature that are highly invasive.

\section{Groynes}

Groynes are an example of people intervening in an ecological system in an invasive manner. A groyne is a hydrological structure positioned in the sea or a river, which interrupts the natural water flow and drastically slows down the movement of sediment. Slowing down the sediment widens beaches and prevents them being washed away by longshore drifts (Pruszak).

Groynes are highly effective for their intended purpose, but they are also highly invasive and disrupt and reshape the land and shore with finger-like protrusions. Hard infrastructure like this is extremely expensive, requires constant maintenance and typically does not add to the human experience.

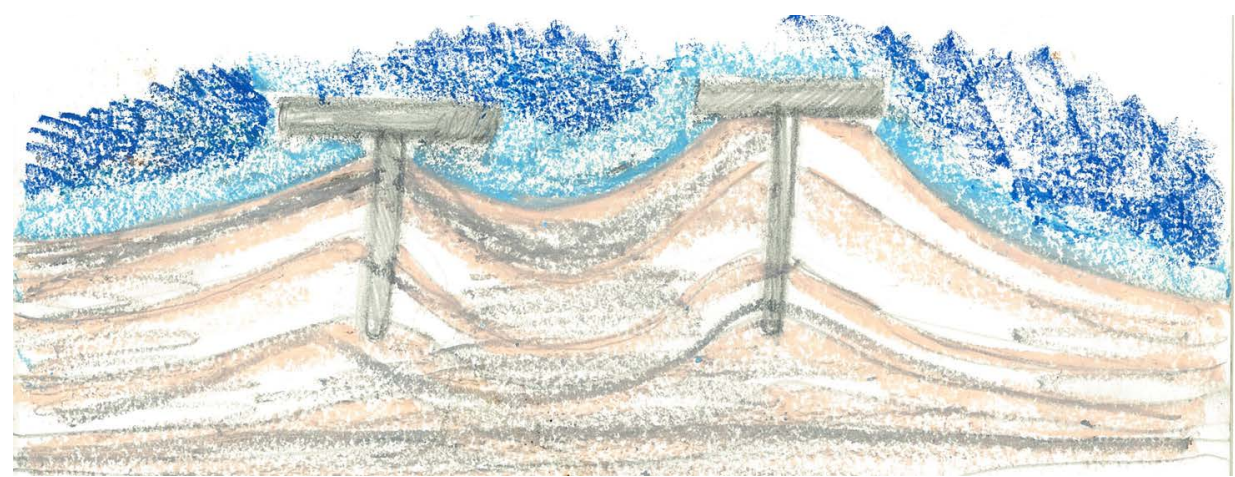

Figure. 43. Drawing of groyne and sand formation

A fundamental principle of this research therefore, is that soft infrastructure is the focus with regards to tapping into the ecological systems of Kapiti. This is why the term 'small poiesis' was coined. The decision was made that any and all structures would have a light touch on the land whilst still having a big positive impact.

(a) tides

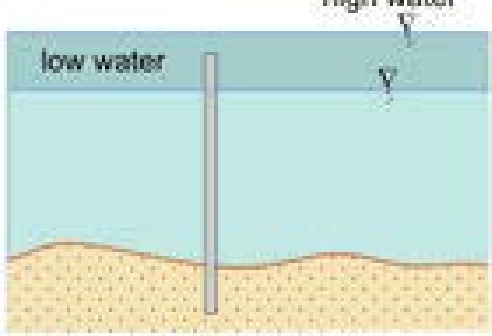

no tides

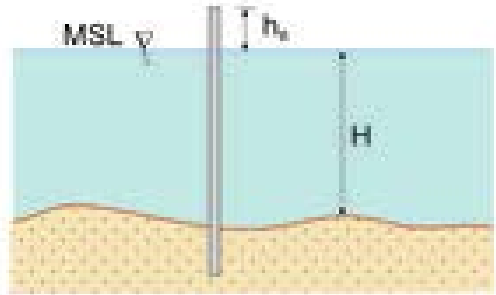

(b)
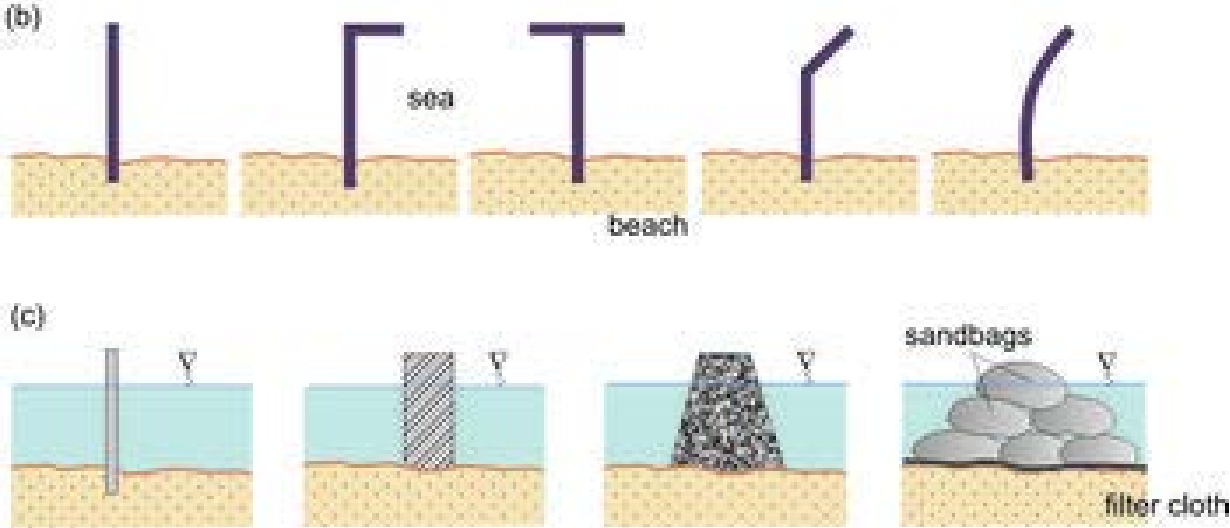

Figure. 44. Various Groyne shapes, sourced from 'Groynes' coastalWiki 


\section{How reading a site}

\section{can be generative}

It is crucial be able to draw and represent the systems at play in Kapiti, and the way in which we interact with landscape. The landscape surrounds us in a limitless way, the scale is big in relation to other things.

When people talk about its enormity, they are talking about it in relation to themselves. This is why it is so important to understand the systems at the human scale. The scale of the landscape envelops the body as well as the imagination and spirit. It may be something we do not realise we are experiencing- for example, the systems affecting the dunes and the wetlands - because it is the effect all of the systems have when they are combined, their physical expression. The spatial complexity of the landscape can't be represented without alteration or reduction: as it is not all measurable. It cannot be quantified without firstly being simplified.

It is also important to note that landscape cannot be frozen in a single point of view or in time. So how does one identify, represent and draw out the poetics of landscape systems if they are so ambiguous and so based on one's own perception?
Below is an exploration of how the techniques of the Wolseley and Halprin could be applied to devise a way of documenting the systems at play in Kapiti and how they connect with people at a smaller scale.
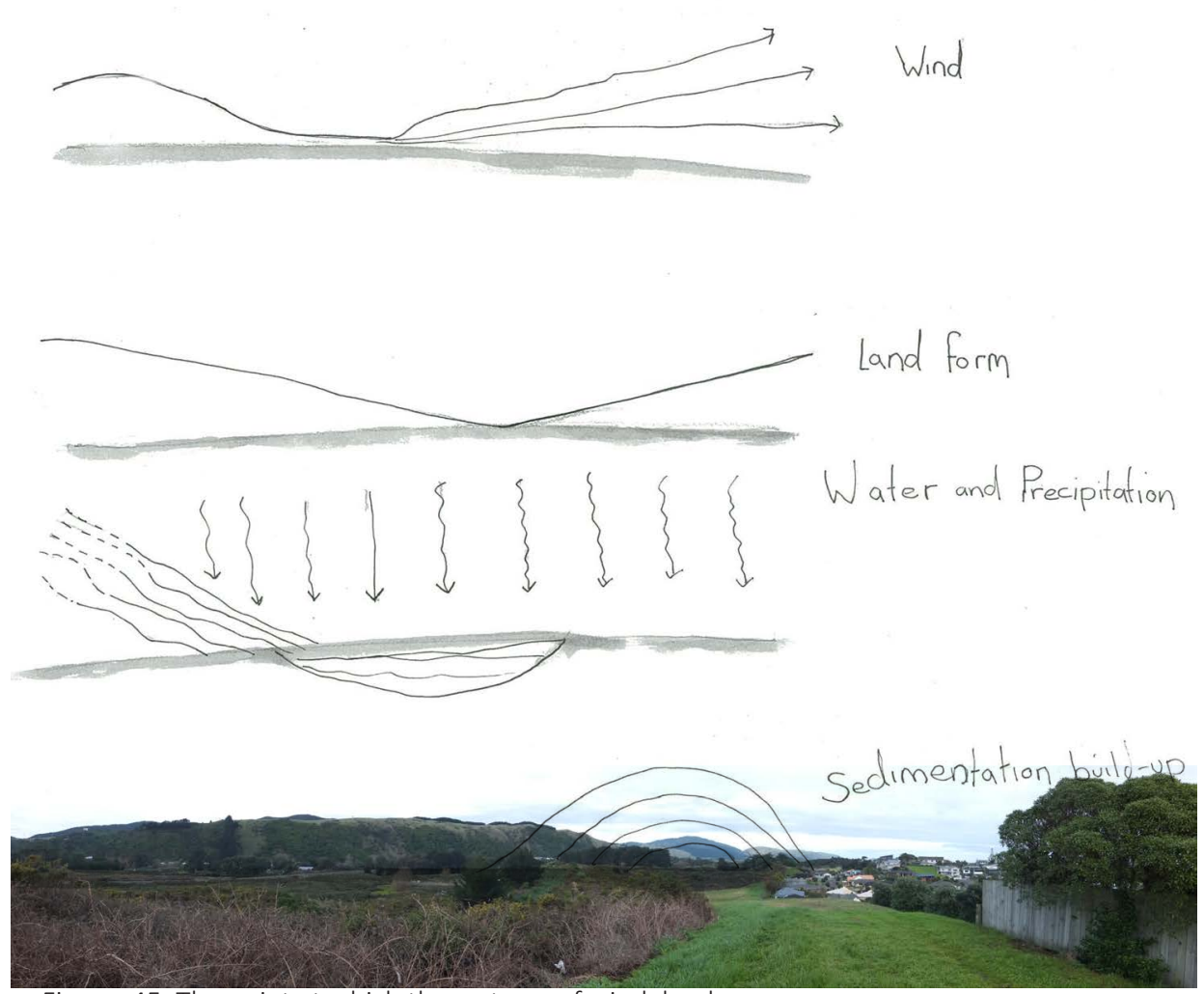

Figure. 45. The point at which the systems of wind, land

formation, water and sediment build up converge 
The key to conveying how these systems operate and how they relate to the human scale is layering. There are distinct differences in the way Halprin and Wolseley depict the landscape: both have their merits, but neither convey the actualities of the systems nor their experiential qualities. Layering images of both begins to tell a more complex story, as this is how systems tend to operate.

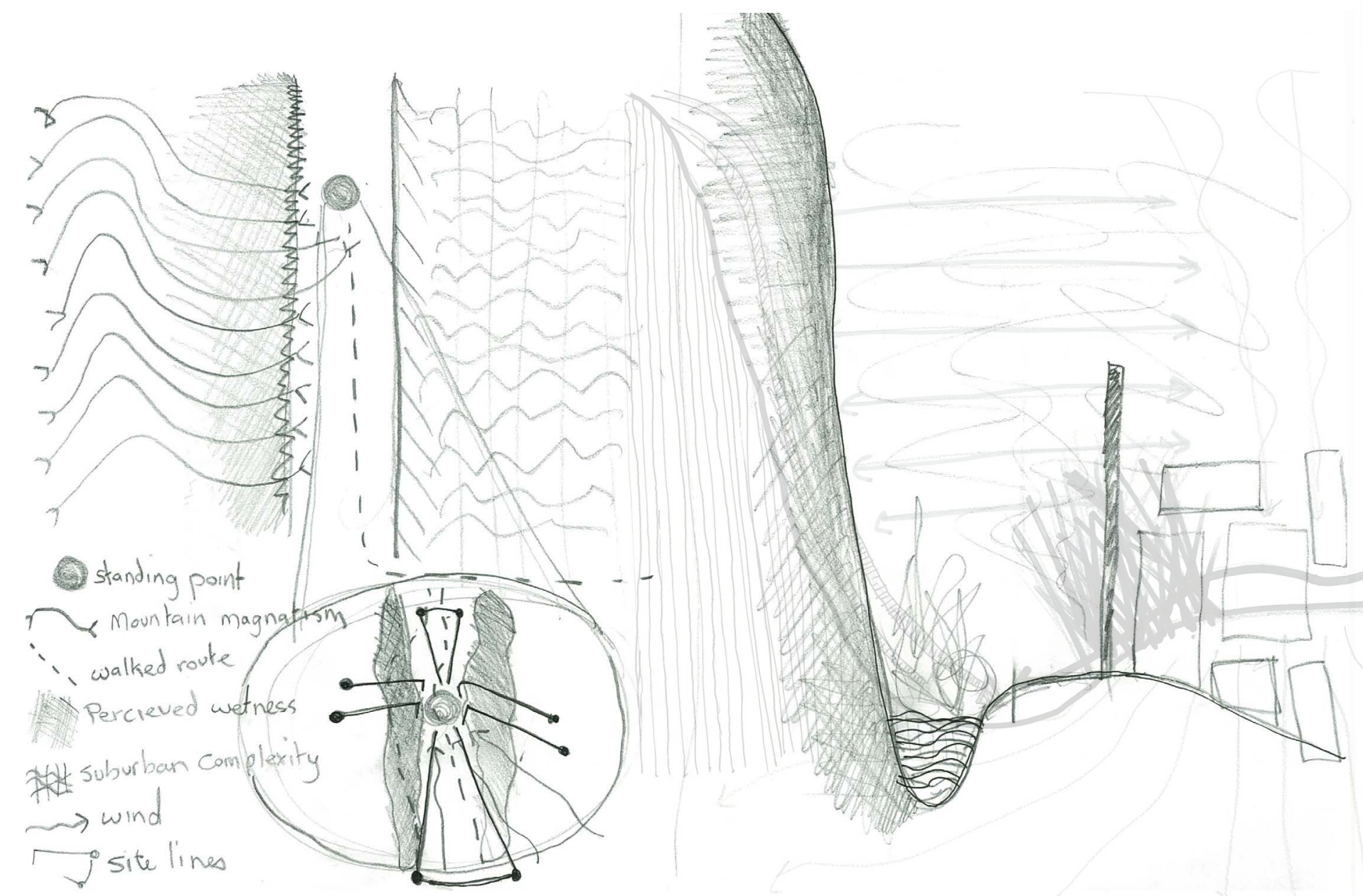

Figure. 46. Layered drawings of site specific analysis about where the different systems of Kapiti overlap 53 and meet. These moments became a focal point to begin exploring where interventions may happen 


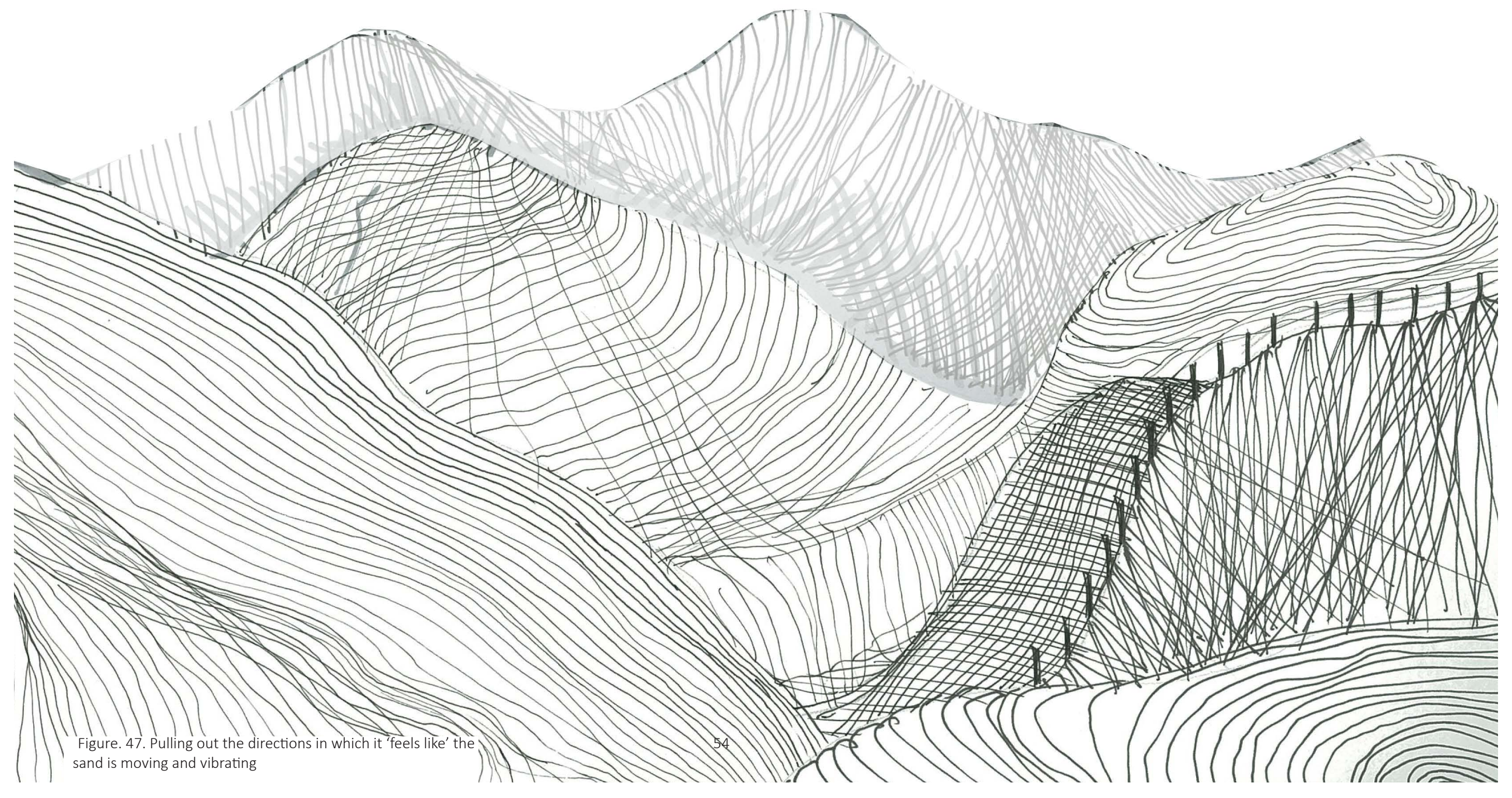




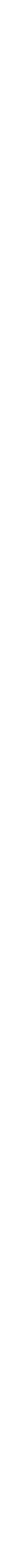




\section{How to Negotiate a Site}

Typically, when designing we go from the broad scale to detail, but if we eliminate scale from the equation there is a different way of looking at things. This point is more about representation than actual design logic, and is referred to extensively in the Landscape as Structure chapter. When we start designing based off an arbitrary scale we have set, our designs begin looking like objects in space or we create a subconscious hierarchy based on scale to determine which design elements are the most important. Of course it is incredibly important to draw designs to scale, but as a final representation not as a means of designing.

As written in the scientific portion of the literature review in chapter 2, my site analysis went beyond GIS data and locating moments on a map. I attempted to map how the systems where affecting me as I was in parts of the landscape. I then recorded this with pen on paper, in a very basic 'as it happened' way. Following are the key areas I recorded while analysing my site specific experience.

For each of these areas I sat still for 6 minutes and recorded sensations I noticed.

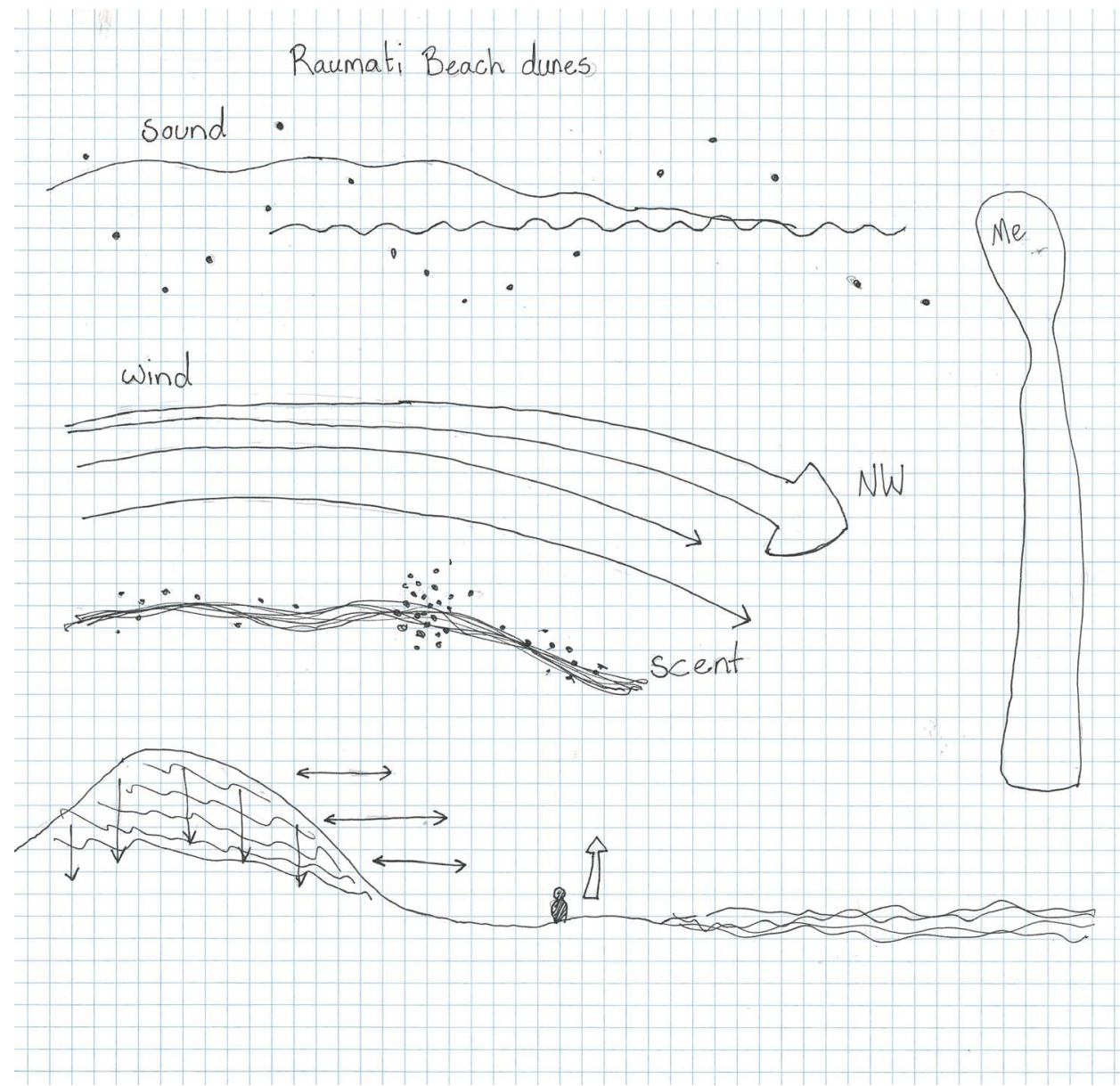

The sounds here took most of my attention. As small movements made with my body or the wind would completely shift the auditory sensations. The ground was soft, but felt very still despite the movement of the sand and sea. Even with Kapiti Island ahead, I still found my gaze falling southward towards Paekakariki. I had the urge to scavenge all the rocks and driftwood to construct things.

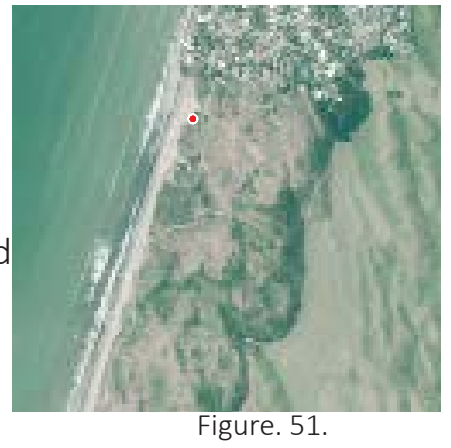




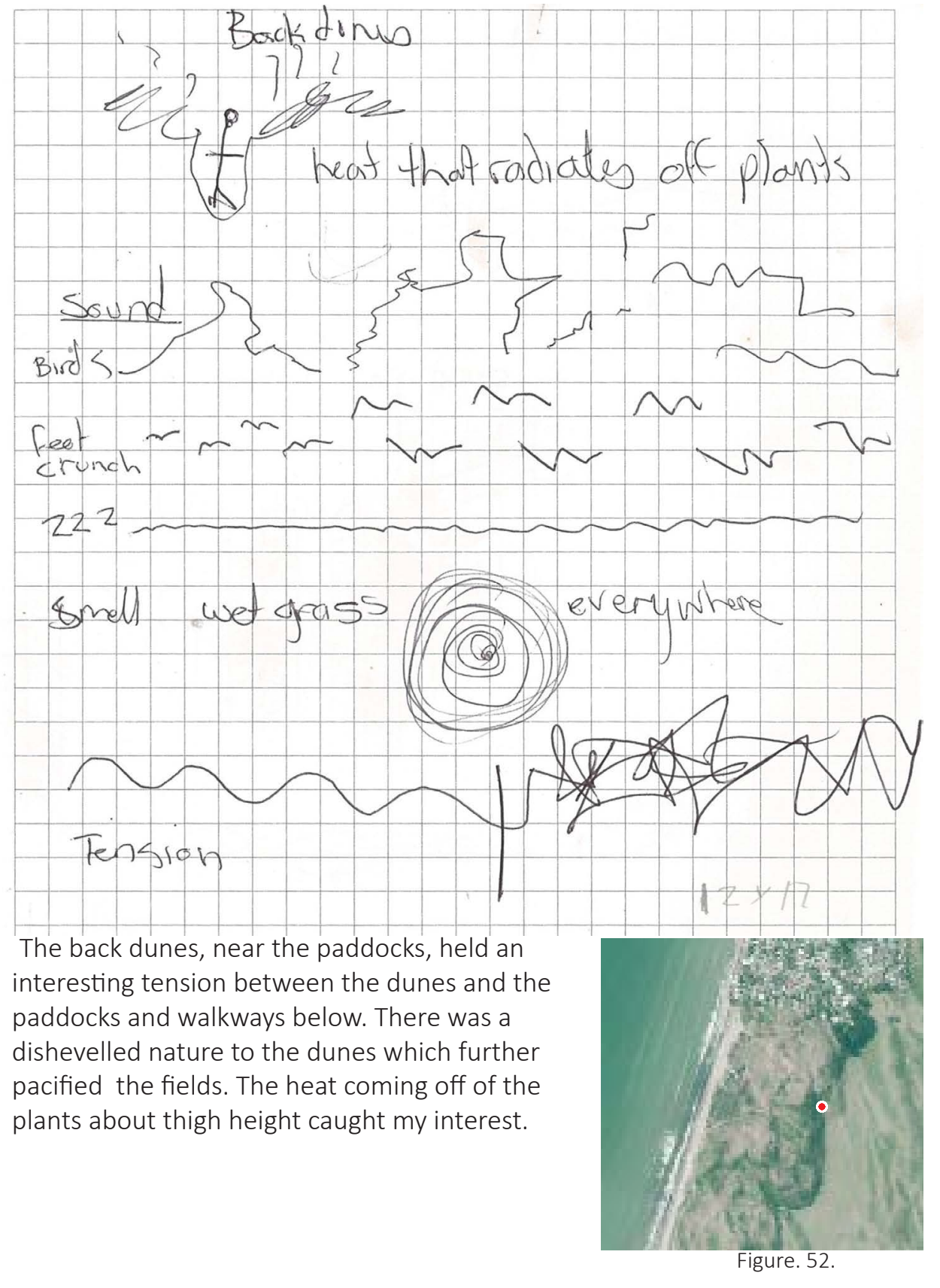

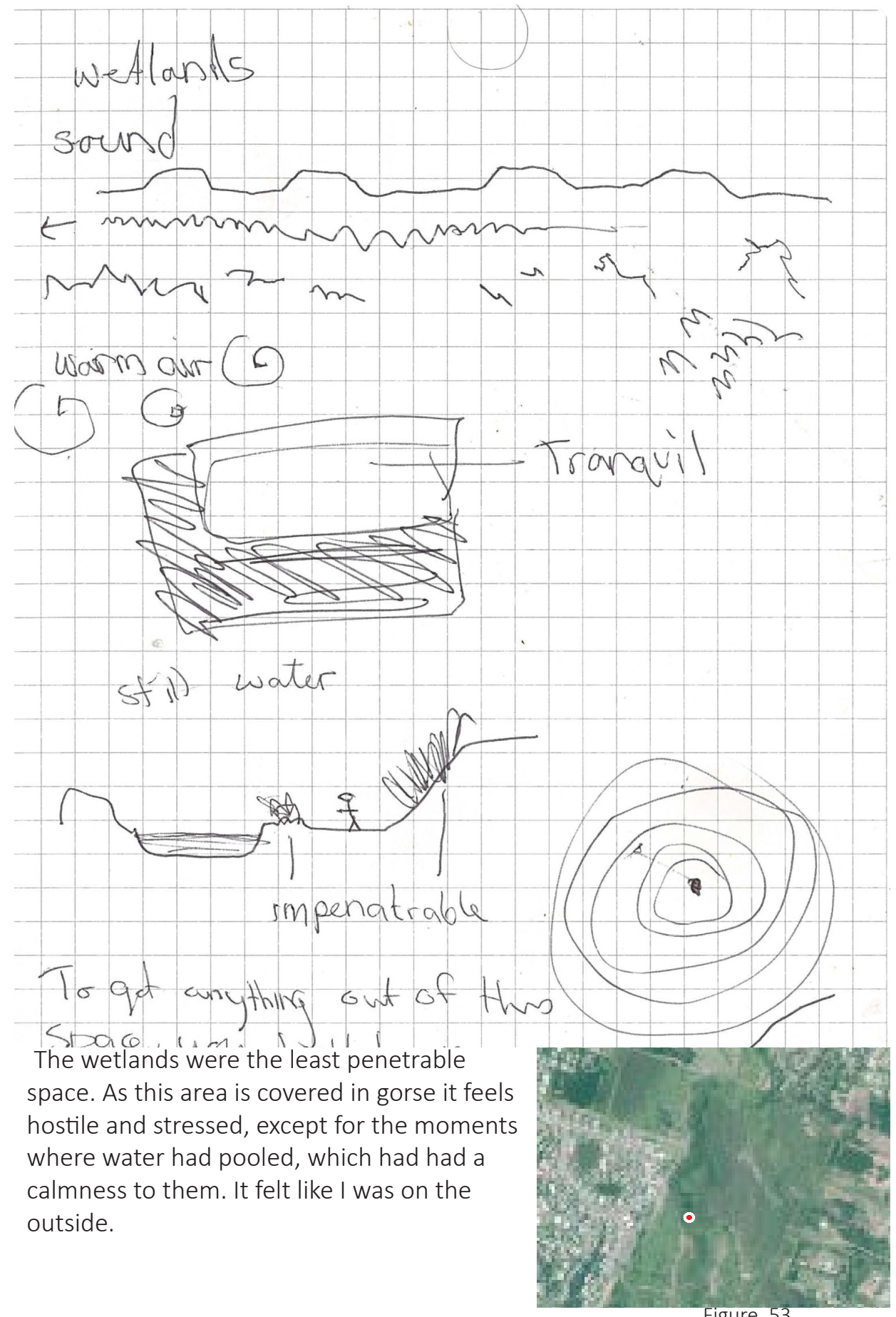

Figure. 53 


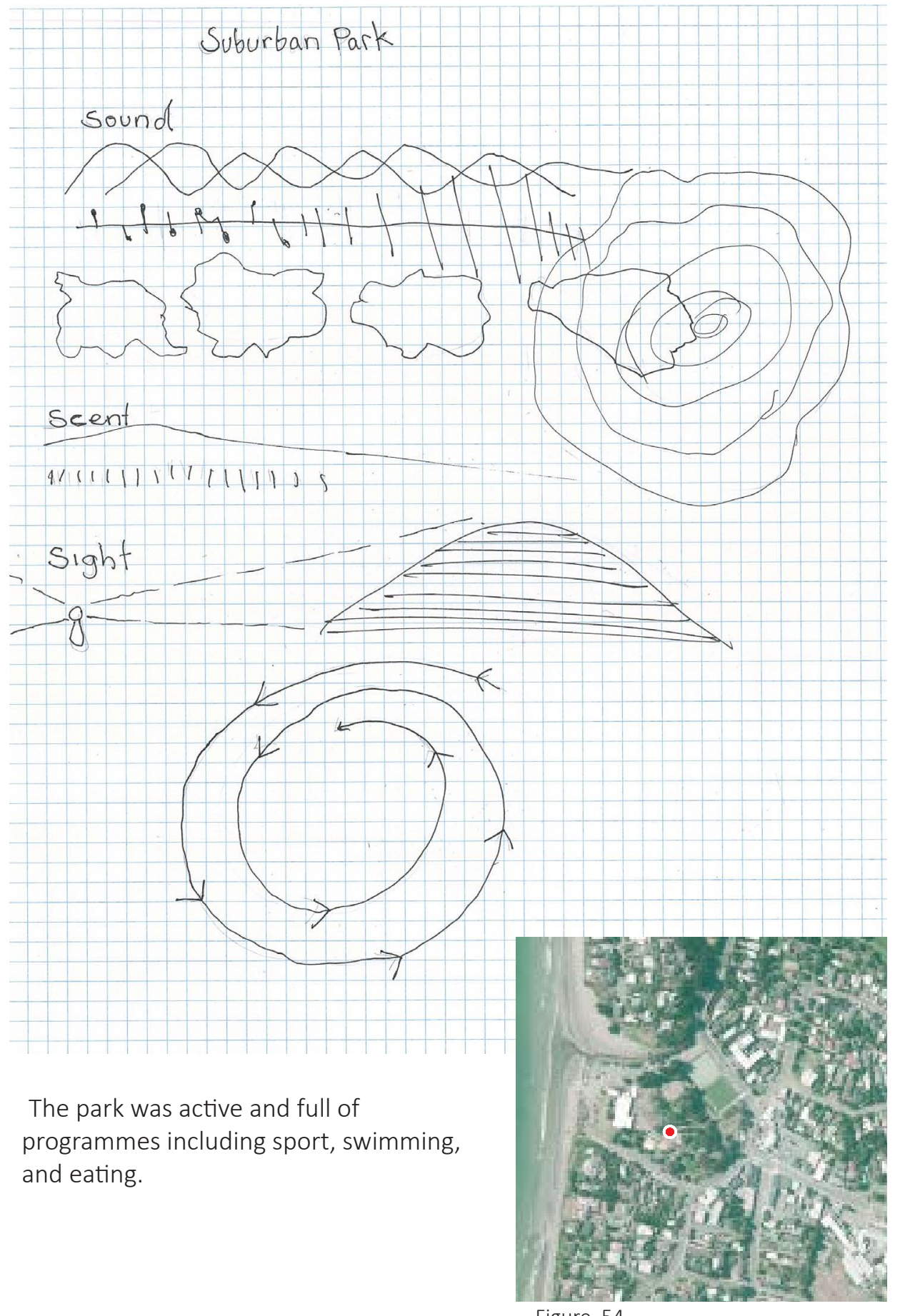

Figure. 54
These analytical site studies began to formulate where structural catalysts may go, and in what way different spaces could benefit from an intervention of small poiesis. The chapter Using Poles to Build and Connect Ecosystems delves deeper into site specific analysis. 
Allowing the space to perform

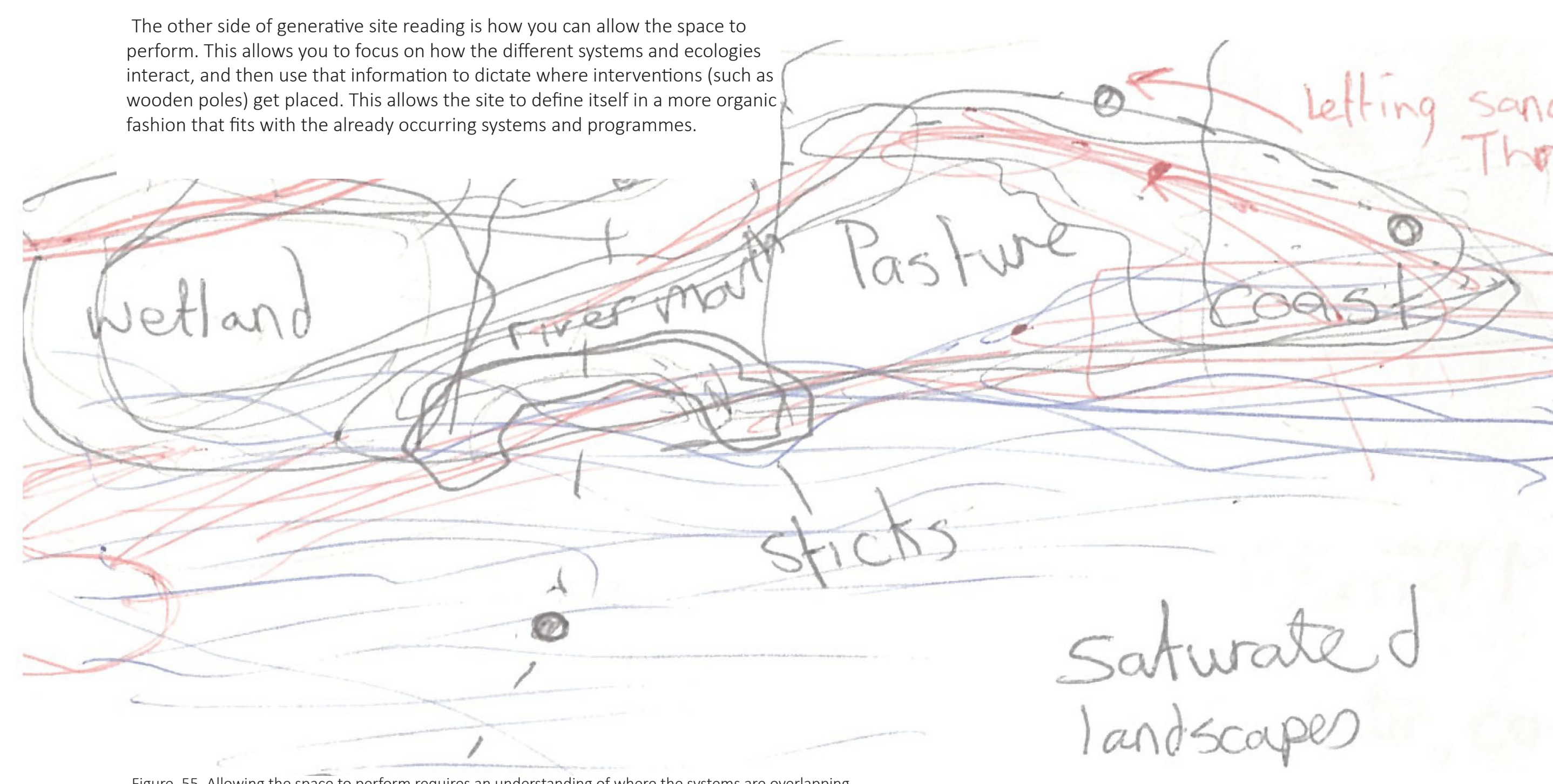




\section{Experiment one.} (15) th $\rightarrow \rightarrow$ $\cdot$<smiles>COOOOCOO</smiles>

(6)

(-)

(-)

(6)
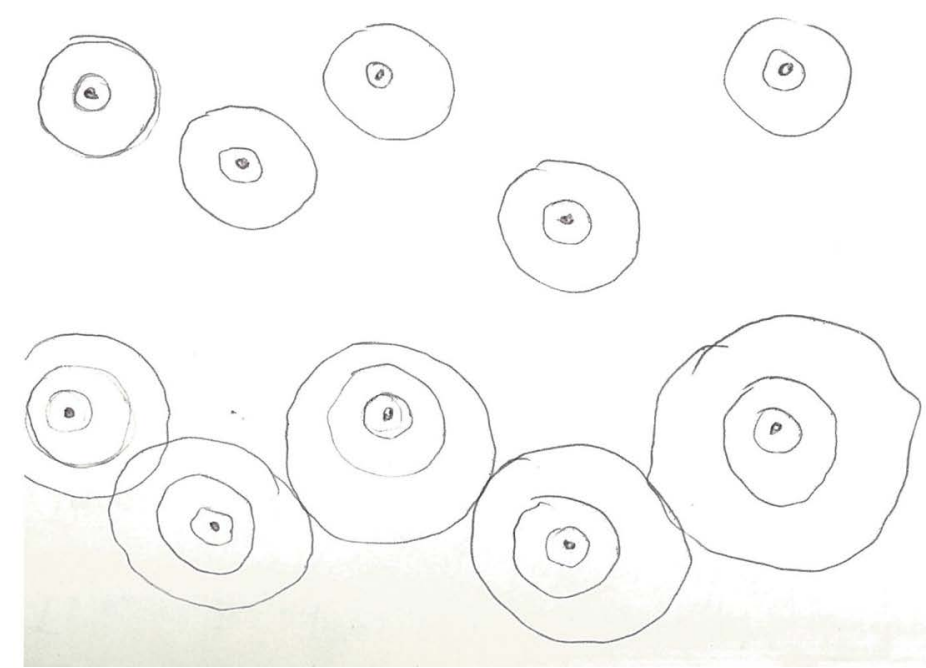

Figure. 56.The process that the intervention will perform void remoteness

aturation $\Delta \otimes \Delta \square$ axis $00 \square \square \square$ Elevated axis

r.
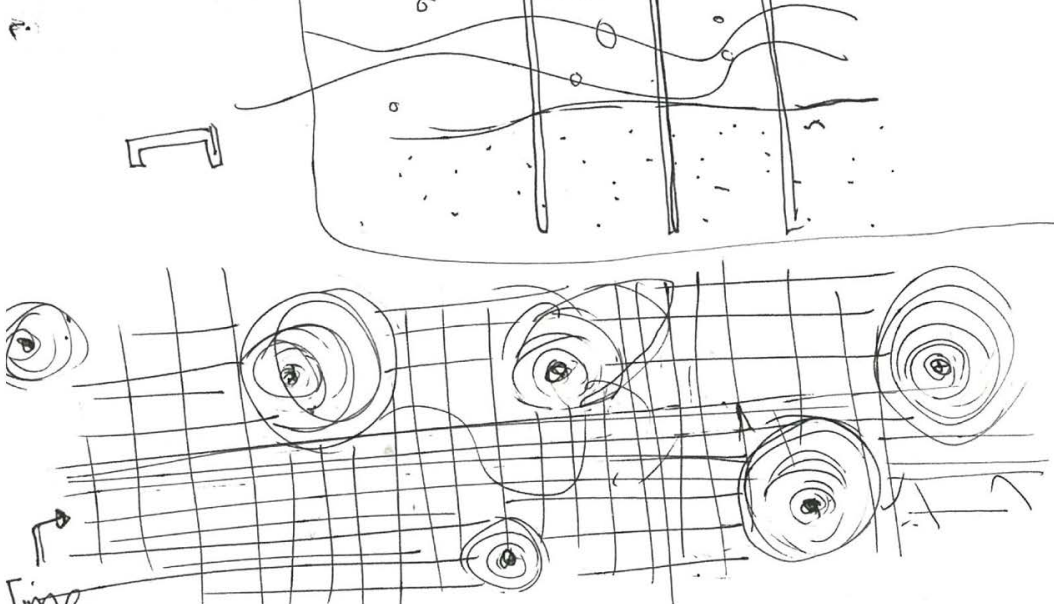

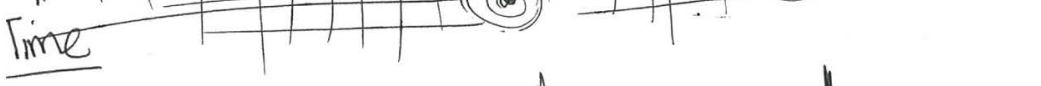
ristid.
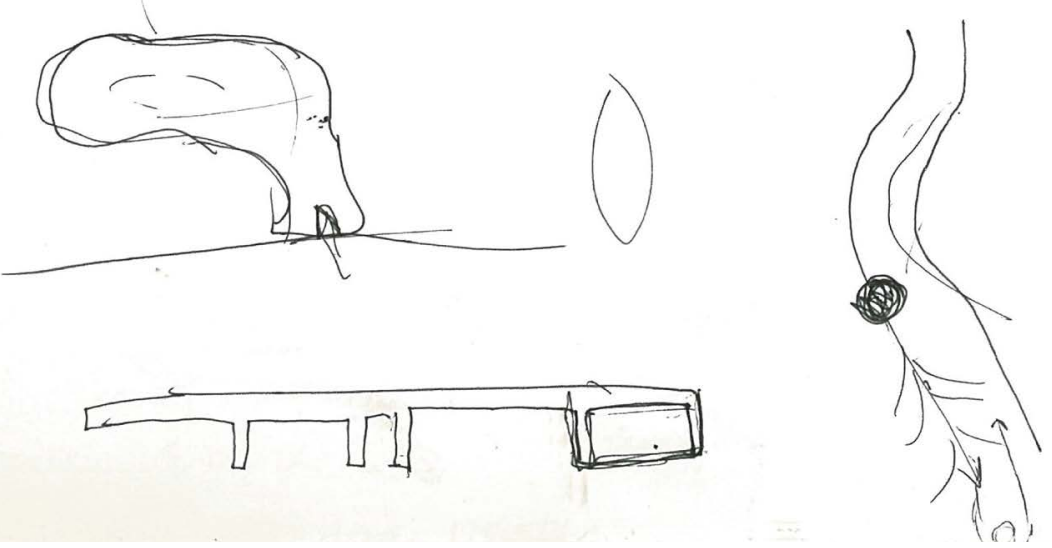

Figure. 57. Understand how it is interrupting the current patterns. In this example the suburban grid and water edge 

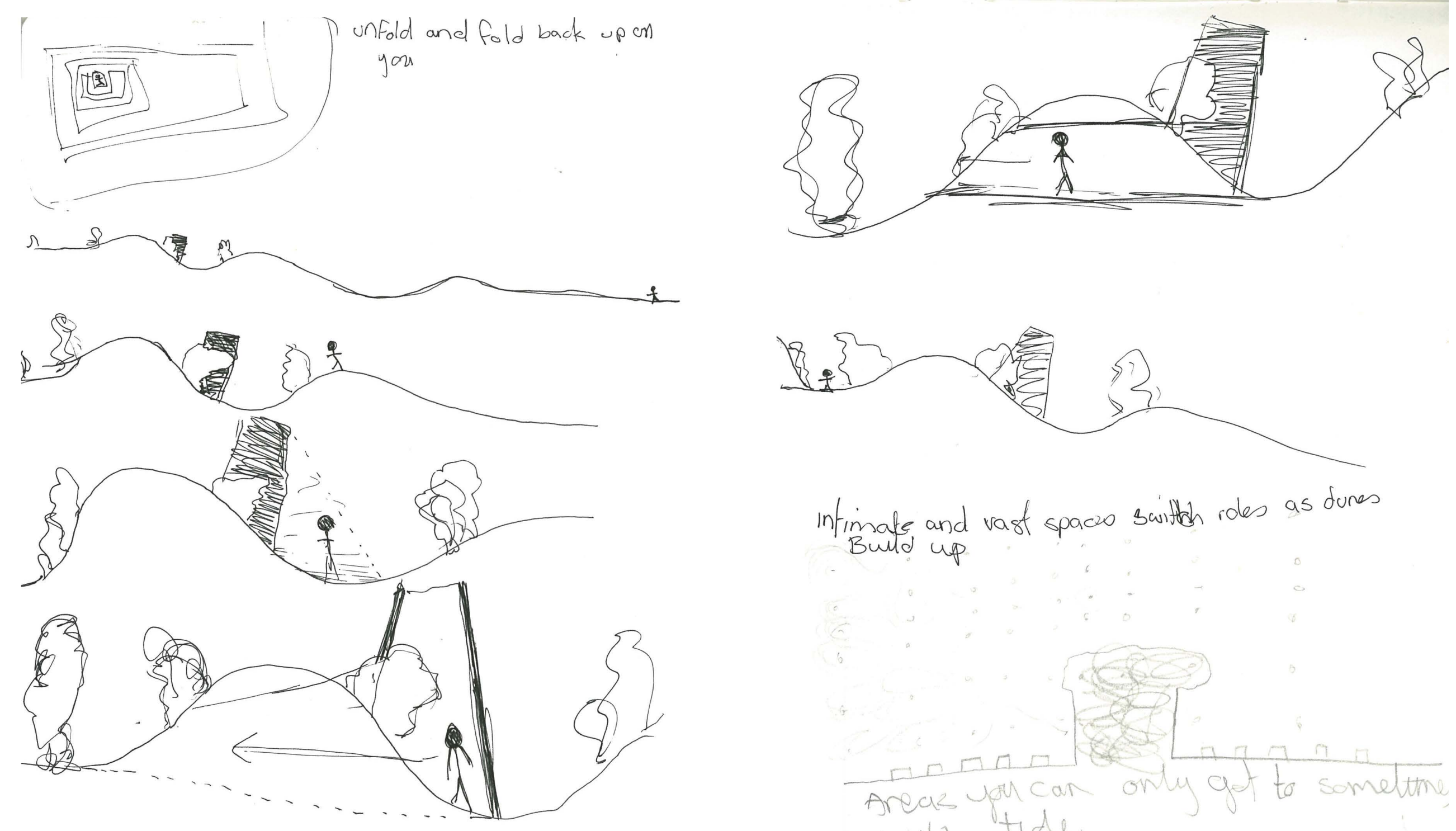

Figure. 58. Examine how human interaction will take place in and around the intervention. 


$$
\begin{gathered}
\text { Preliminary } \\
\text { Designs }
\end{gathered}
$$




\section{Navigating a Site}

I wanted to connect the flat land and coast with the mountains. Initially this was done through experimenting with creating a sense of journey and navigation.

The early iterations explore meandering paths that keep directing a person's view towards the mountains and takes them the under, above and around landforms to envelop the user and produce a stronger engagement with the space.
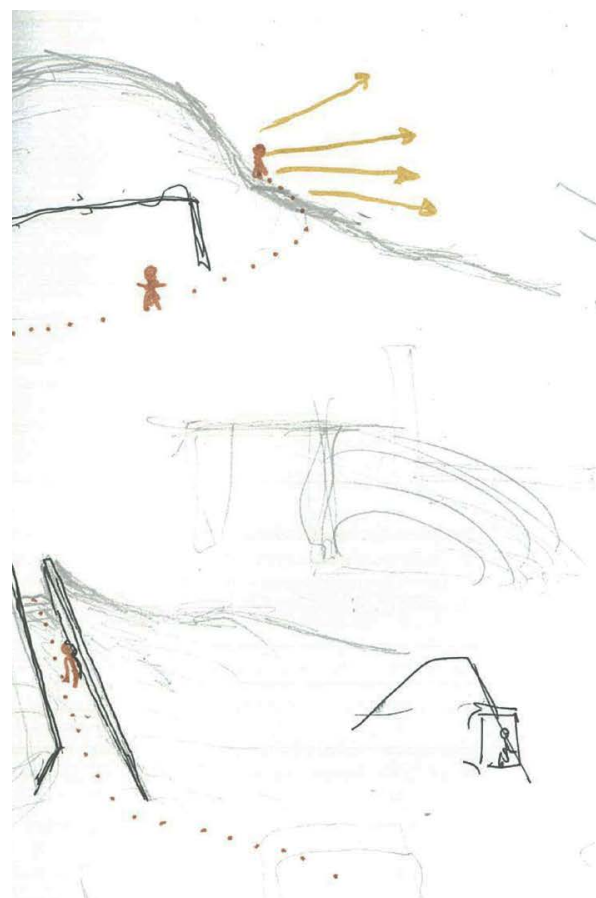

$$
\text { The mone it gets used, the stronger it gets }
$$$$
\cdots
$$
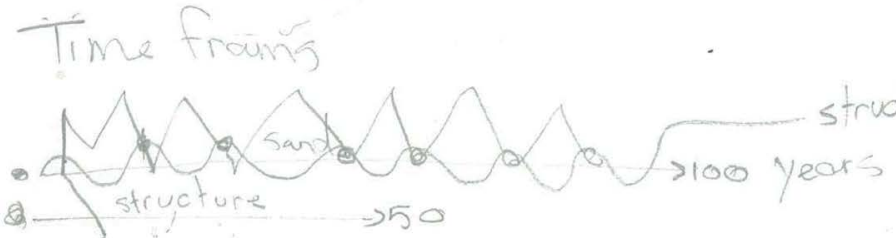

Peope
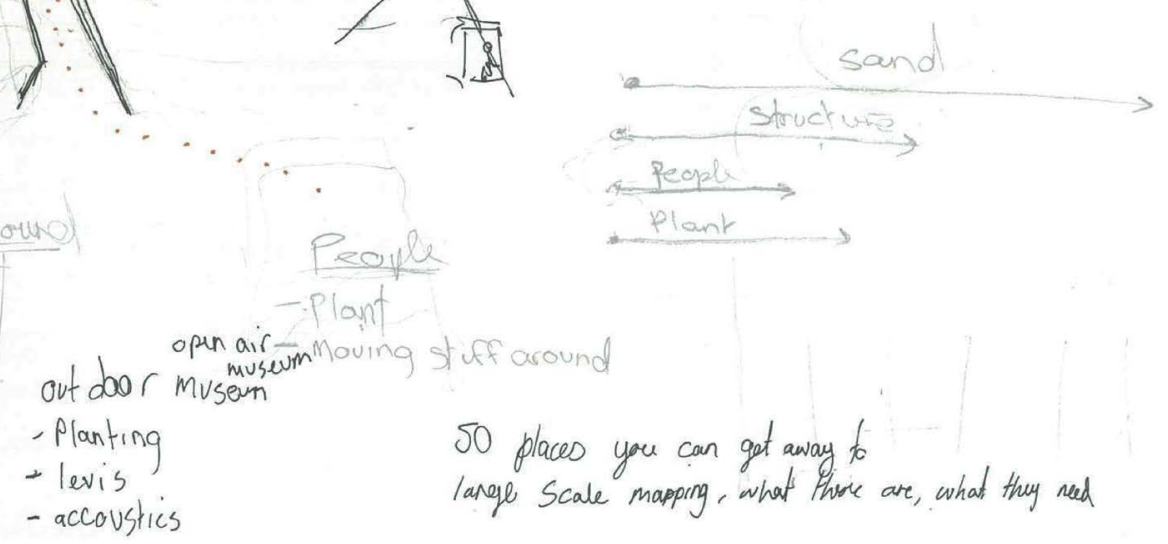


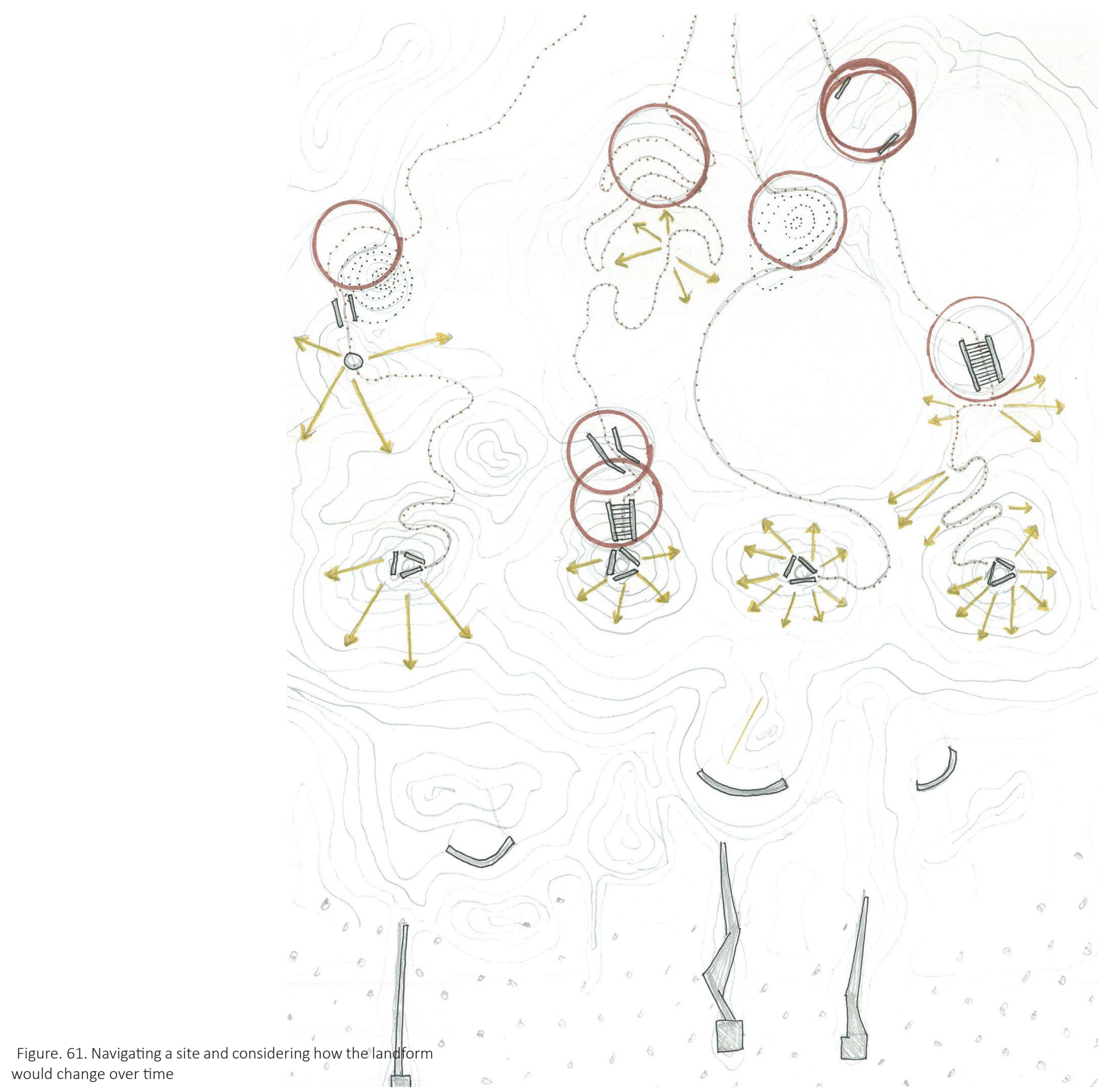




\section{Engaging with Birds}

I wanted these seed dispersal structures to be more engaging for people and birds. A possible solution was to incorporate play, and give people access to seeds. I explored ideas like sling shots, to allow people to fire the seeds out into the wetlands or dunes, or alternatively feed birds, who will then spread seeds in their natural way.

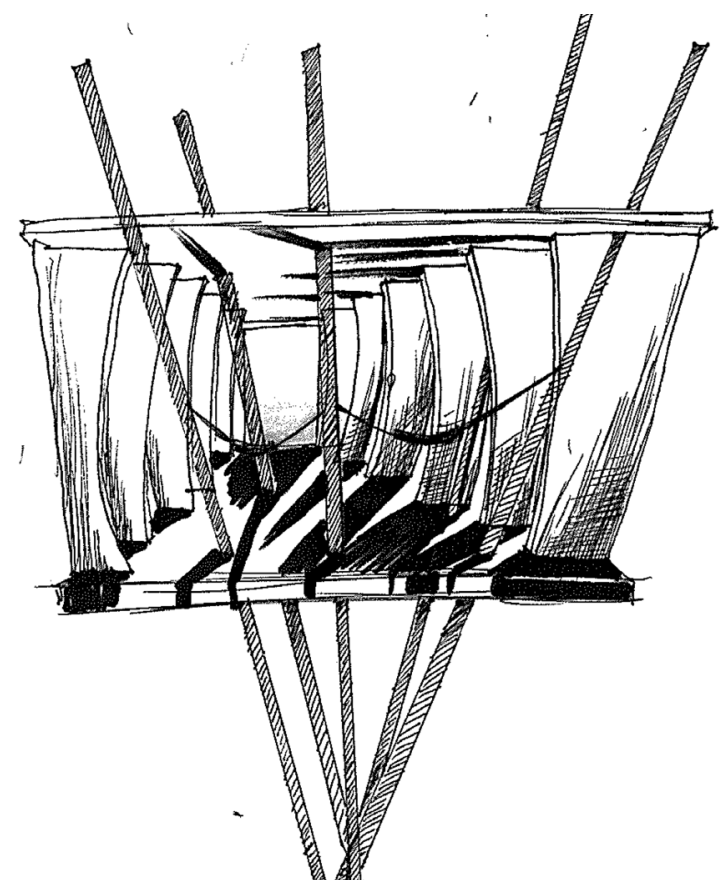

Figure. 62. Lookout with sling shots

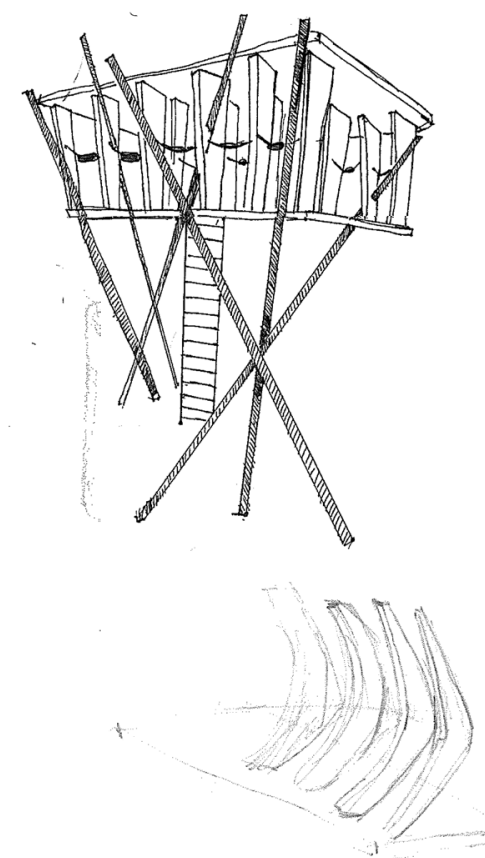

Figure. 63. Open air structures to climb

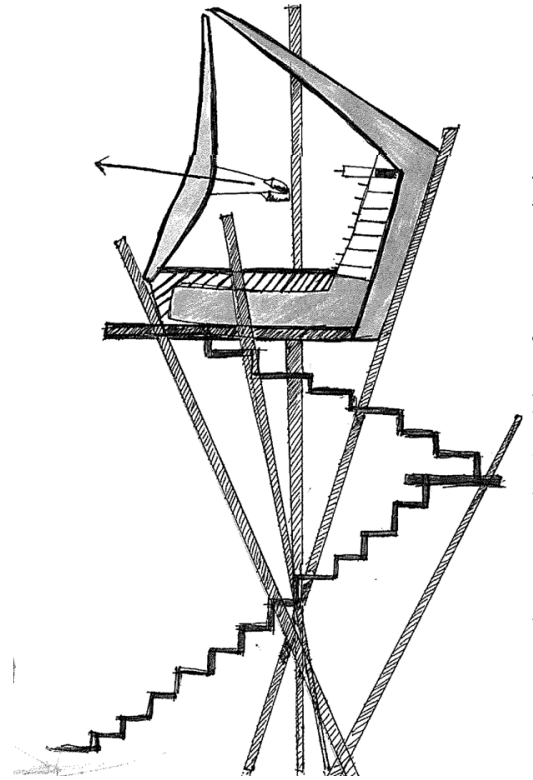

Figure. 65. Open air structures to climb

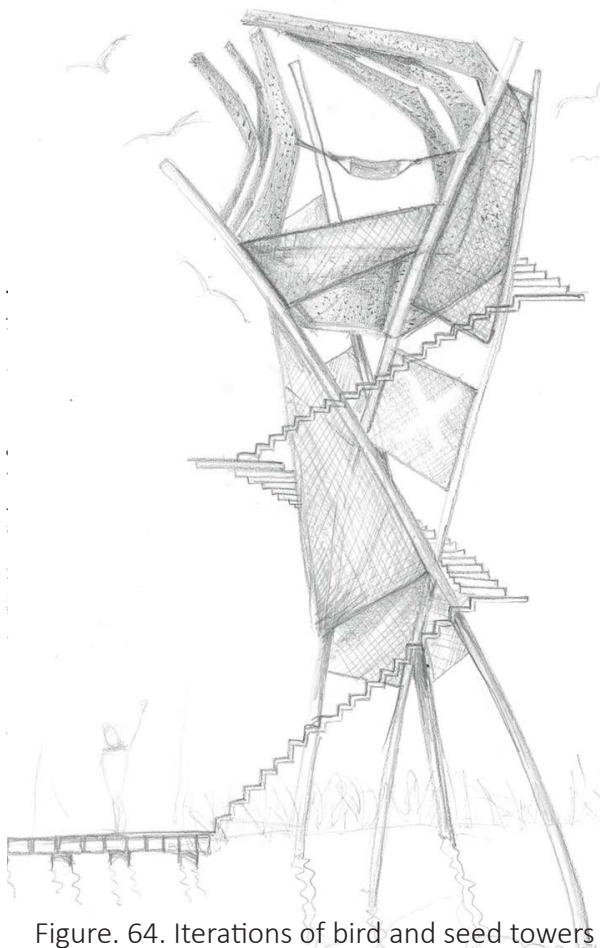

Figure. 64. Iterations of bird and seed towers 


\section{Agricultural machinery}

An aesthetic I chose to explore for a while was that of machines and silos commonly found on farms. I wanted to express that this landscape (dunes and behind dunes in particular) were an everyday aspect of Kapiti and that they played a role in the performance of the land. This idea emerged as the research shifted from inhabiting the dunes to them performing as more of an interactive park space. I began formulating ways in which people play a participative role in dispersing seeds As the scope of the research was refined the decision was made to not pursue seed dispersal mechanisms further as it was deemed more important to focus on other elements, such as sand accumulation and water collection.

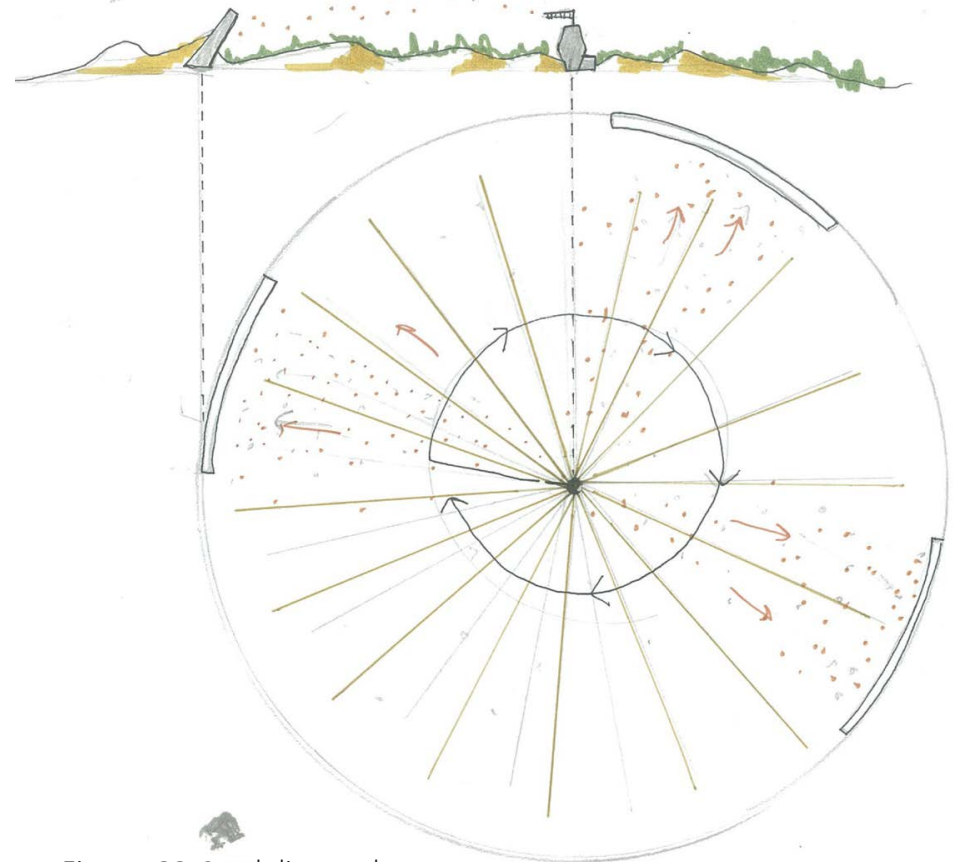

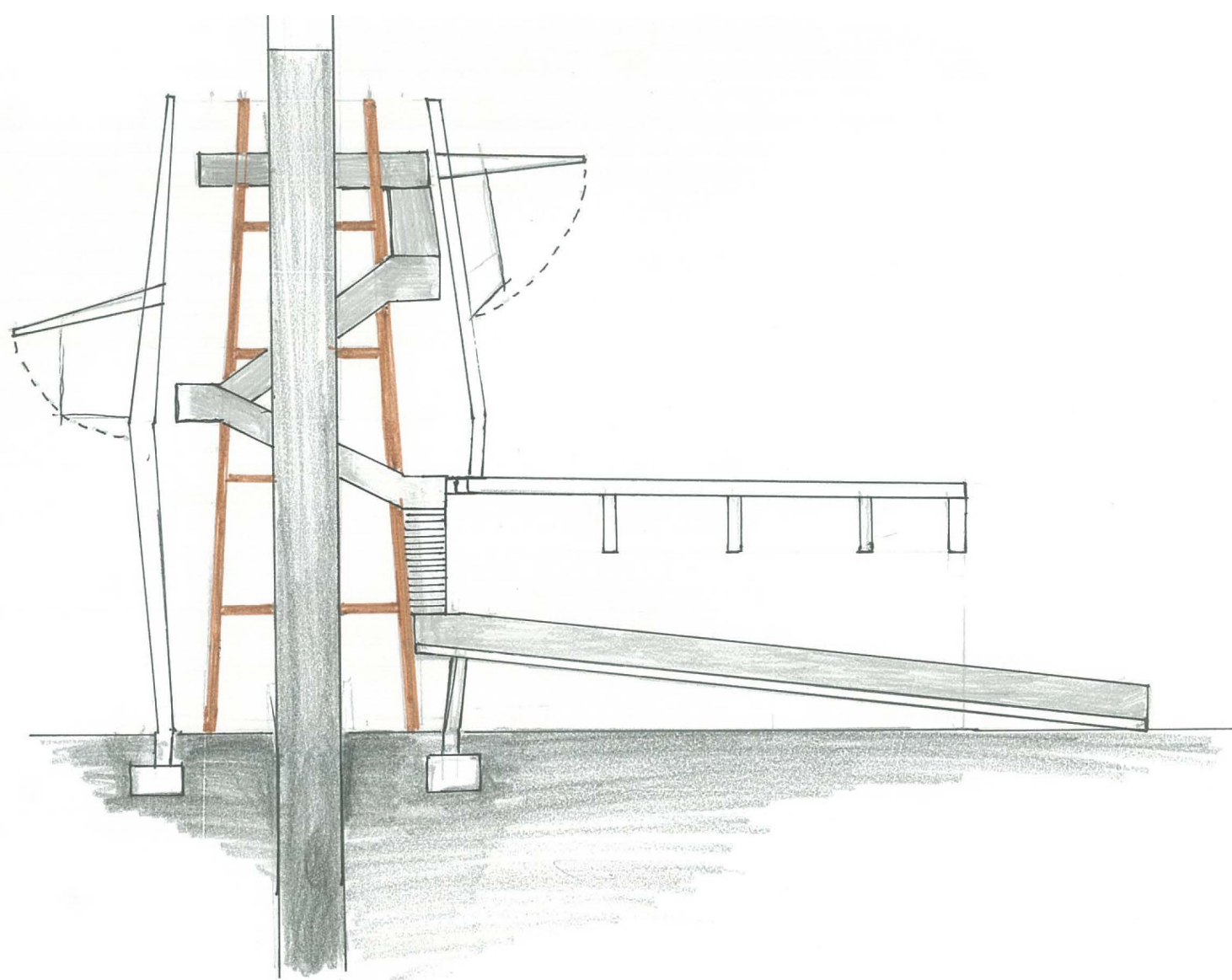

Figure. 67. Seed Bank tower / Lookout 

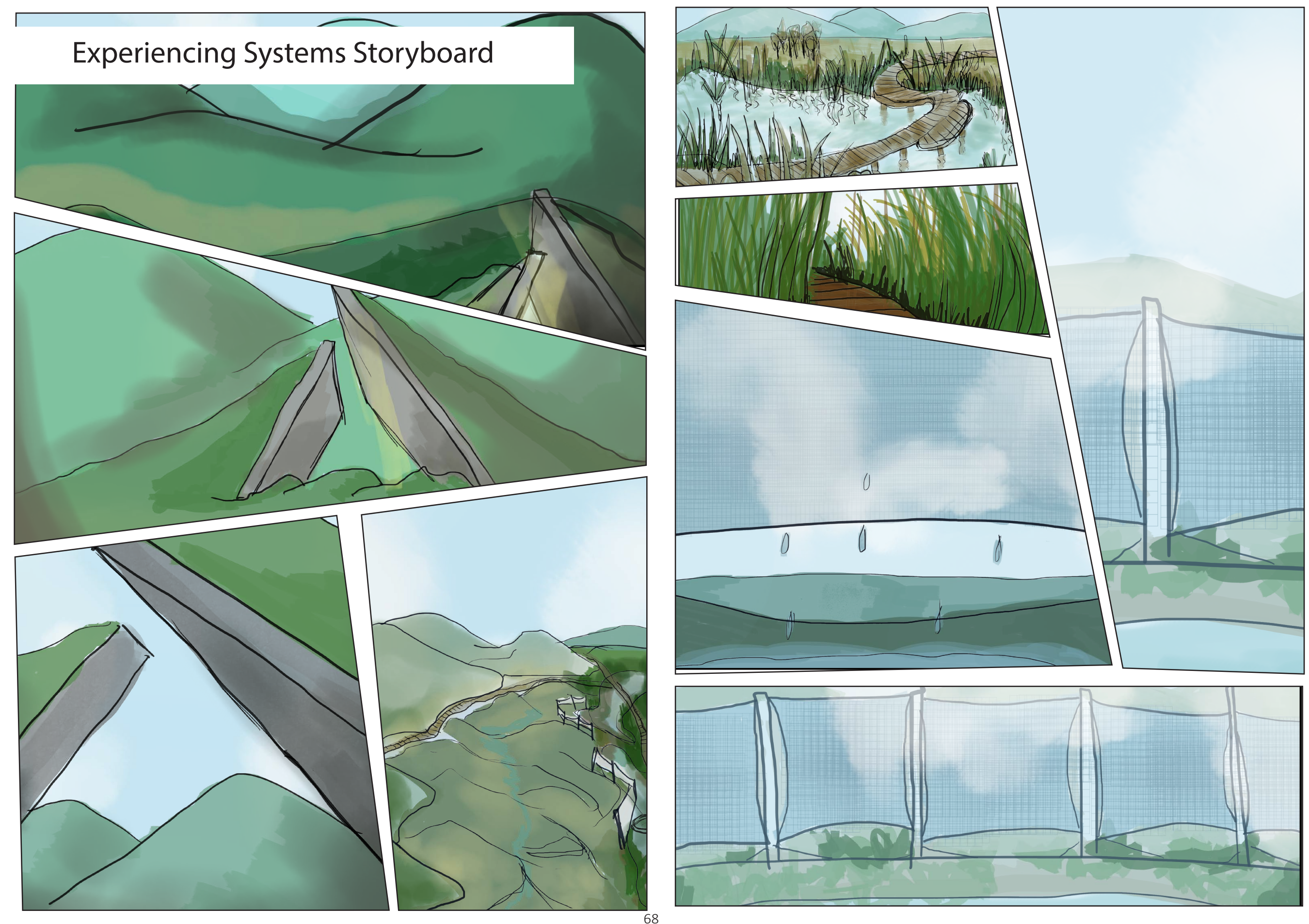

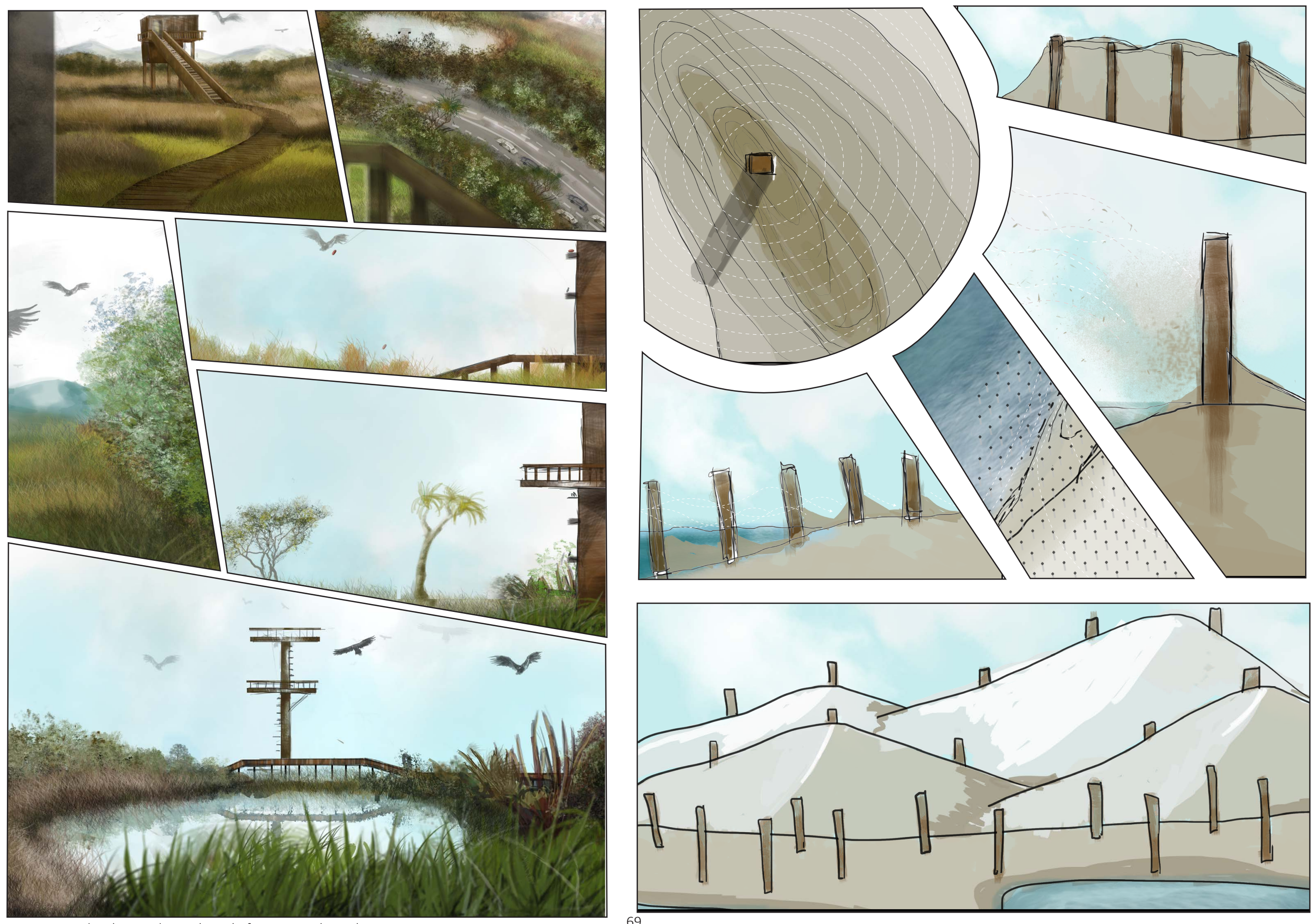

Figure. 68.(Both pages) Storyboard of a journey through Kapit

69 


\section{Design Reflection}

Storyboarding was a method chosen to produce preliminary design ideas with intention of keeping the design in the realm of human experience.

Storyboarding allows design to be represented without a defined scale and for the simplicity of the design to be measured against the simplicity of the drawing style. I used this is a constraint to work with.

Typically, when dealing with large scales landscape architects work in plan, design with large brush strokes. This makes it difficult to understand the experiential qualities of a site and can mean smaller details are left out. Storyboarding offered a solution to this by negotiating a site by drawing in perspective. This encourages one to consider how people will view and move through a space moment by moment. A comic book frame only shows you exactly what you need to see in order to be able to read the situation, this is how I chose to approach this design.
The key limitation to storyboarding is the lack of depth within each image. Storyboarding fails to acknowledge the landscape and environmental qualities of the site that have informed the design. It also lacks the complexity revealed in analysing the site and has the tendency to come across as vague and ungrounded. A solution to this lack of complexity and information is layering.

Layering is explored in the literature review of John Wolesley and Laurence Halprin. It is a means of showing an abundance of information in one image while offering the ability to create a hierarchy. By combining what I learned from the images of Wolesley and Halprin with storyboarding I was able to portray the design and the systems influencing it at the same time while also being able to represent the passing of time.

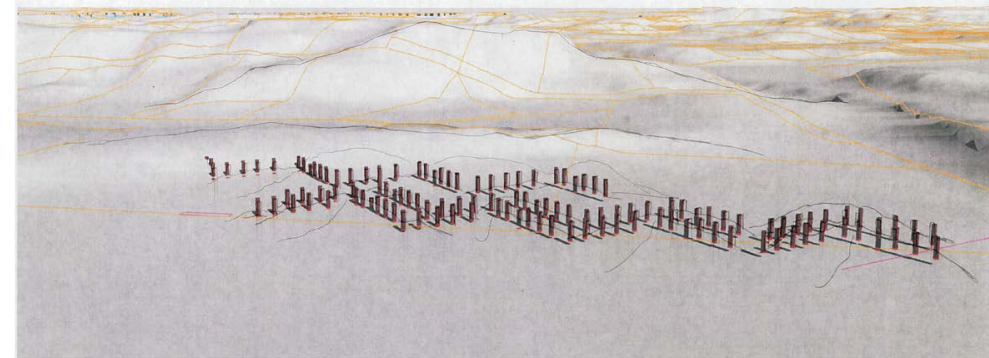

Figure. 69. Designs drawn directly on Kapiti's landform. This was an attempt at applying 2-D drawing methods onto 3-D spaces in order to push storyboarding to be more site specific

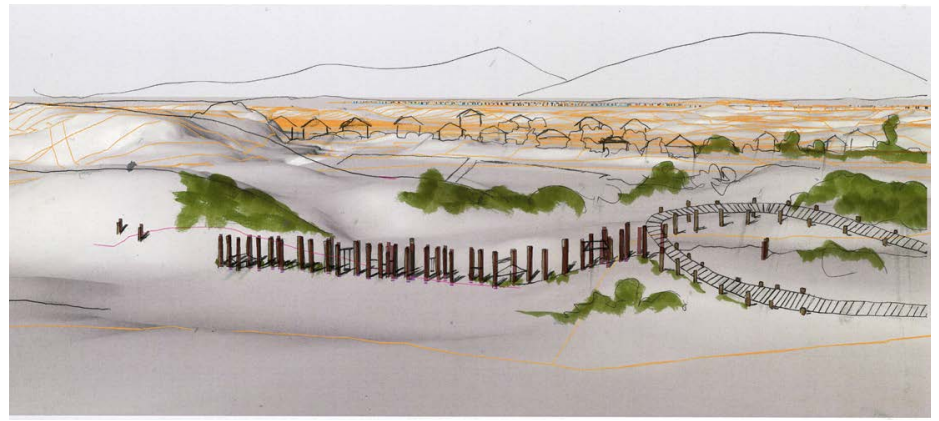

Figure. 70

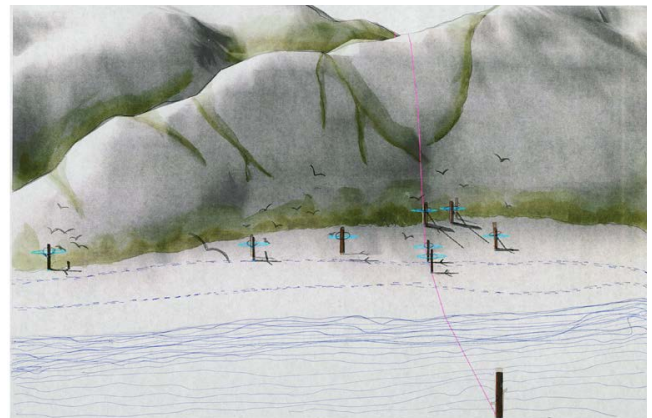

Figure. 71. 


\section{Layering over Analysis}

Act One - Birds and Seeds
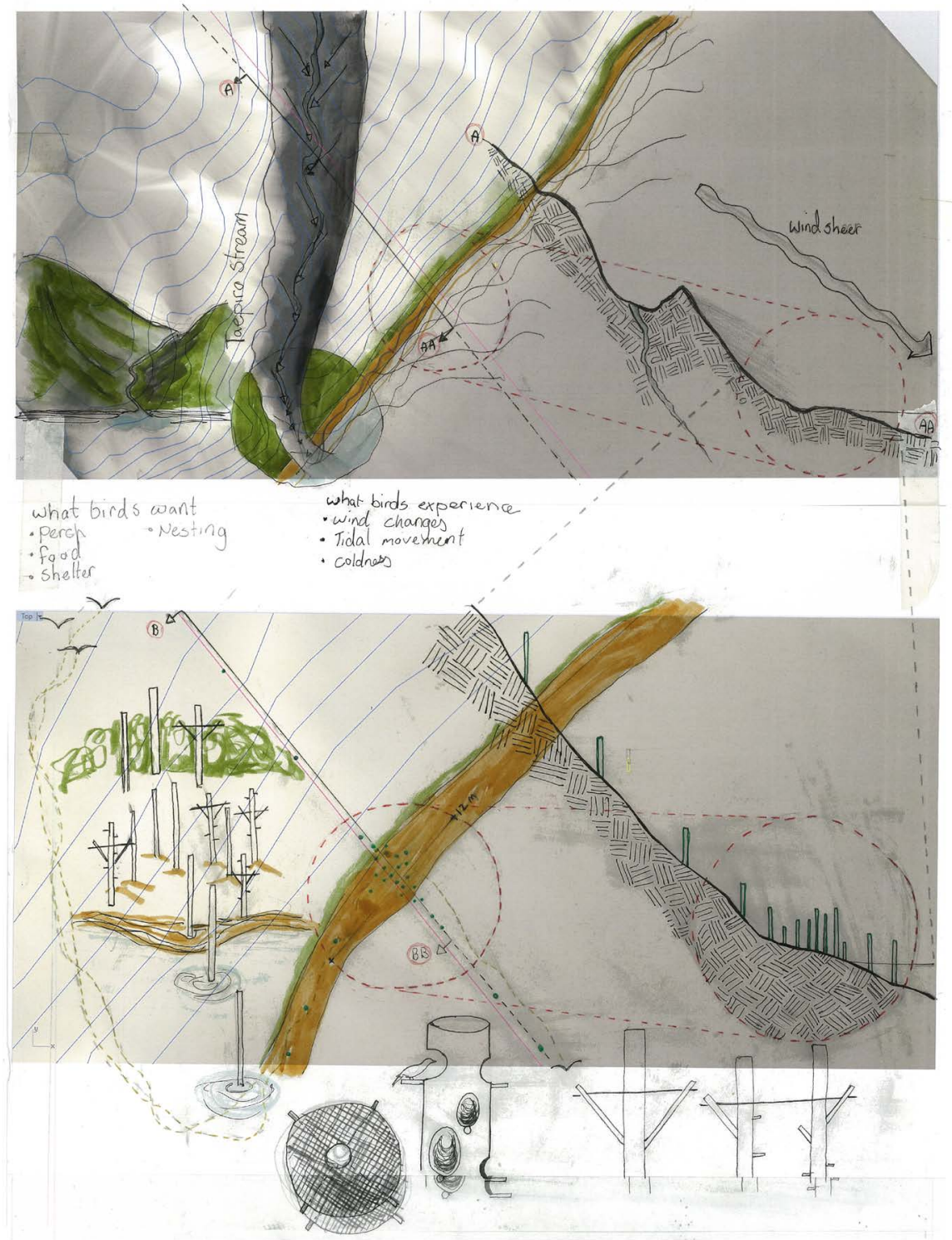

Figure. 72. Bird Perchers at the foot of Kapiti Island mark the beginning of the birds journey to the mainland. The poles in the water are also perchers, but the submerged sections can house shellfish
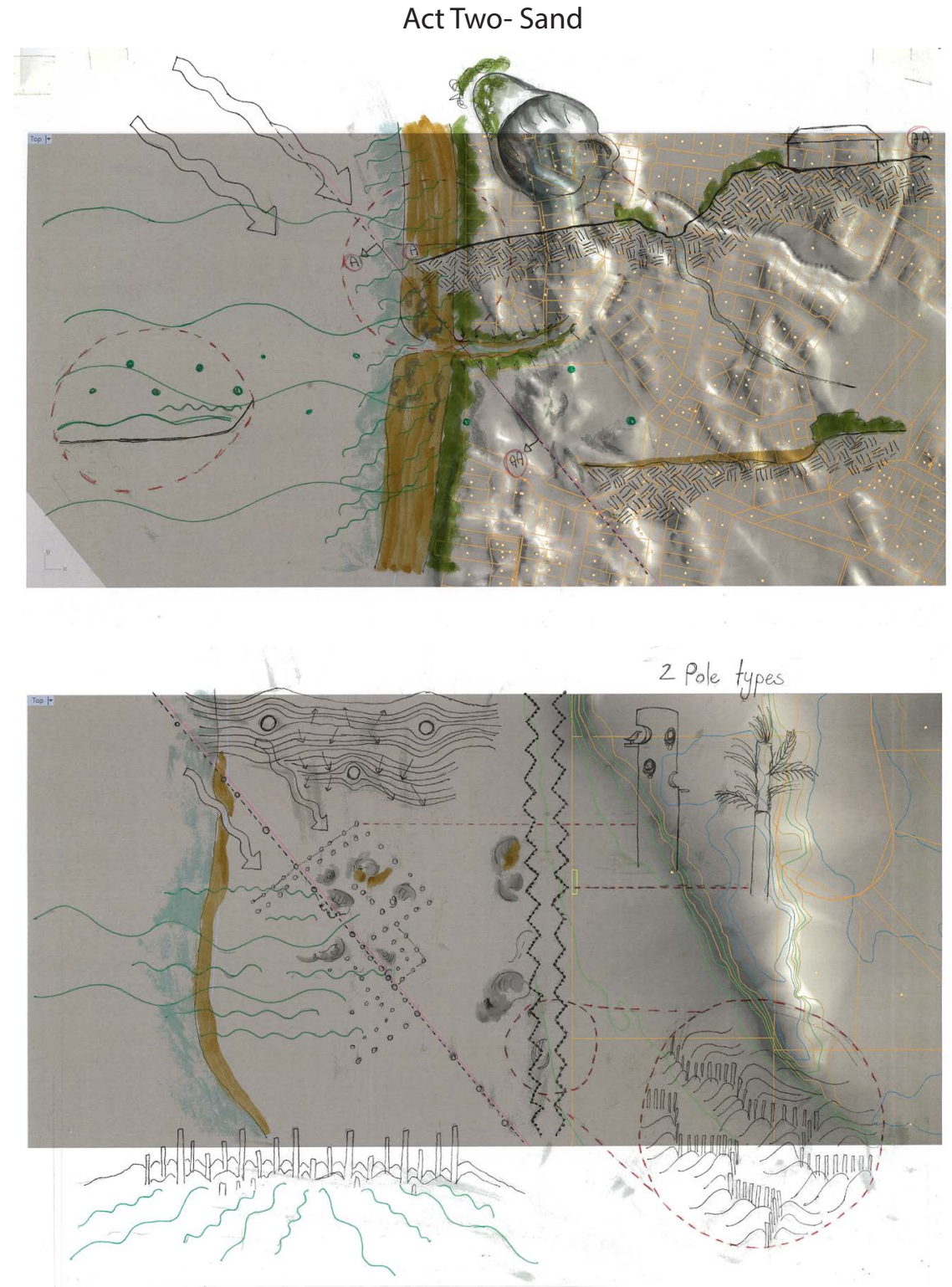

Figure. 73. Based off of the sound waves experienced on the site the sticks have been placed in a series of triangles which will funnel sounds towards people. They will also build up dunes where the site is eroding most 
Act Three - Play

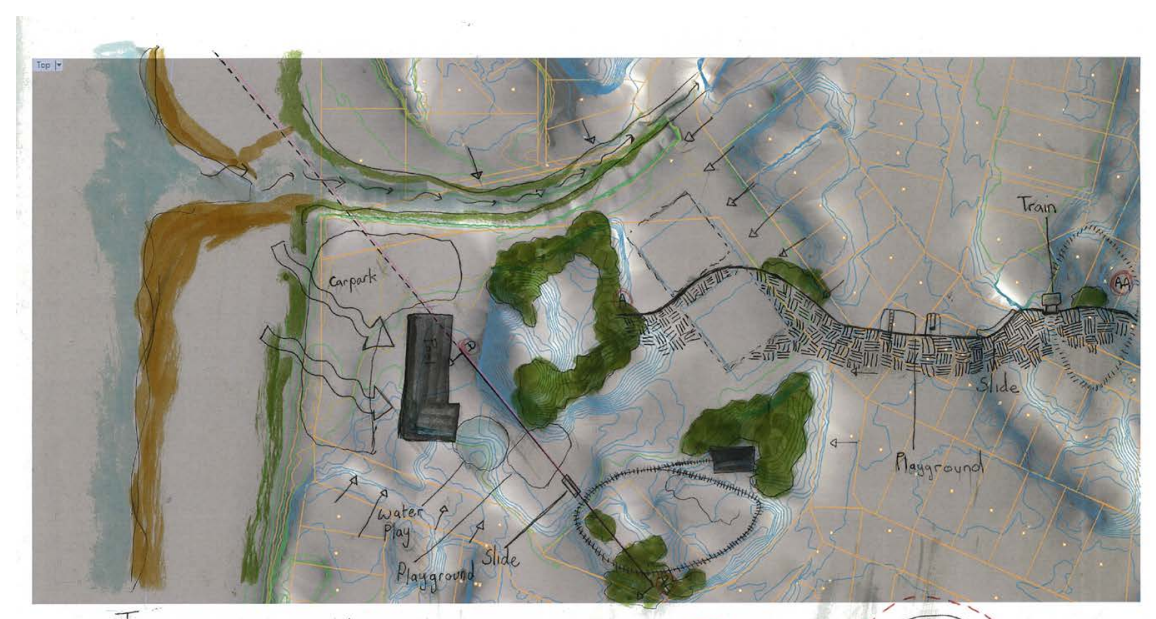

Tapping into play - kid catahers

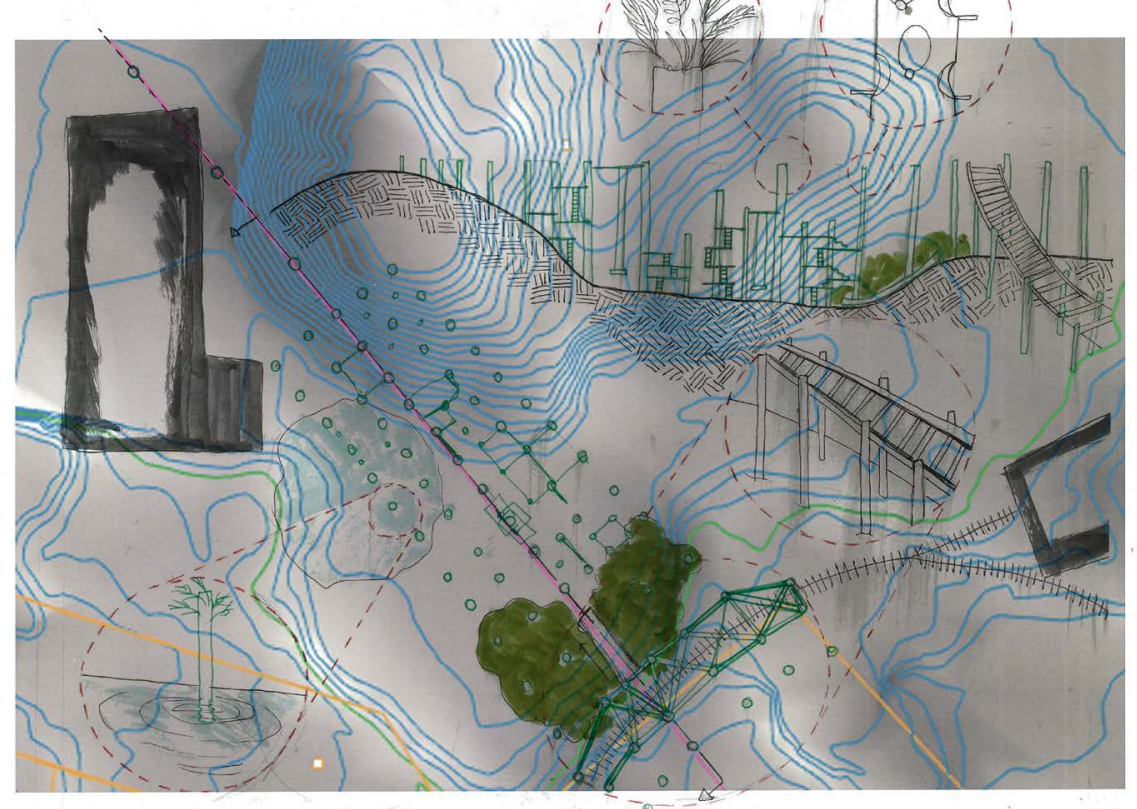

Figure. 74. This intervention is in the centre of a big park in Kapiti, which includes a children's train ride. The poles here will perform as a jungle gym and prop up new train tracks
Act Three - Play

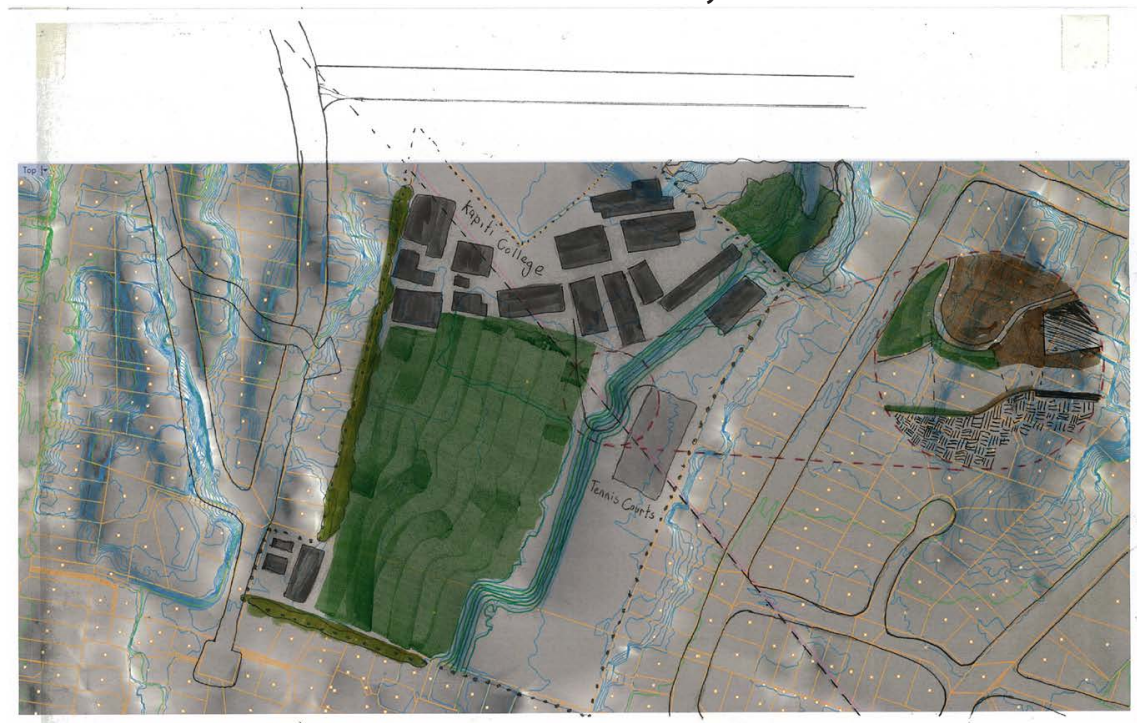

space is used for sports
students have typically bike to school.

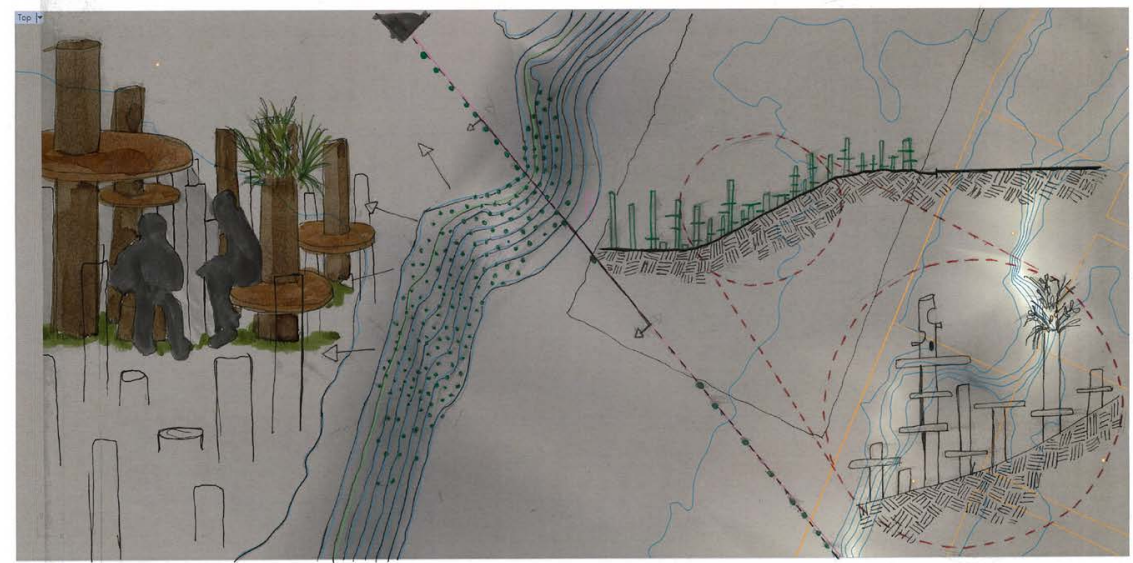

Figure. 75. This second area of play is to the side of Kapiti College's sports field, the site lacks any spectator area for the games and lacks in and structures for students to appropriate. 


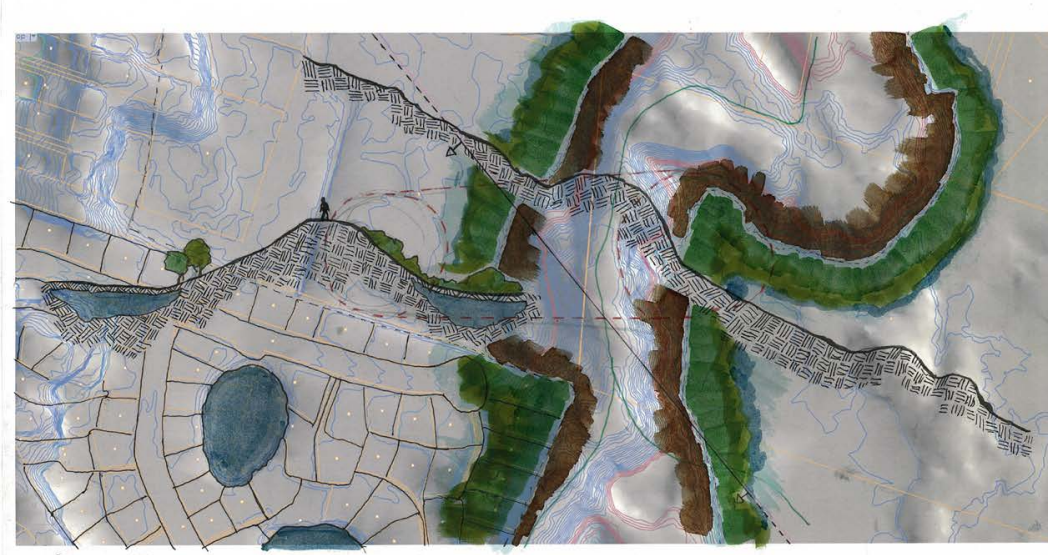

og catchers

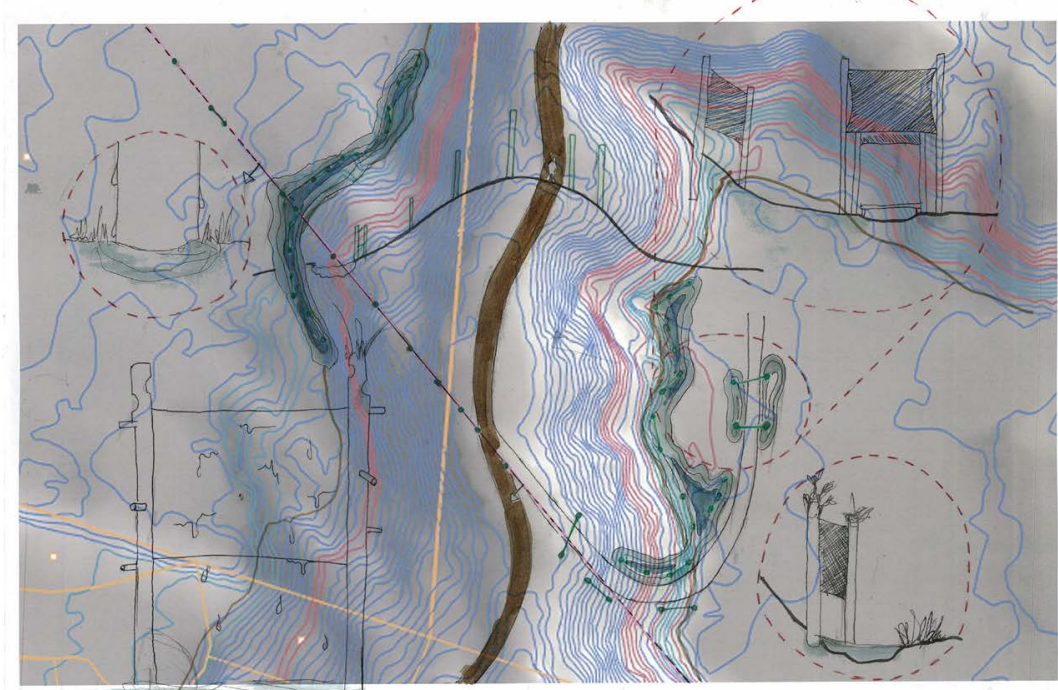

$$
\frac{2}{2}
$$

Figure. 76. The fog catches work best at the foot of dunes as this is were the ground is most saturated and there is plenty of rain water run off. There will also be giant fog catchers ascending the mountain in order to collect more water for the earliest wetland established stages
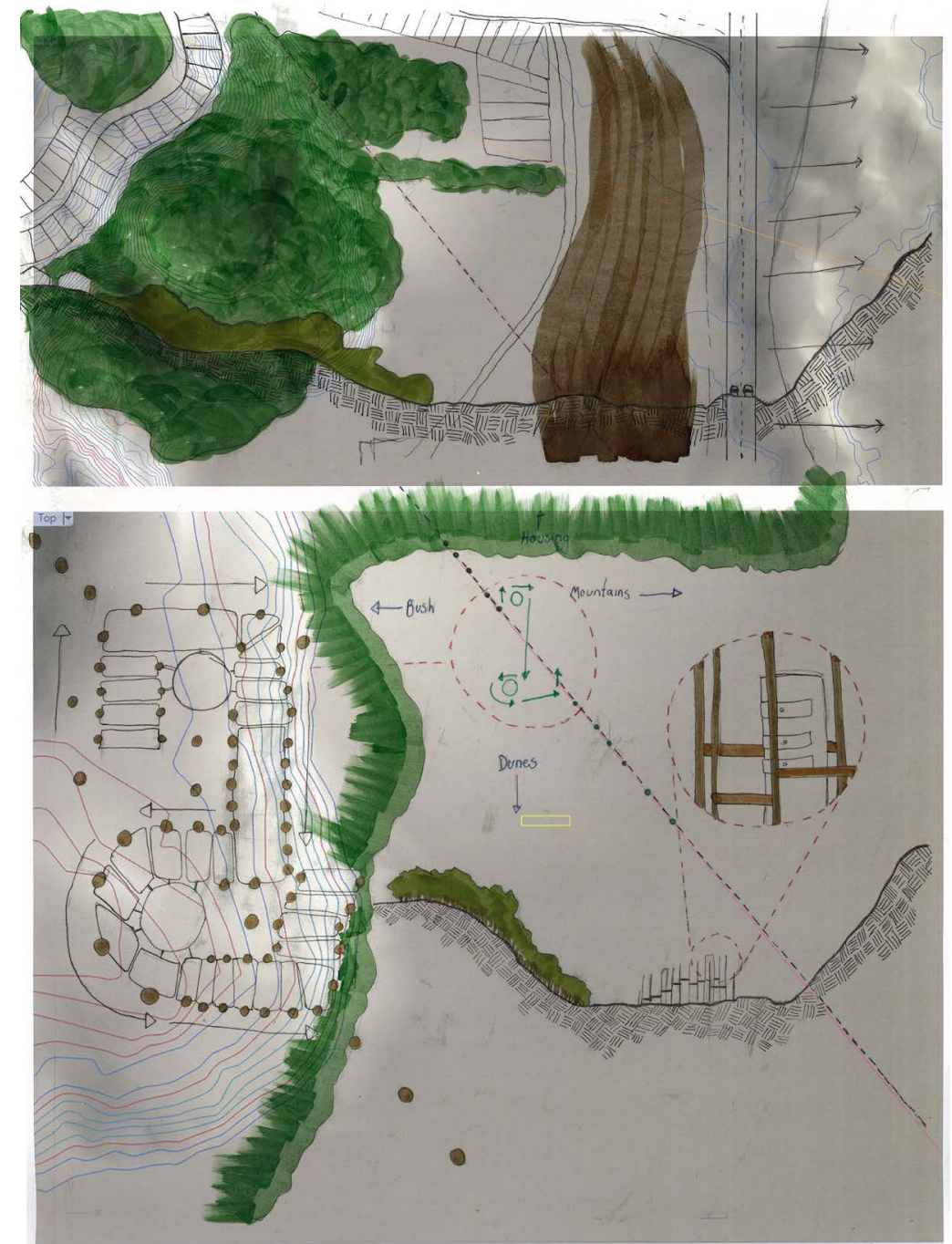

Figure. 77. The elevated floor plans, which double as seeds banks allow people a different perspective of the site and create new view lines. There will be multiple of these across the transect focussed on wet areas 


\section{Early site parameter evolutions}

The above images document the systems in specific parts of Kapiti while at the same time laying the foundations for some early design possibilities. The different drawing styles exhibited in one image add depth and complexity without much need for writing. Layering while storyboarding has allowed me to push the design further and explore ideas with more site relevance- such as the depressions that the water pooling at the bottom of the fog catchersBeing able to pull a design directly out of the analysis means the designs are more robust and precise. This technique of layering began to inform the parameters of site for this design research. As I began exploring through drawing the systems and design in more detail, it became clear what spaces were more relevant and best suited to design intervention.

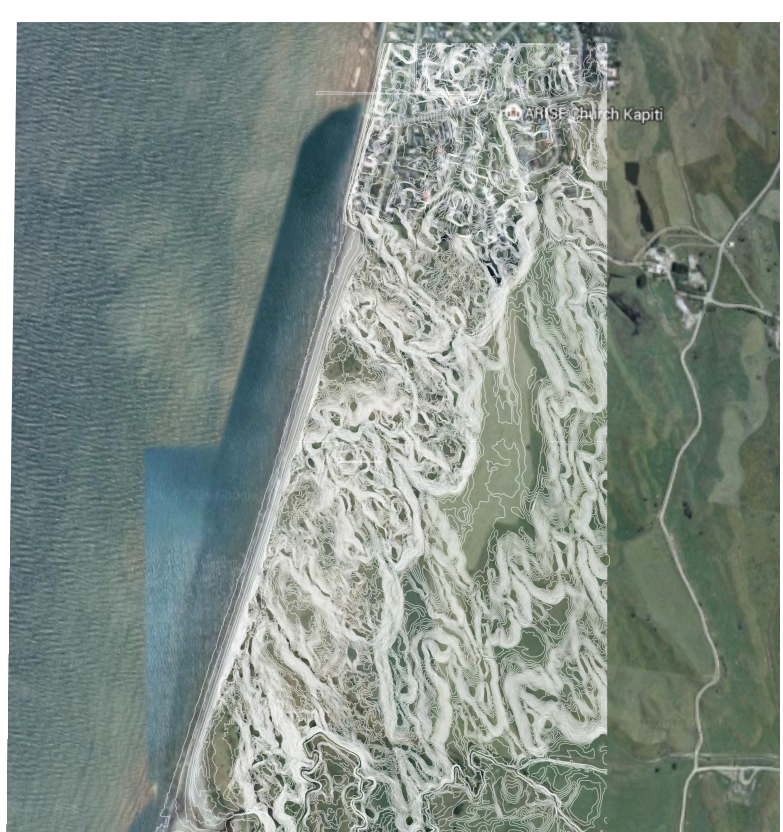

Figure. 78. Initial site only covered Raumati

South

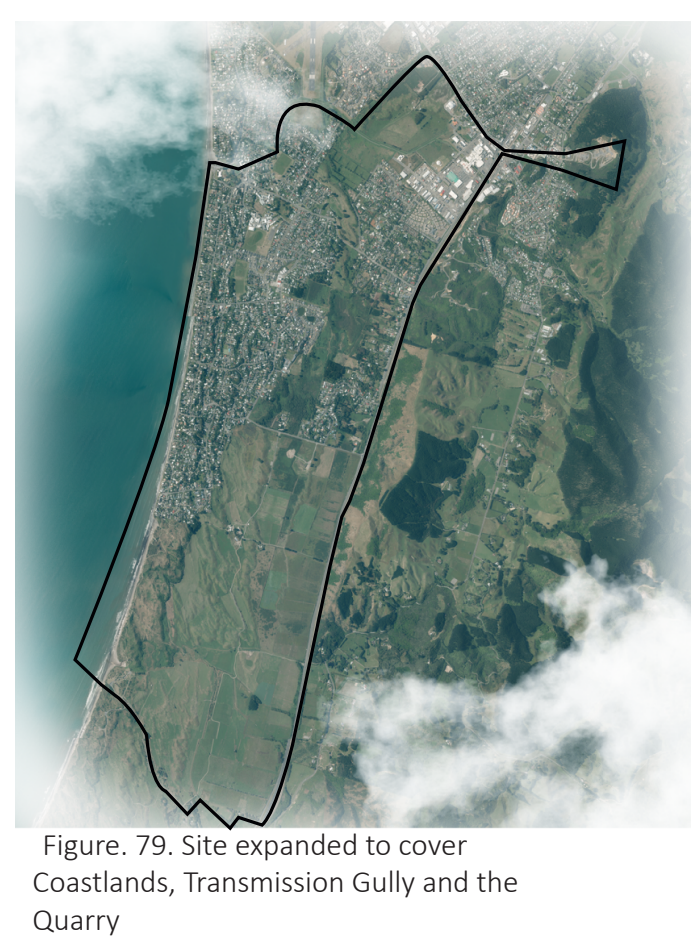

Quarry
One of the earliest steps in designing a landscape is identifying the site. Often this is a set space with given parameters within which the architect is expected to design. I have chosen to frame this work differently. Through the process

of layering I have chosen to shift the boundaries of my 'site' multiple times as I understand more about the systems and ecologies and identify some of the key moments in which systems intersect. Through experimenting with varying locations of minimalistic design interventions I am understanding what areas will be considered the 'site'. It is productive to invert this process of site as it offers the chance to design a space that fits into the existing processes of the region.

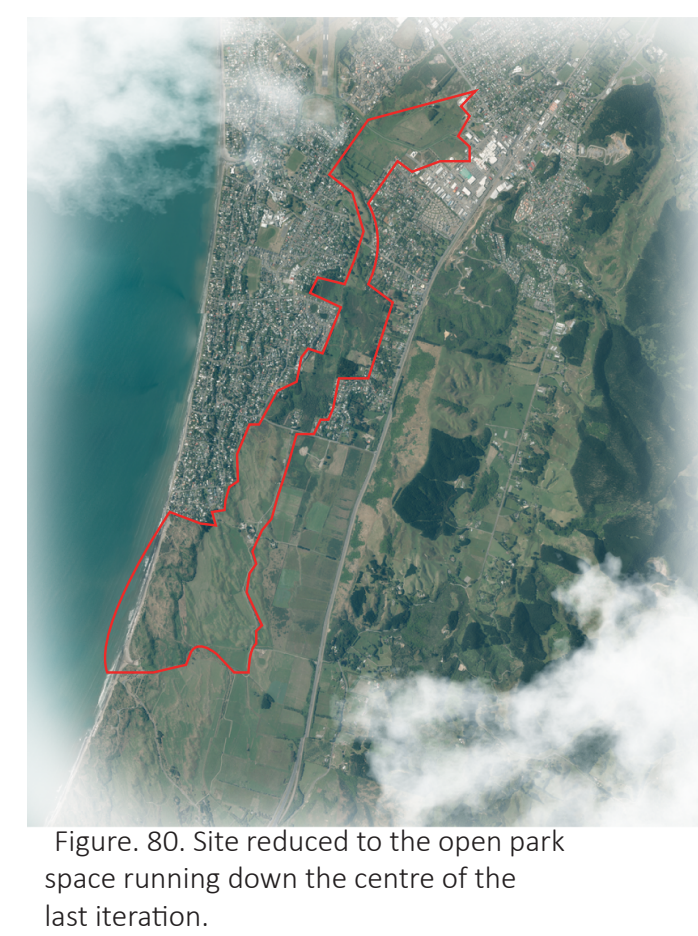




\section{Various pole interventions}

Out of the layering explorations came the final site. The ecologies of Kapiti change horizontally running north to south. Running a transect line east to west means there is the possibility to engage with all the ecological systems that make up Kapiti. Below is a drawing of this transect and the different key systems along it.
Figure. 81. Basic breakdown of the ecological systems that are, or should be happening along the transect

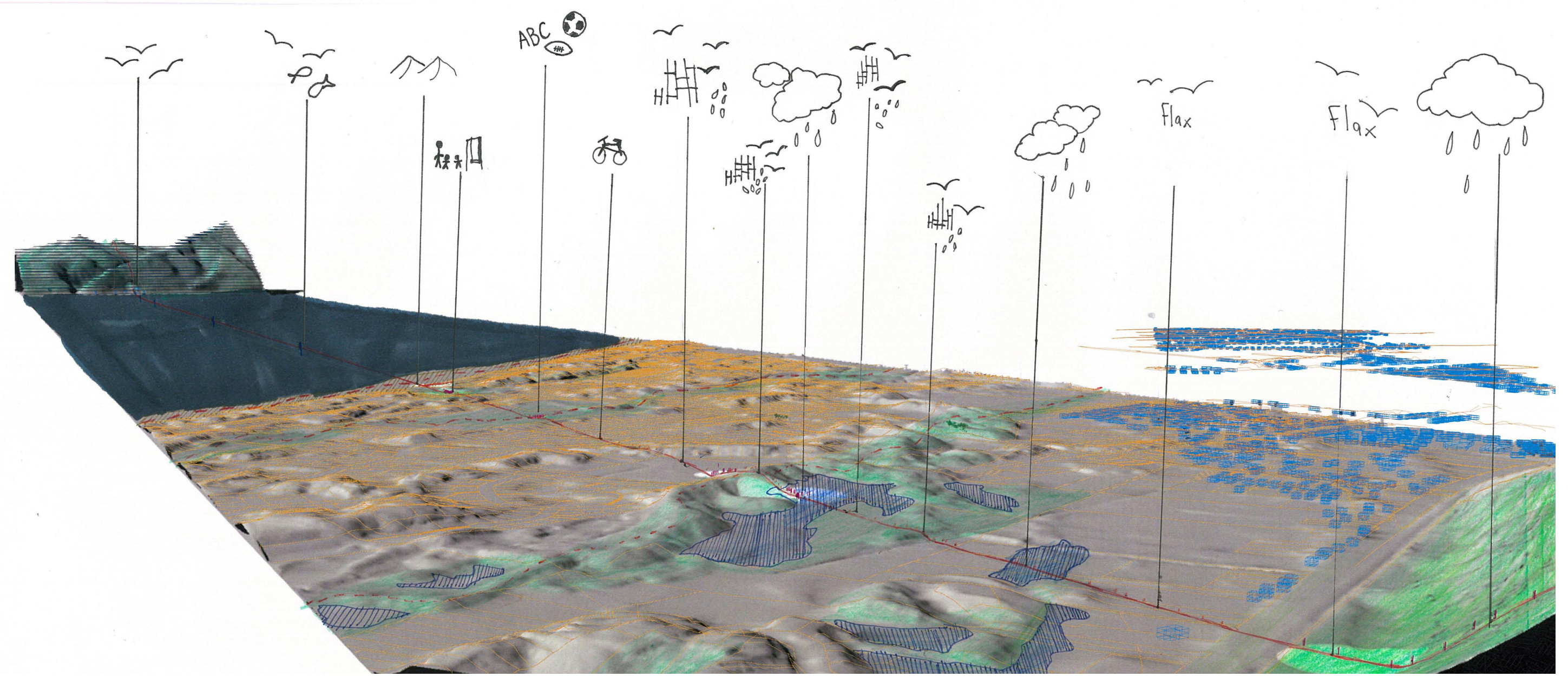




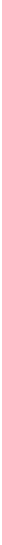




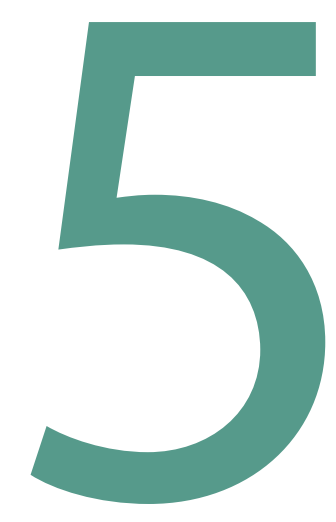

Poles to Build and Connect Ecosystems 


\section{Beginning with the Details}

The idea of beginning with the details has come out of this design research. I have typically begun with designing at smaller scales and expanded outwards. I found that through understanding and designing the precision of the details I began to gain a full knowledge of what was happening on site. My third objective - to develop designs which will over time show the processes operating in the landscape while allowing people a participative role in activating this growth - supports this idea of starting with the detail. Landscape architecture typically deals with large scales and designs often tend to be strategic. Considering detail from the very beginning offsets this sweeping broadness and gives the larger scale decisions something to push against.
The details can act as a counter balance or a point of reference for the larger scale. In terms of my design, looking at the detail opened up a plethora of questions and design avenues. Focussing on details has forced me to make some real decisions about my design. In order to achieve my aim, I had to ensure the systems in Kapiti, were not only tapped into at the large scale, but also comprehensible at the smallest scale. I had to begin considering what these structures would be made of, eventually settling on wood because its porous nature allows water to seep in, changing its form and quality. Wood breaks down is eventually returned to the land. I also began to explore how the choices of wood would change the performance of the structure.

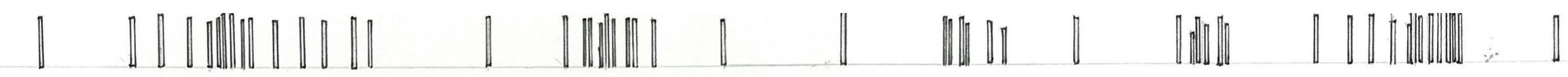

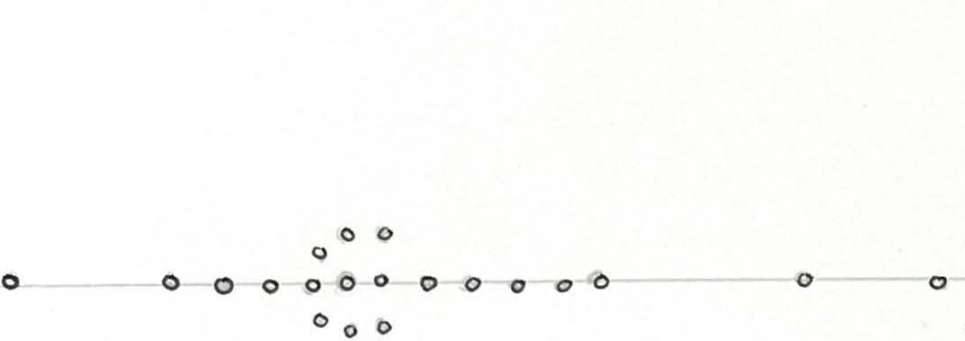

Figure. 82. Clusters of poles forming different spaces

$\circ \circ$

$\circ \circ 0$

00

- $\quad 0_{0}^{0} 0$.

0

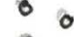

$\circ 0$.

along an axis 


\section{Ocean Poles}

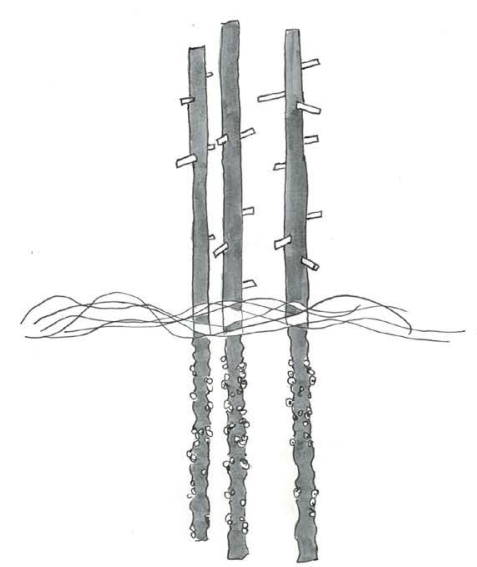

Figure. 85. Ocean poles will sit in the sea between Kapiti Island and the mainland.

The above water section will be bird resting points on the journey east. The section below water will collect shellfish and crabs
Dune Poles

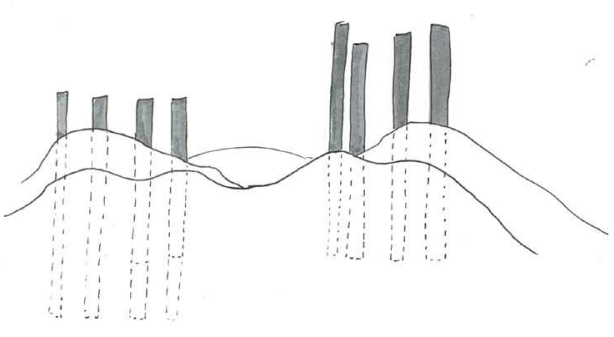

Figure. 86. Sand dune poles will be placed in clusters that will create auditory moments and place with sound waves

\section{Seed banks}

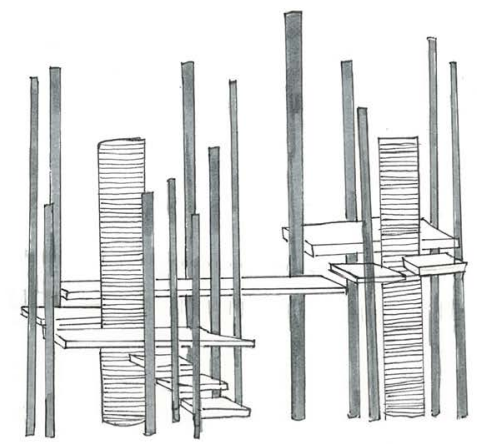

Figure. 83. Elevated floorplan, propped up on poles takes people over wetlands, large draws in the centre filled with seeds for people to scatter

\section{Fog Catchers}

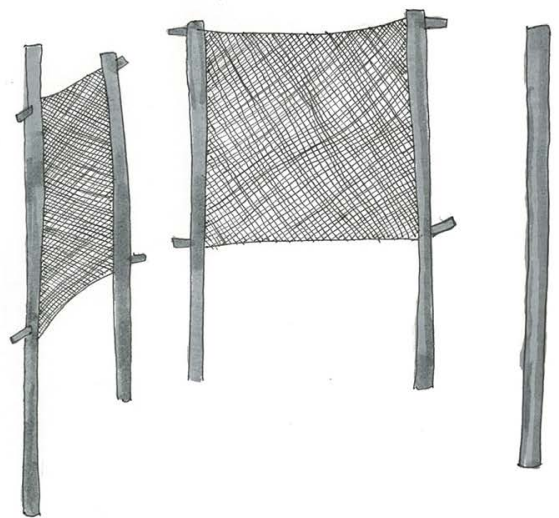

Figure. 84. Fog catchers with bird perches. Made of wood and mesh 
Six design analysis explorations of different areas along the site transect

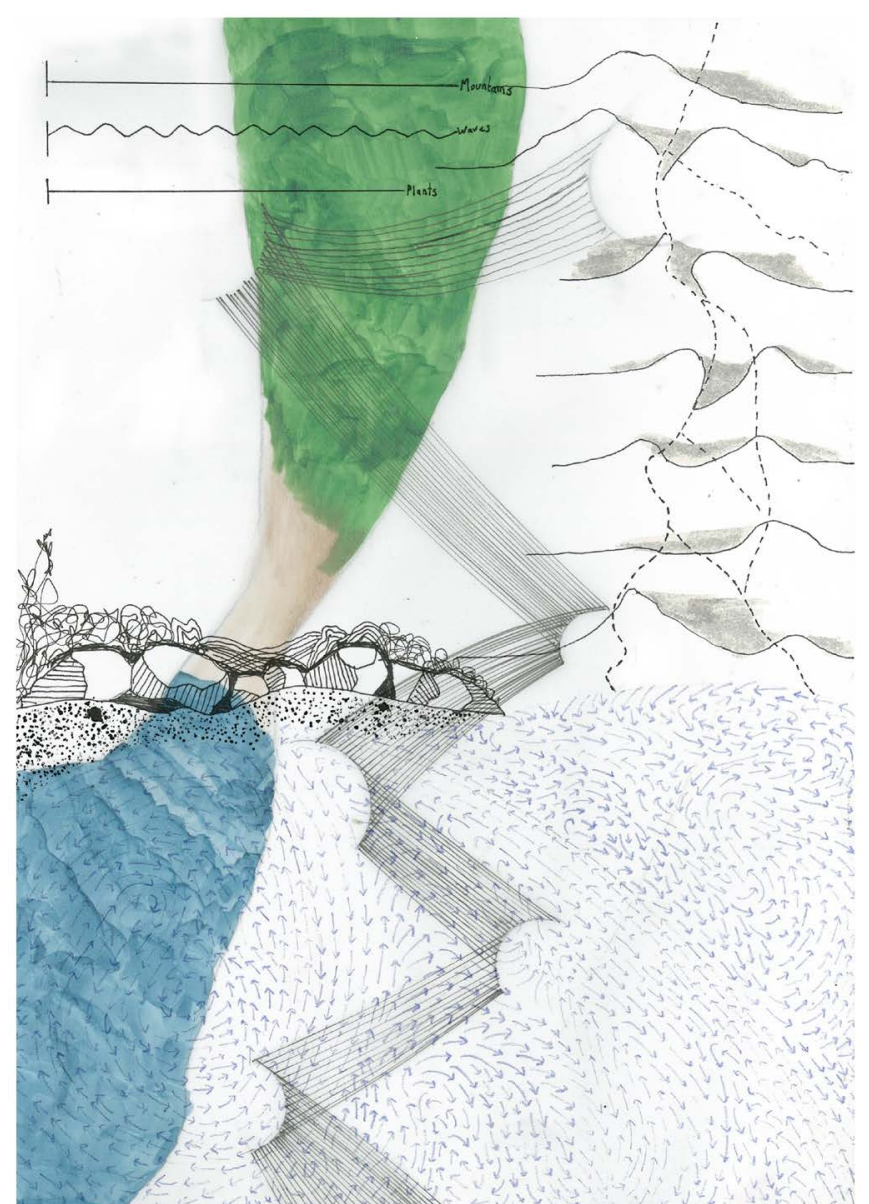

Figure. 87. Kapiti Island
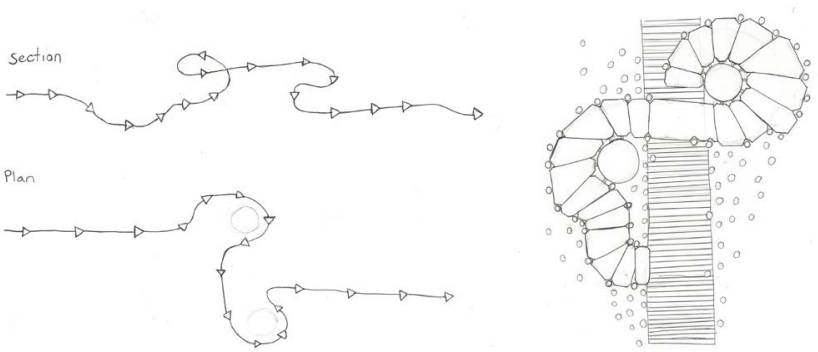

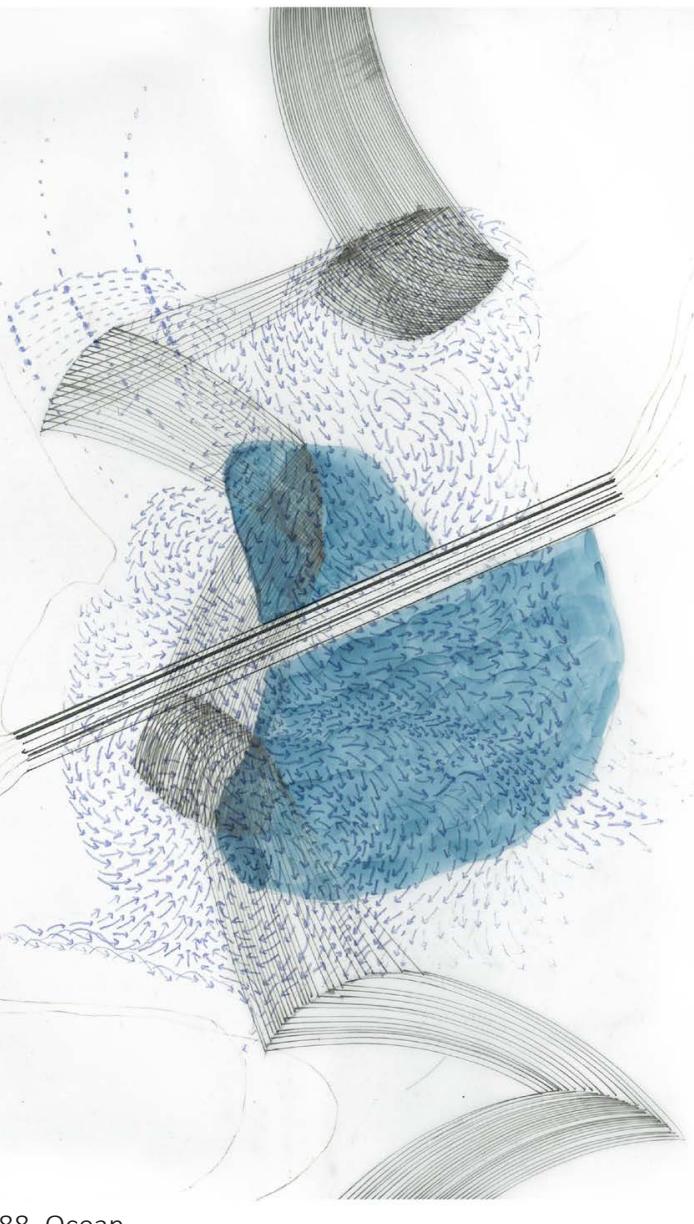

Figure. 88. Ocean
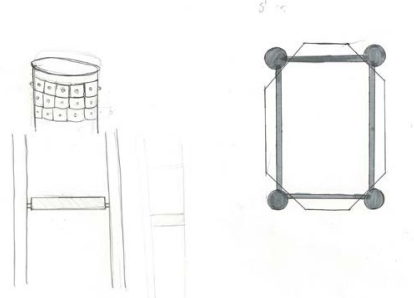

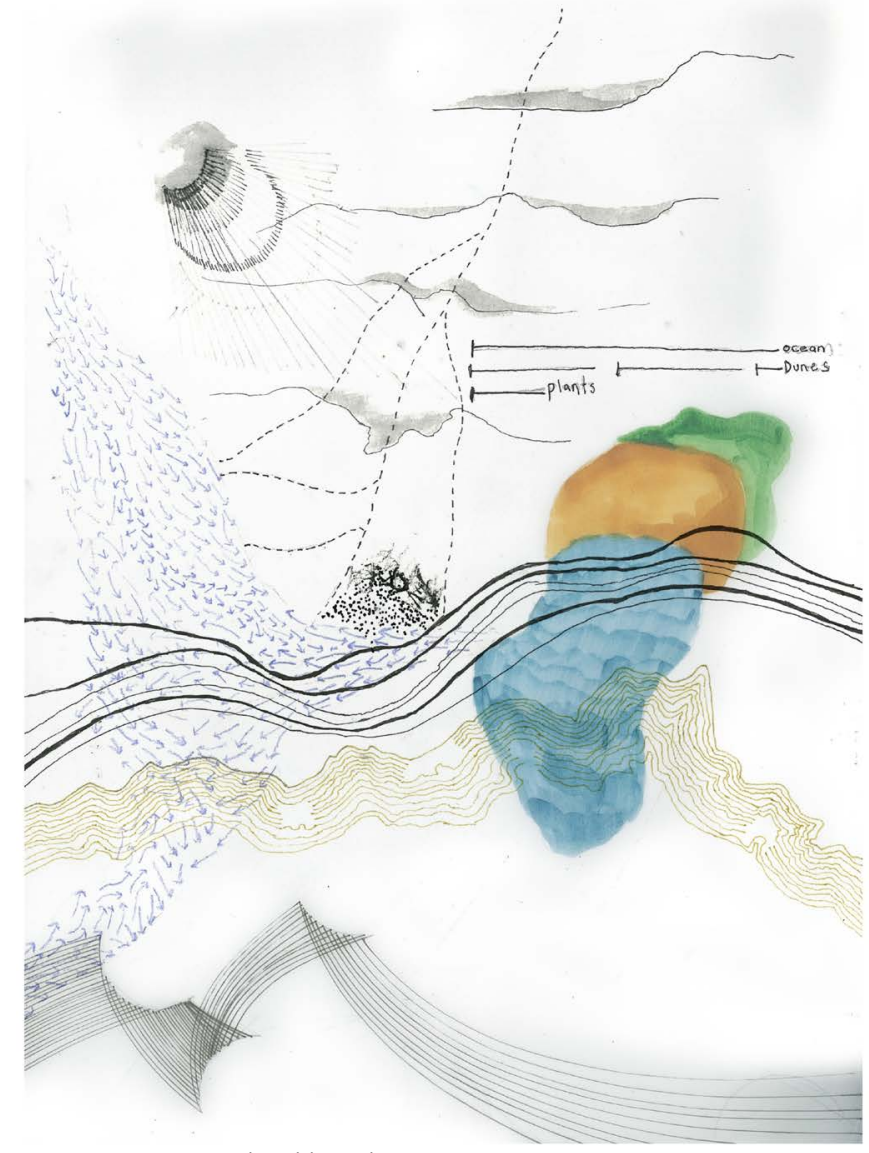

Figure. 89. Mainland beach

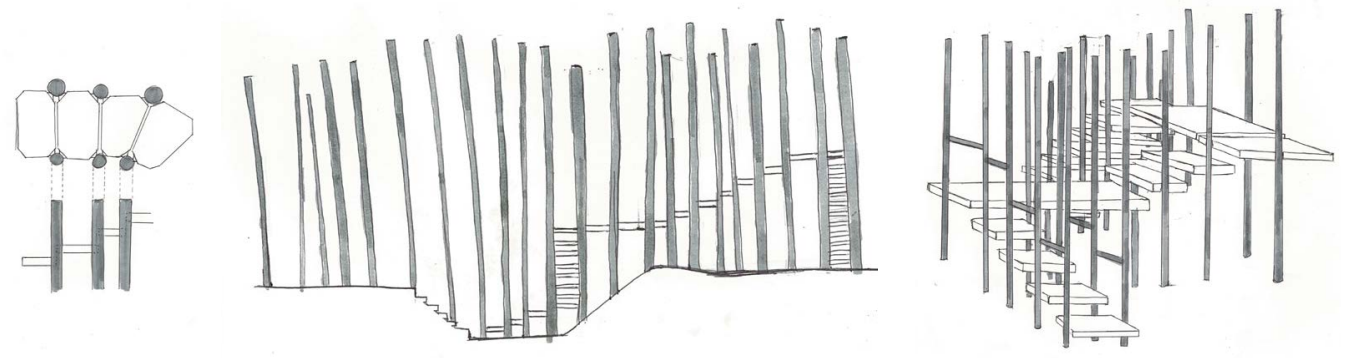




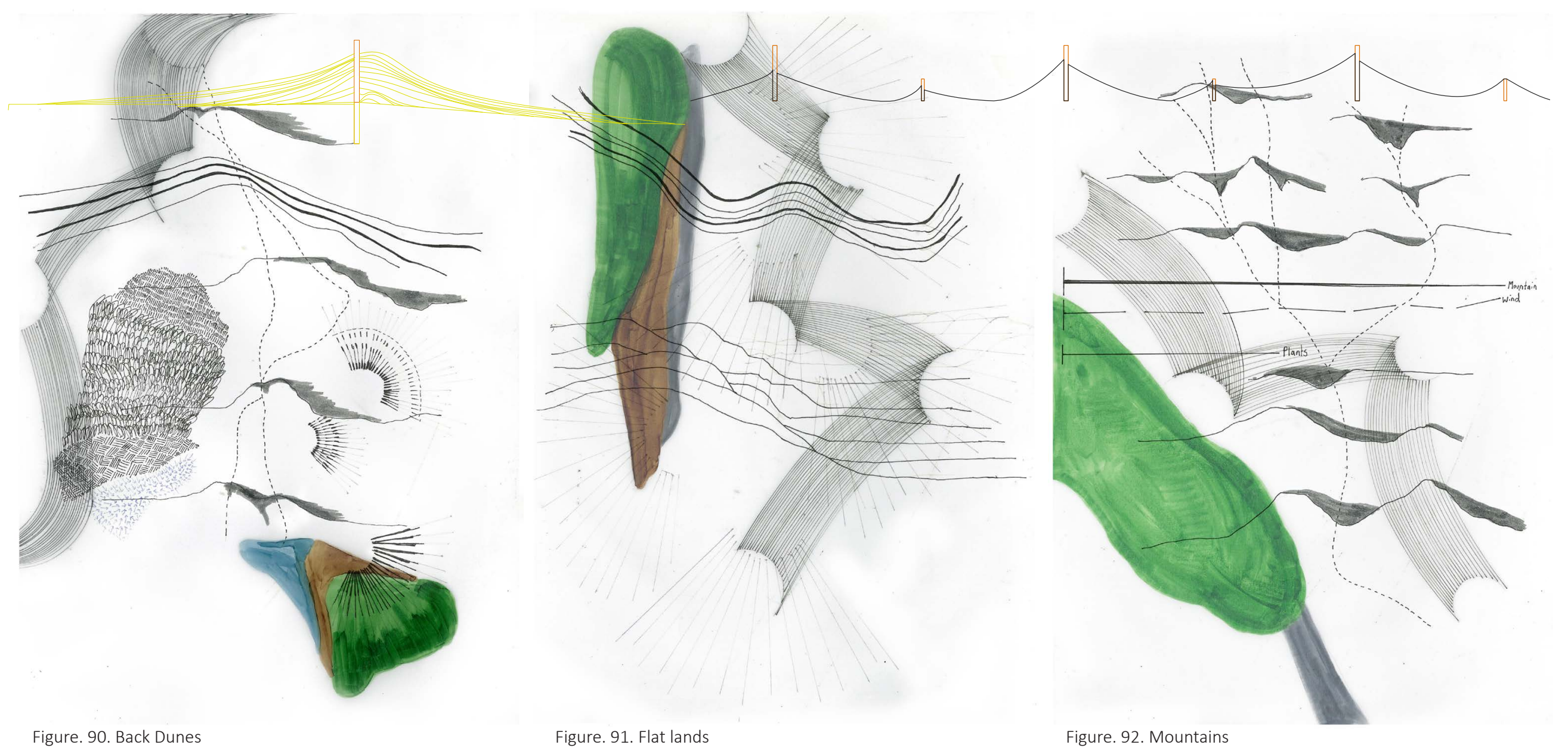
装 Secondary done
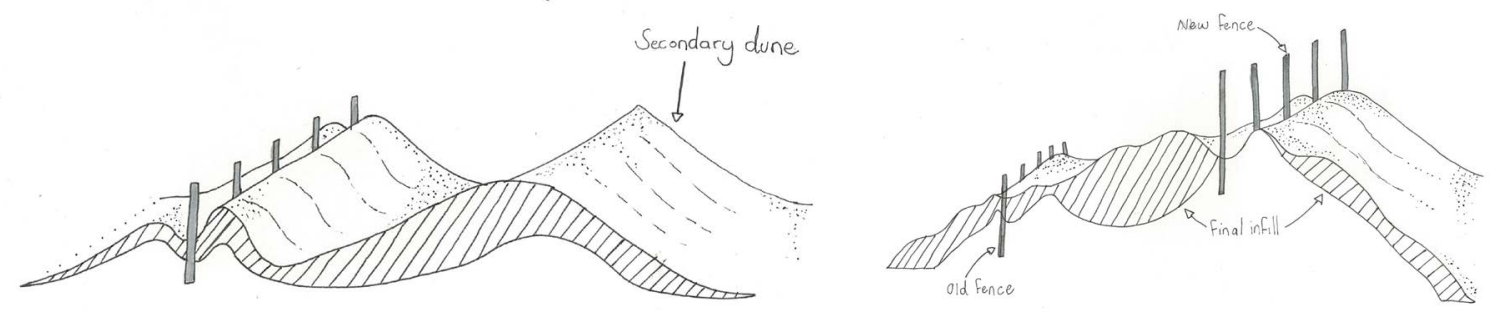


\section{The Different Acts}

I have chosen three ecological systems to design in more detail:

Act One - Birds

Act Two - Sand

Act Three- Wetlands

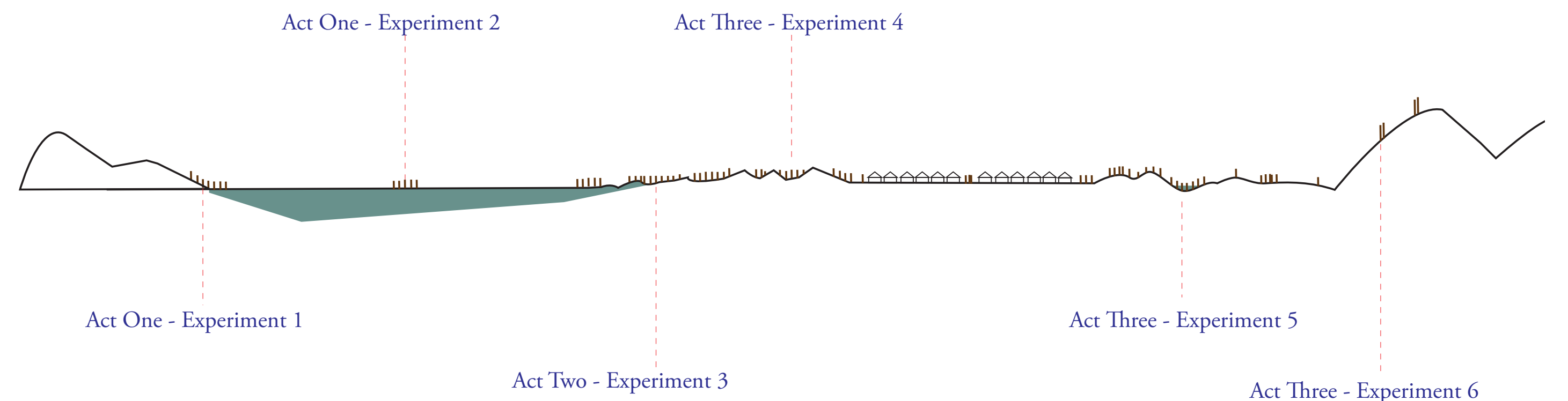

Figure. 93. The locations where these different acts take place 


\section{Birds}

The bird designs are about setting up a nesting and perching site on the Shore of Kapiti Island. This marks the beginning of a bird's flight to the mainland. Unless the conditions are fine, this is a difficult crossing. To make it easier for birds these perches happen periodically along the transect to allow birds a safe resting place.

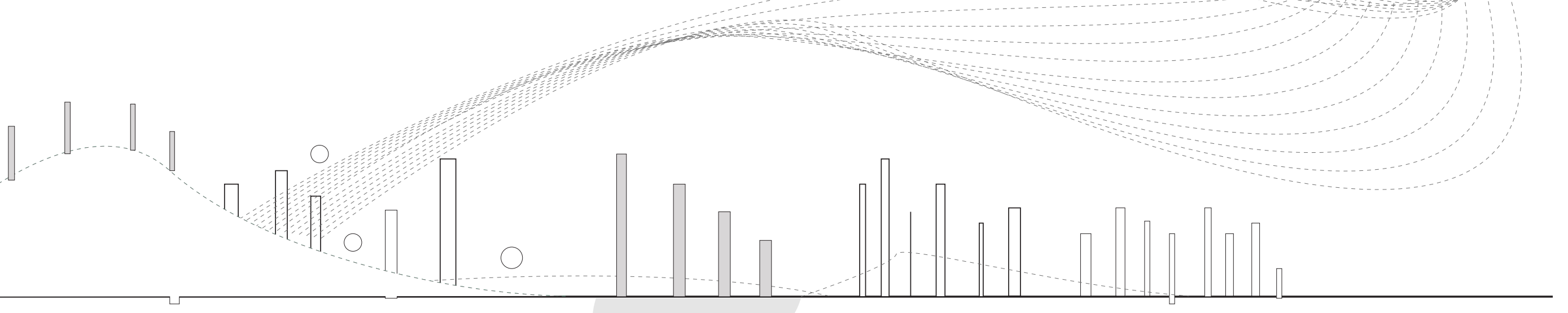




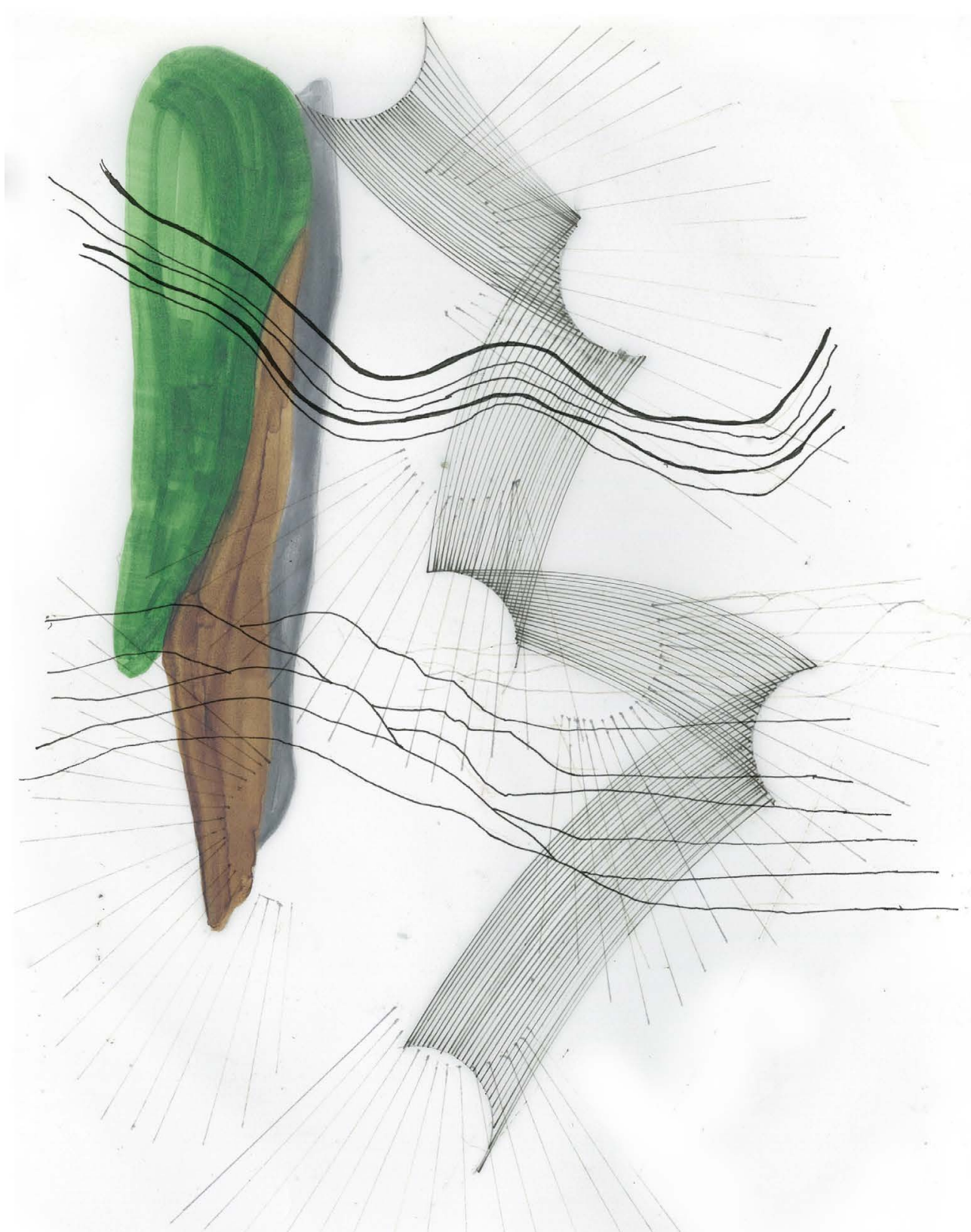

Figure. 94. Through a more rigorous and specific Halprin-esque approach to analysis the design is able to uncover an element of complexity that may have otherwise gone unnoticed

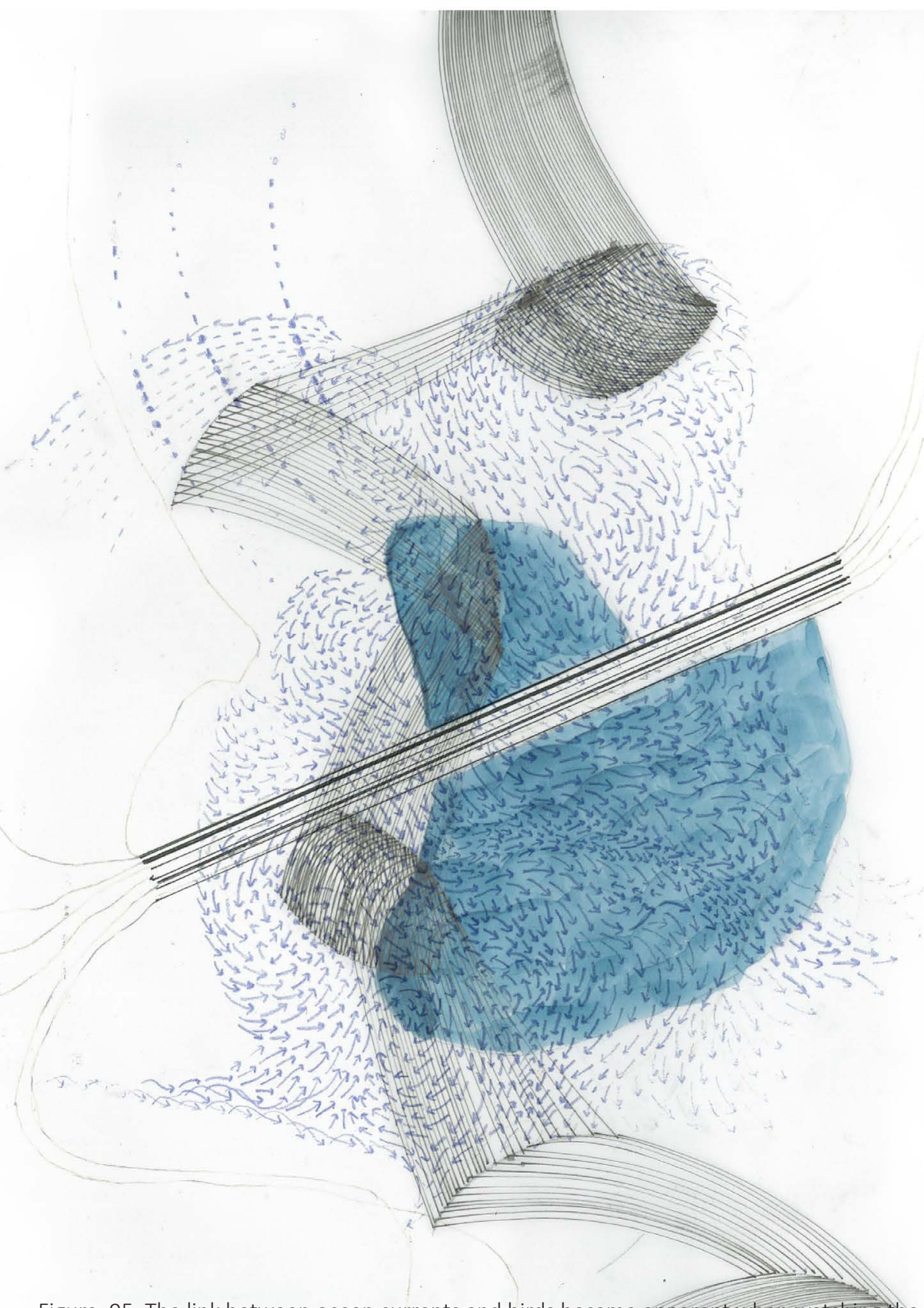

Figure. 95. The link between ocean currents and birds became apparent when watching the site perform. The currents dictate where birds are going to hunt fish and indicate the weather conditions for flying. 


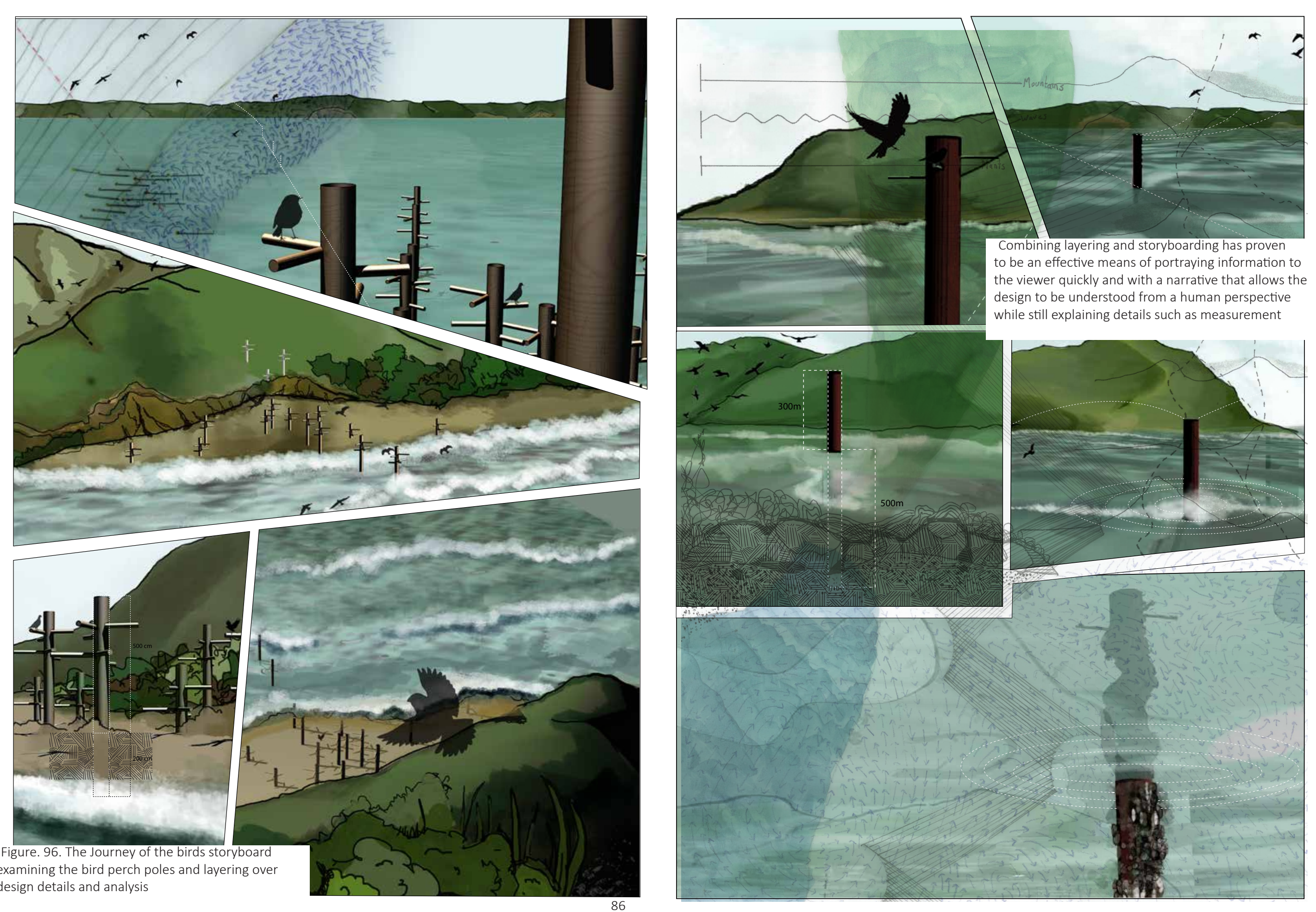




\section{Bird and plant species}

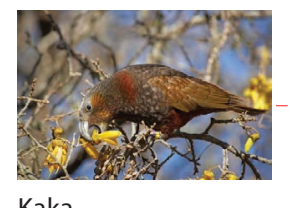

Kaka

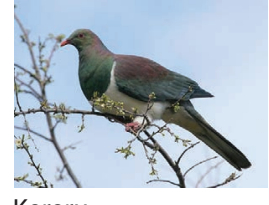

Kereru

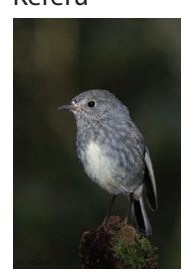

Toutouwai

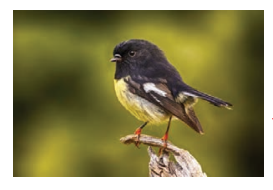

Miromiro

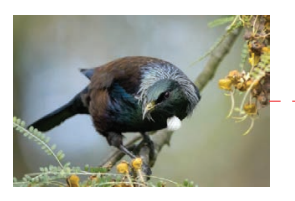

Tui

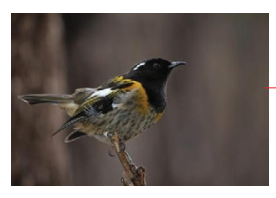

Hihi
Forest Margains

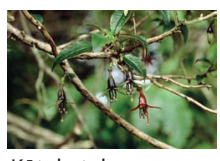

Kōtukutuku

(Fuchsia excorticata)

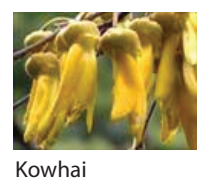

(Sophora microphylla)

Coastal and Lowland Forest

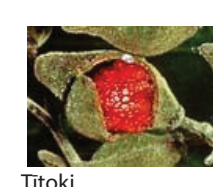

(Alectryon excelsus)

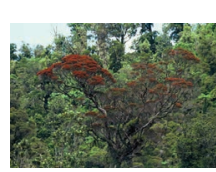

Normern (Metrosideros robusta) (Beilschmiedia tawa)

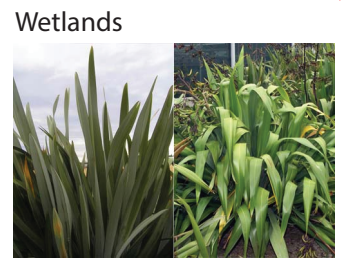

Harakeke Wharariki (Phormium tenax) cookianum)

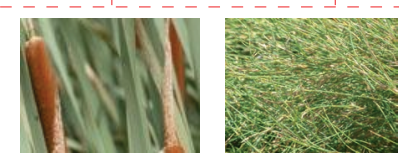

Raupo

Wire rush
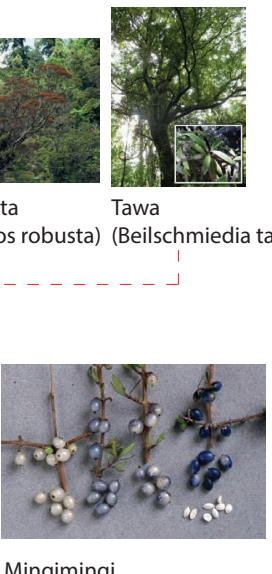

Mingimingi

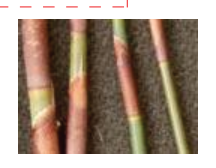

(Coprosma propinqua)

Cane rush ferrugineus)

\section{Dune Faces}

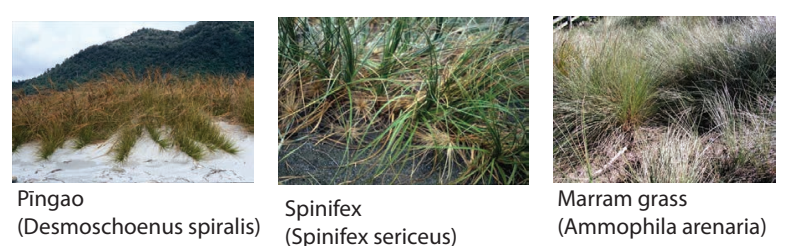

Figure. 98. Target birds, linked to their food source. The seeds of these plants will be stored in seed banks (Each image referenced individually in the image index pg. 108

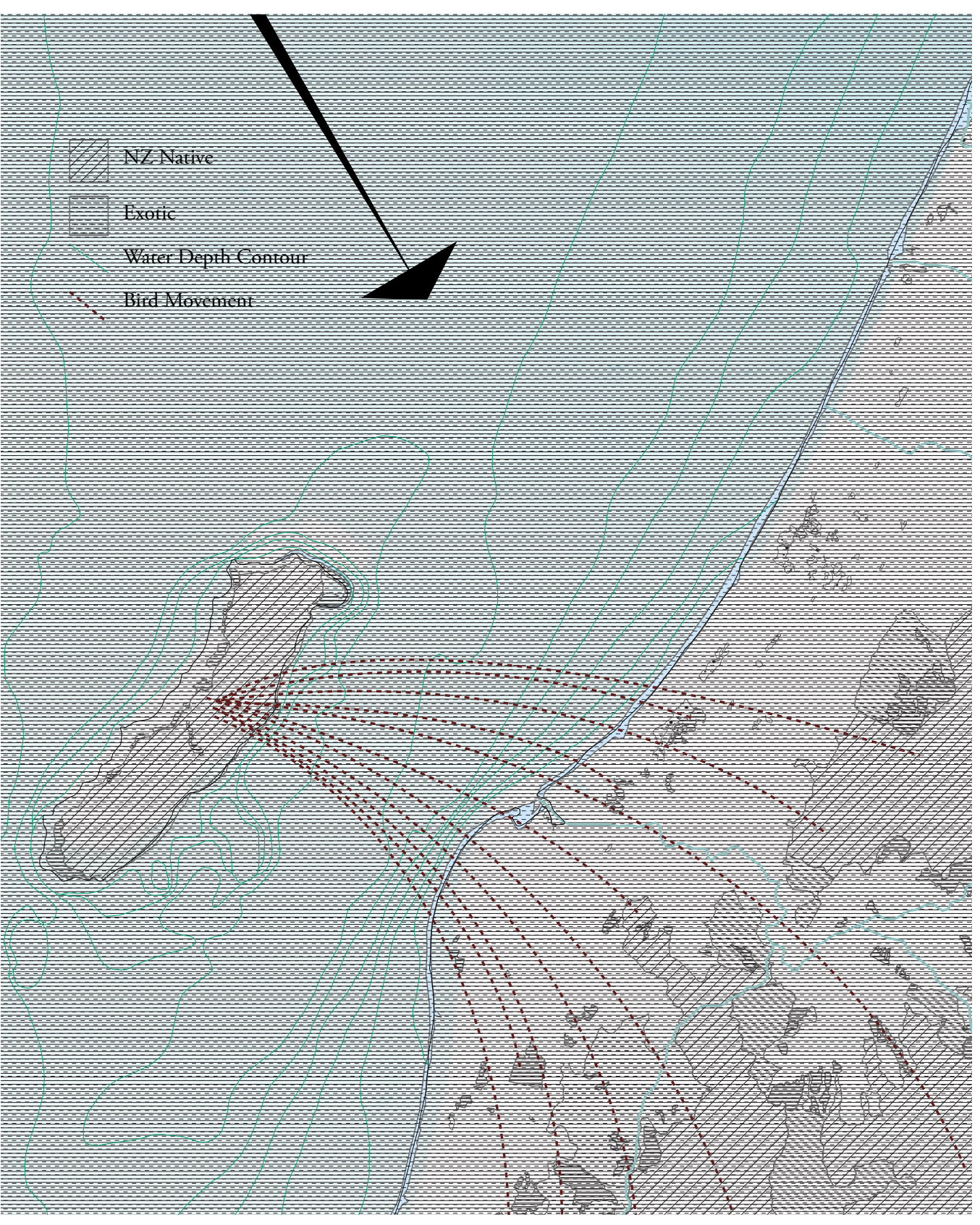

Figure. 97. Flight locations of birds to and from Kapiti Island 


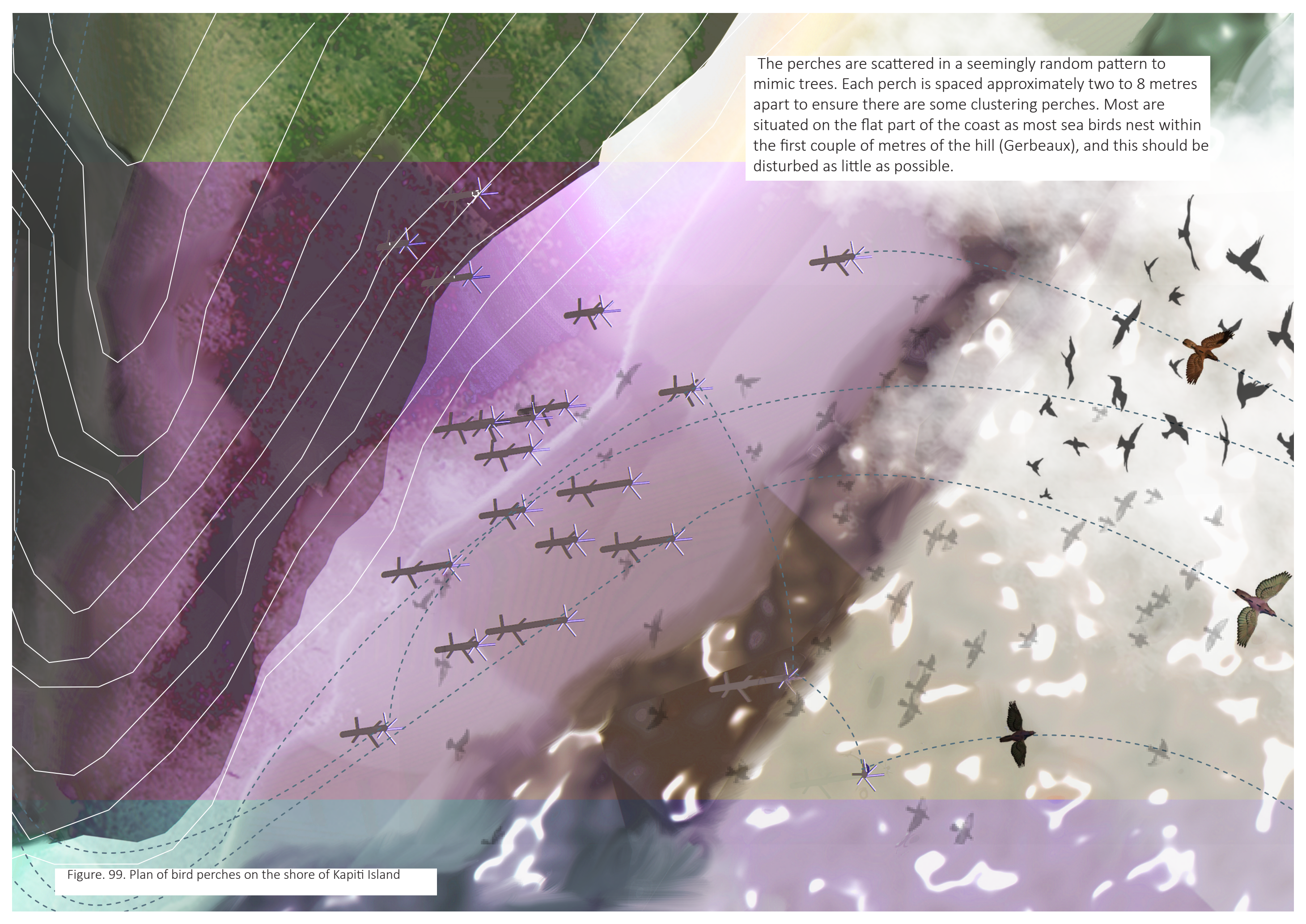




\section{Combined design and analysis}

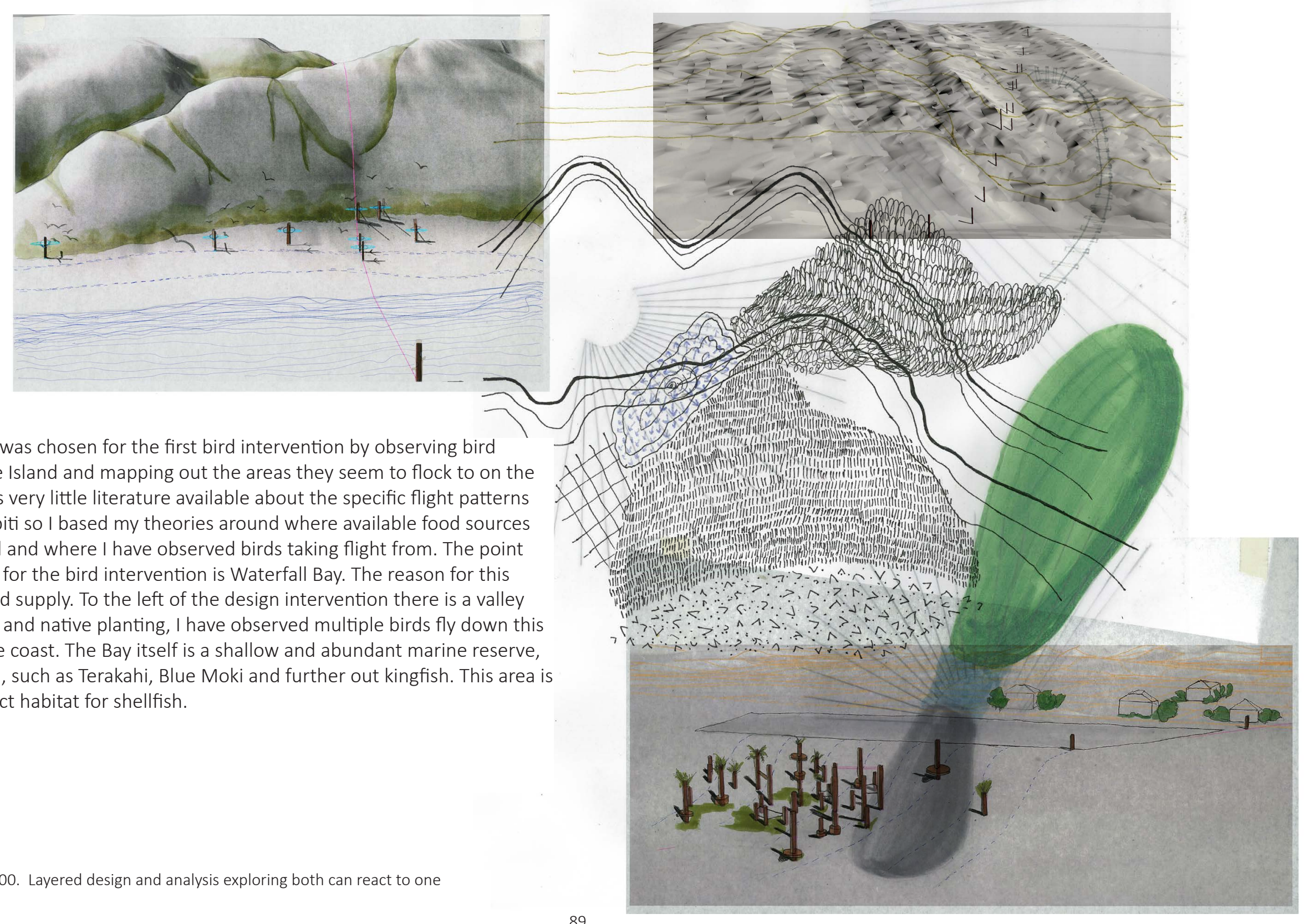

This location was chosen for the first bird intervention by observing bird activity on the Island and mapping out the areas they seem to flock to on the coast. There is very little literature available about the specific flight patterns of birds in Kapiti so I based my theories around where available food sources are and based and where I have observed birds taking flight from. The point I have chosen for the bird intervention is Waterfall Bay. The reason for this is the bird food supply. To the left of the design intervention there is a valley with a stream and native planting, I have observed multiple birds fly down this channel to the coast. The Bay itself is a shallow and abundant marine reserve, filled with fish, such as Terakahi, Blue Moki and further out kingfish. This area is also the correct habitat for shellfish. 
Although the sand dune interventions serve as a coastal erosion strategy, it also functions as a soundscape. The idea of the soundscape arose very early in this design research; dunes already have this natural ability to manipulate sound by either funnelling soundwaves or blocking them. The choice was made to emphasis this characteristic when building up new dunes as it will

help to engage people with the space to show how dunes work.

\section{Sand}

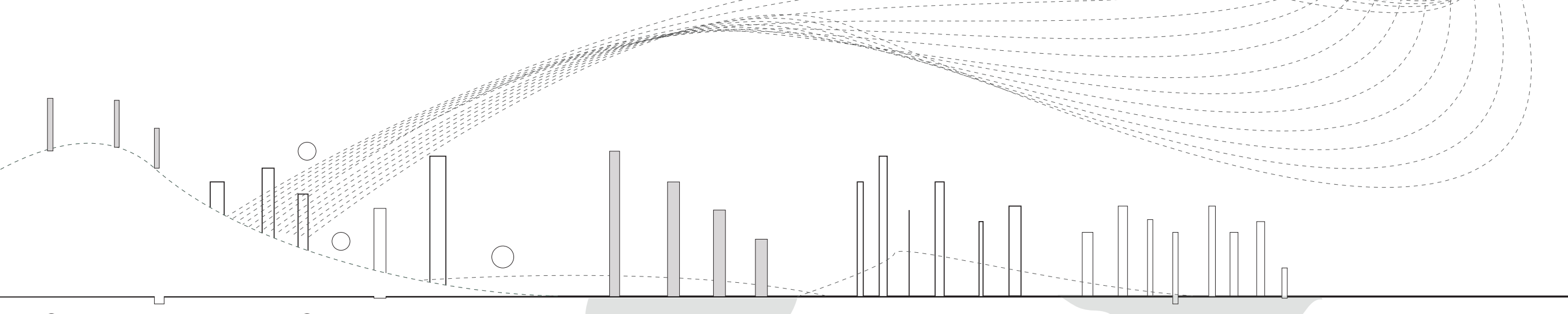




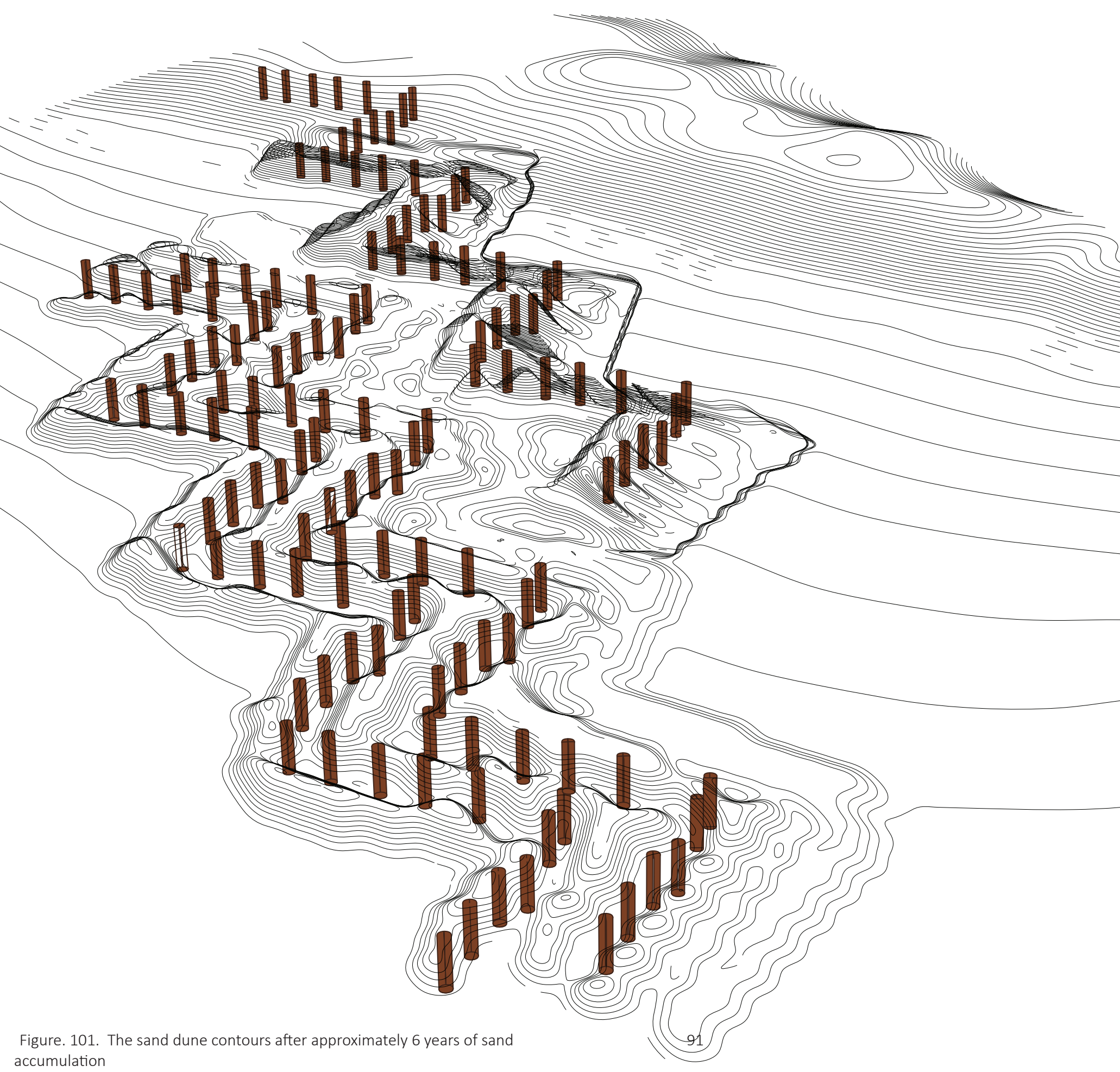



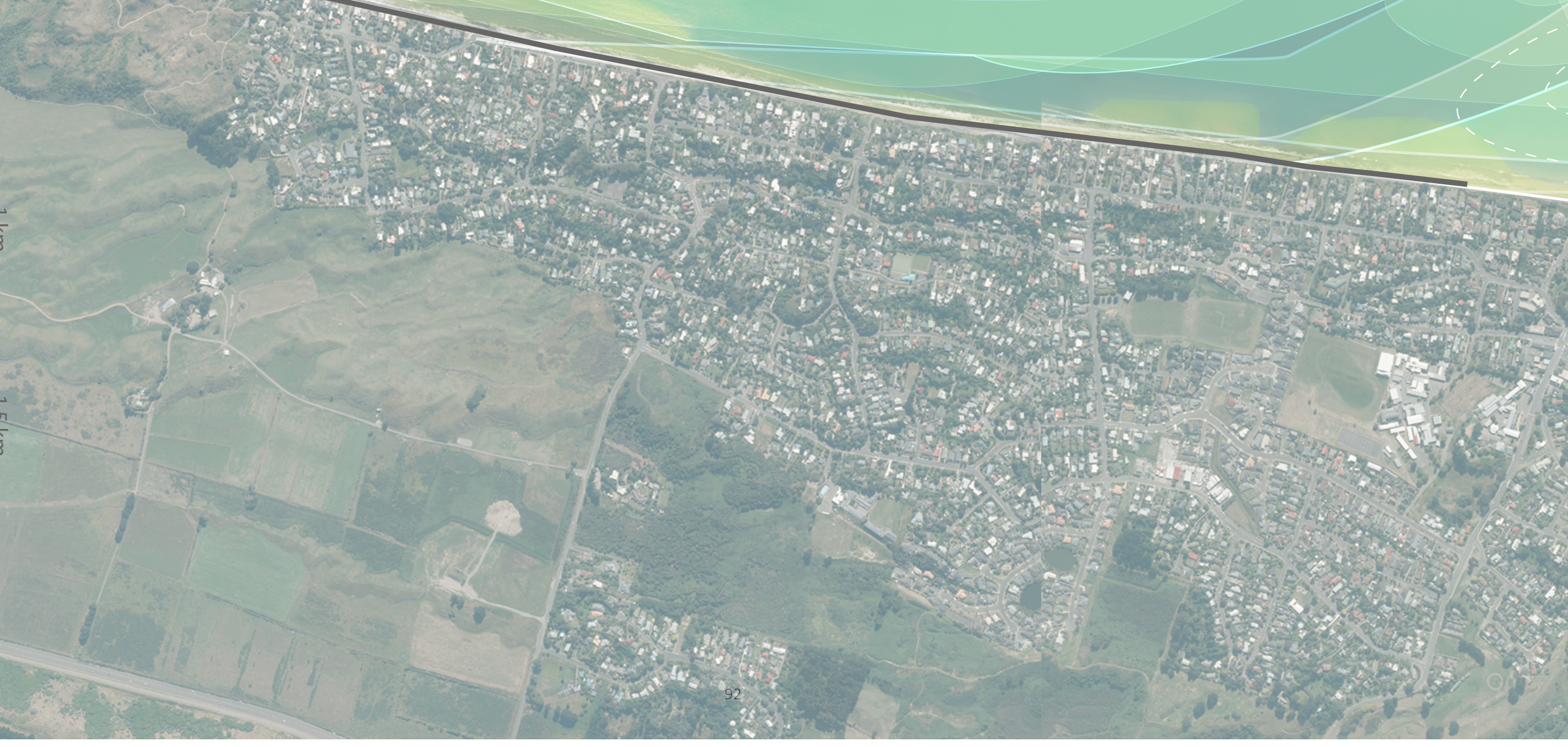


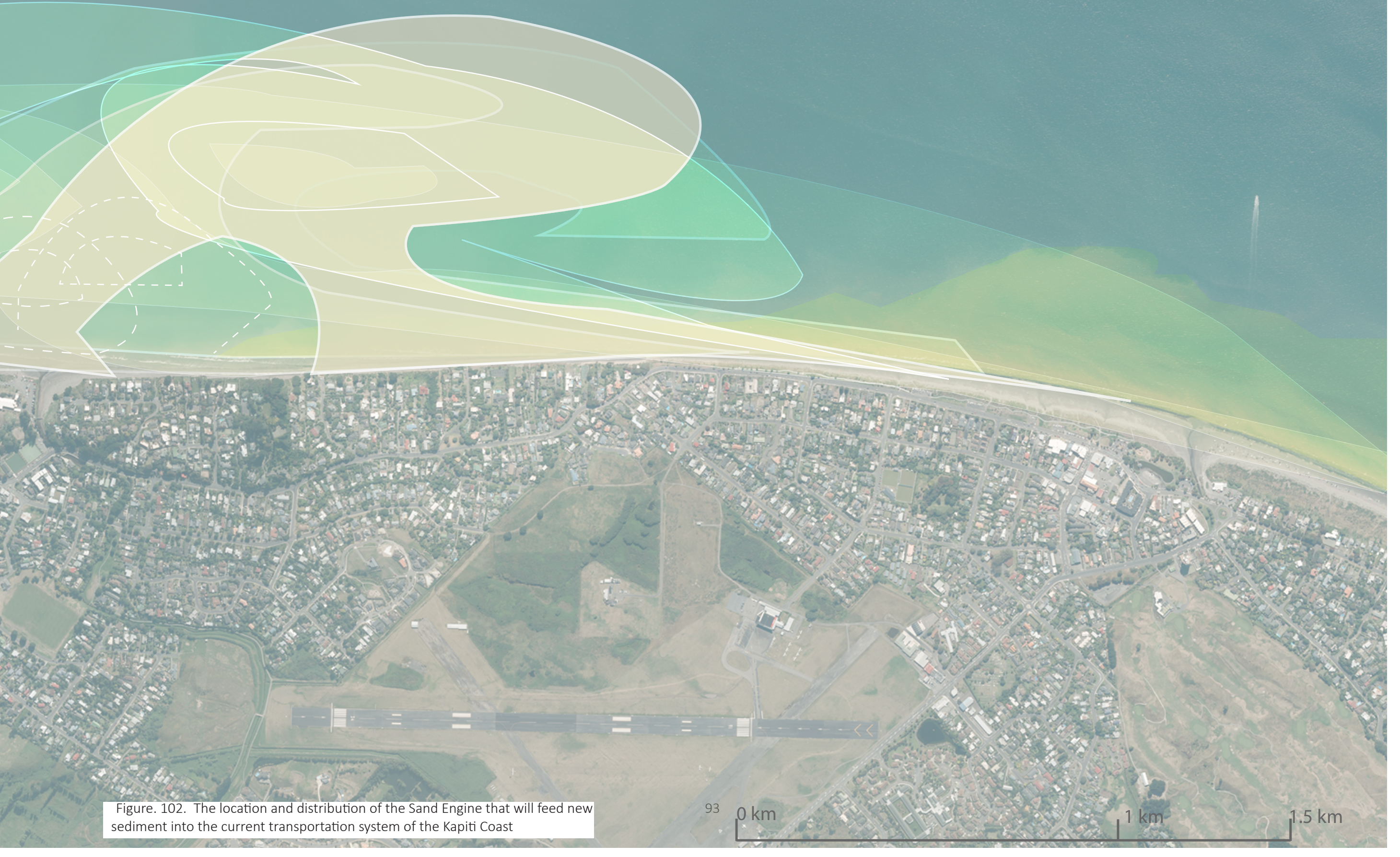




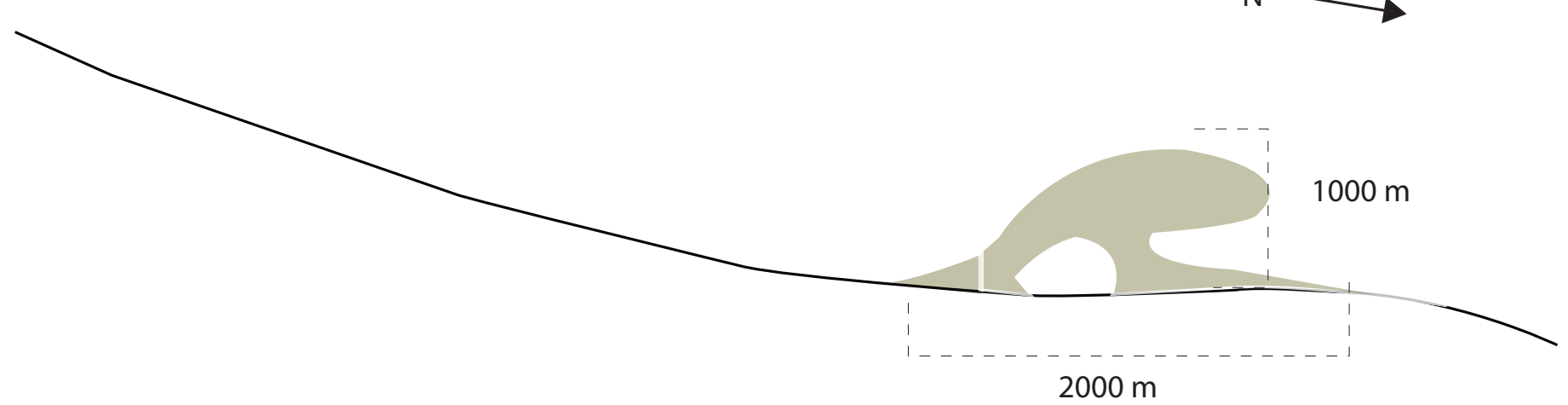

$2000 \mathrm{~m}$
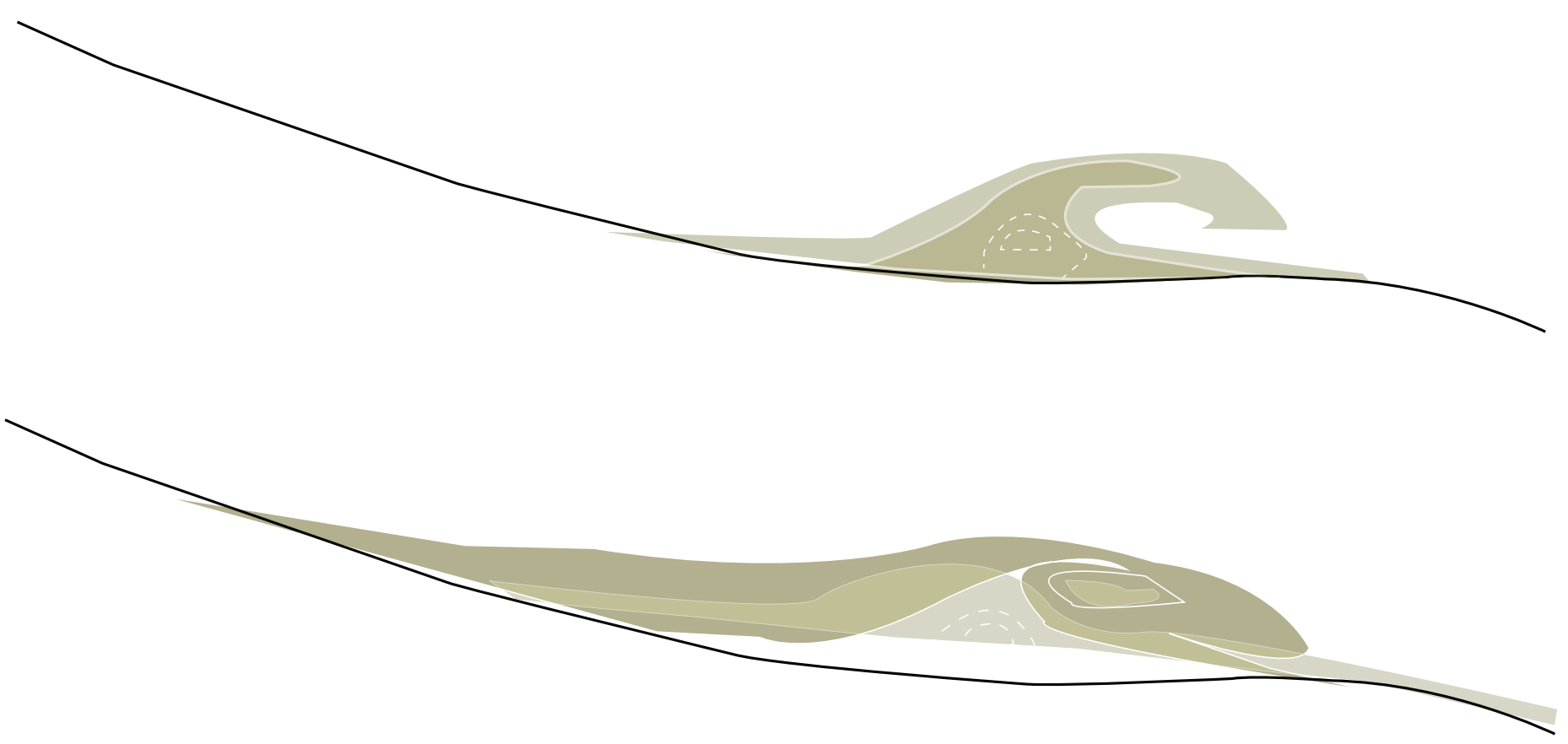

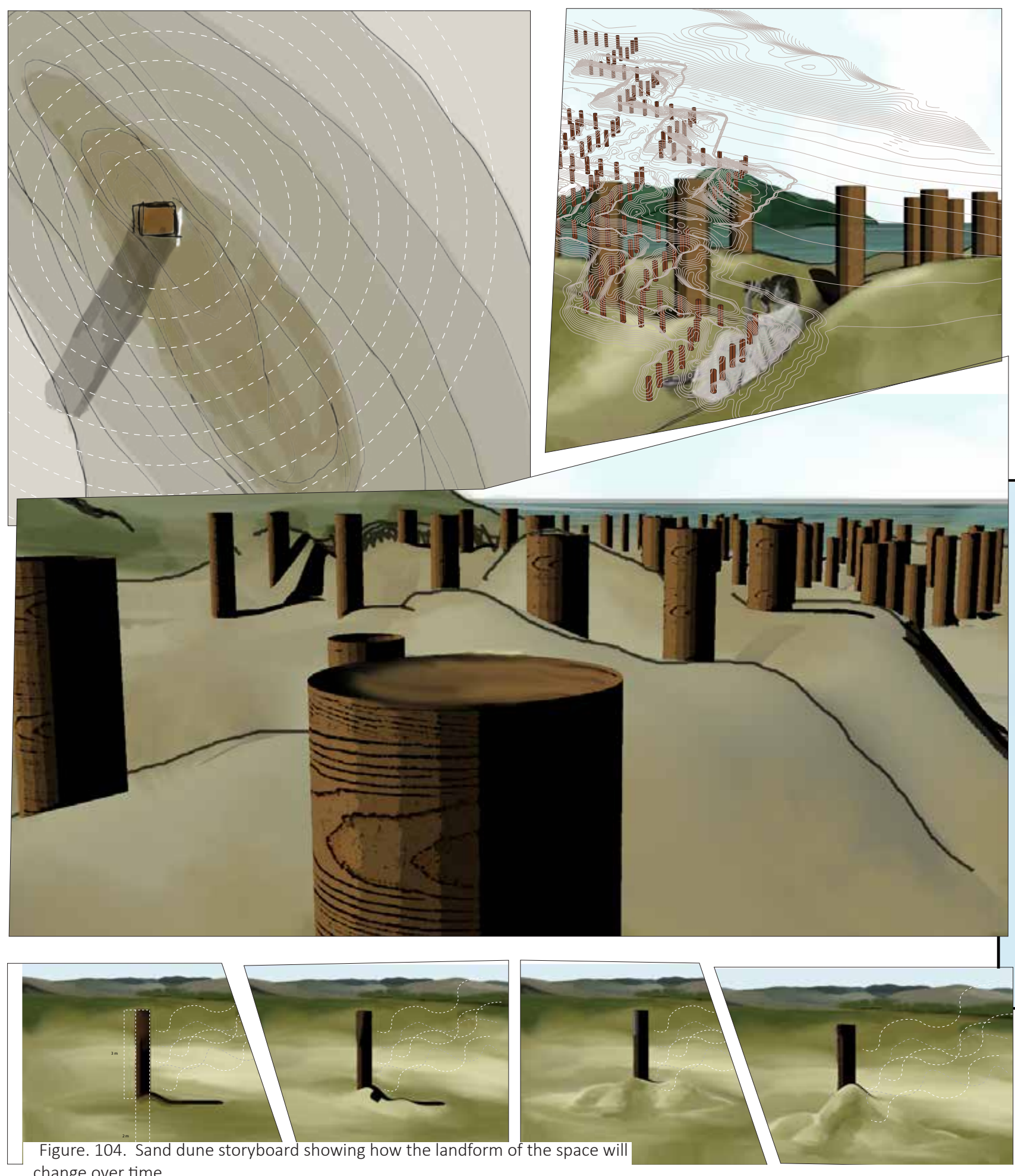
change over time 

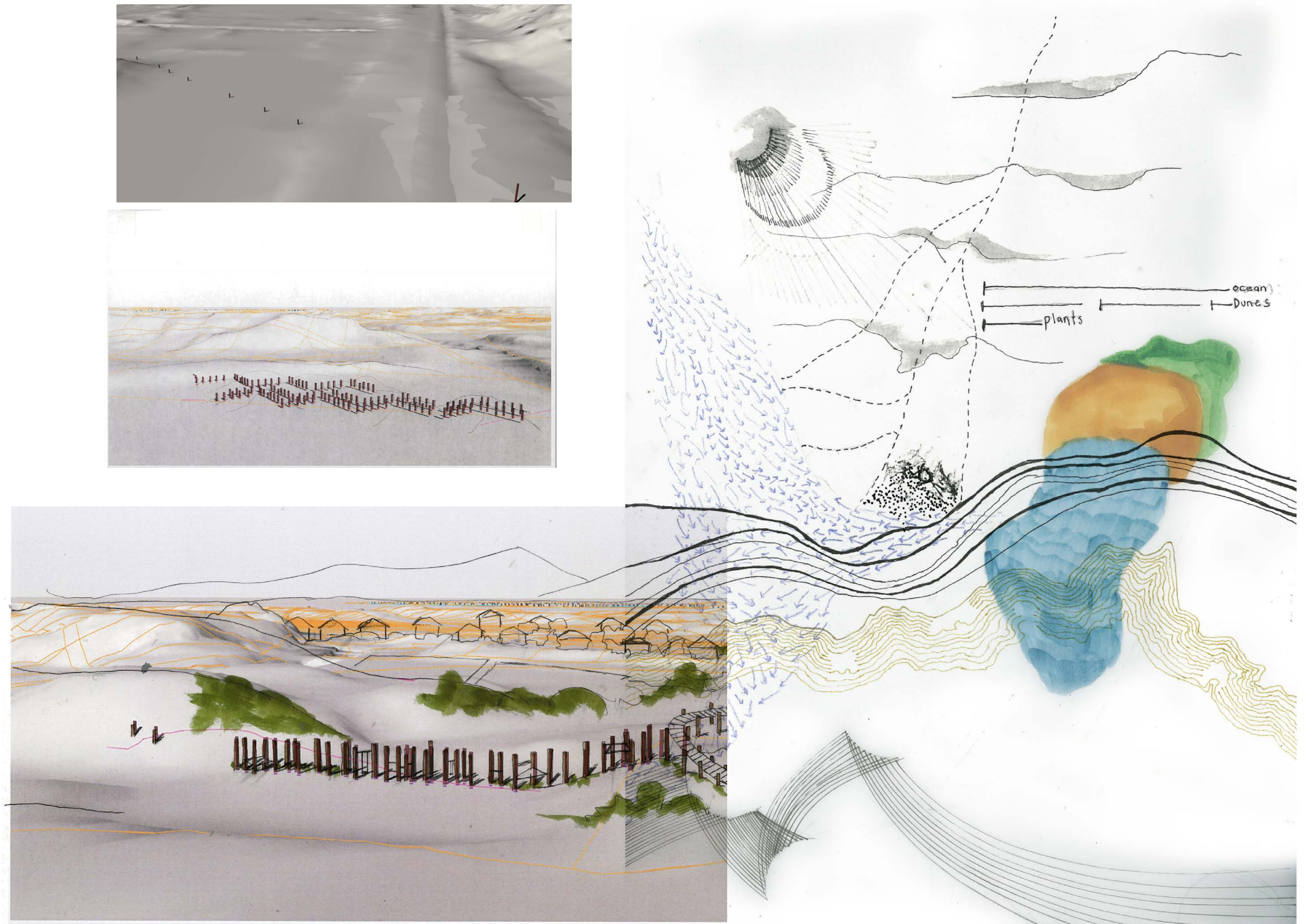
The wetland interventions are all about kick-starting the process of bringing water back up to the surface in either an ephemeral process or permanently. Fog catching technology can work very differently in Kapiti from where they have been implemented in the past. Kapiti is not a parched land, the water table is very high due to the tidal influences. This means that gathering water that pools behind dunes will begin to saturate the land in a process that should slowly bring back the earlier wetland ecosystems that existed in the region.

\section{Wetlands}

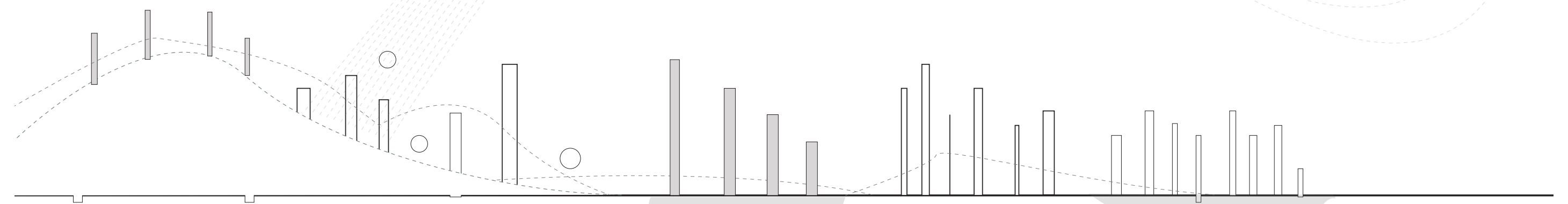




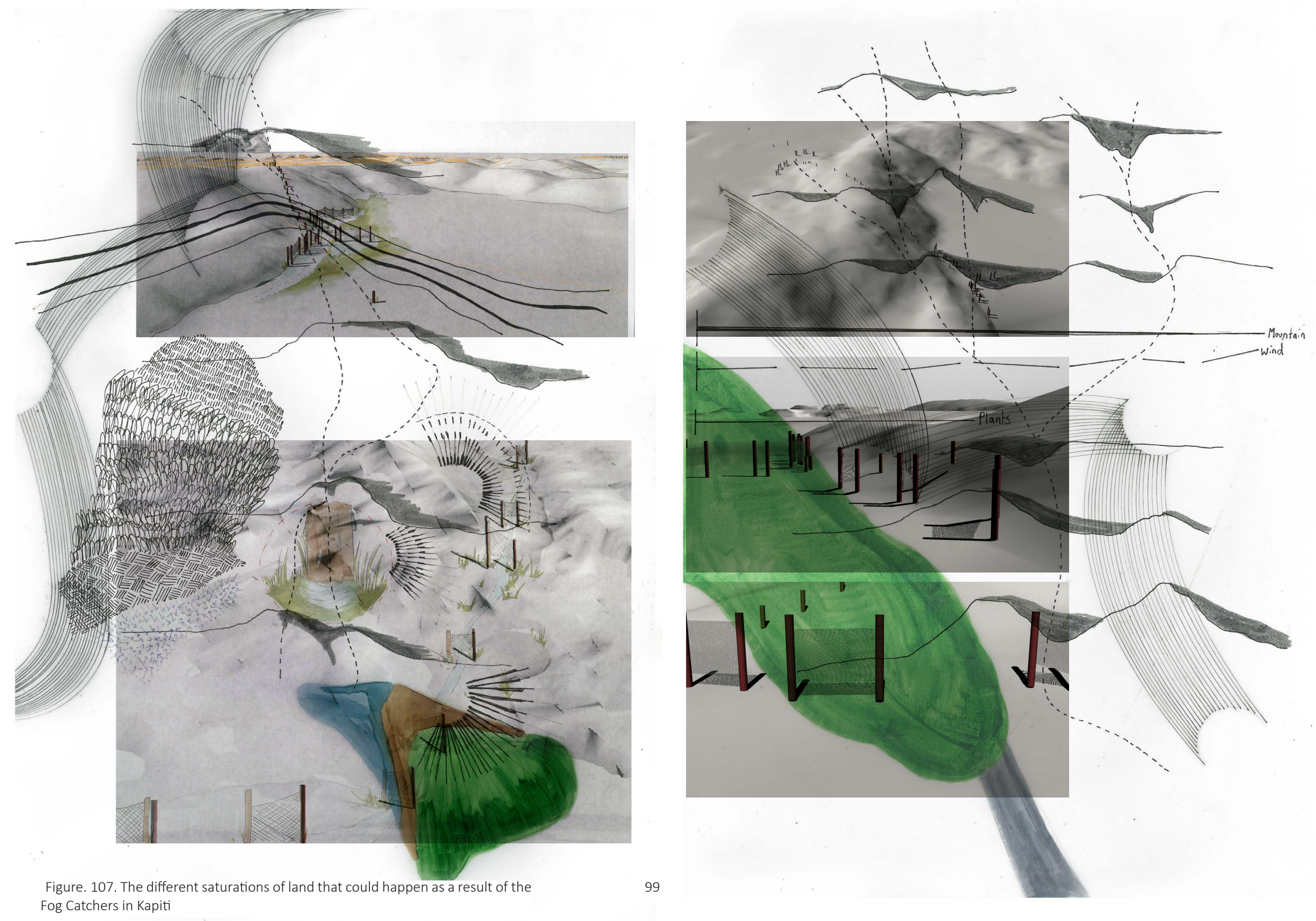




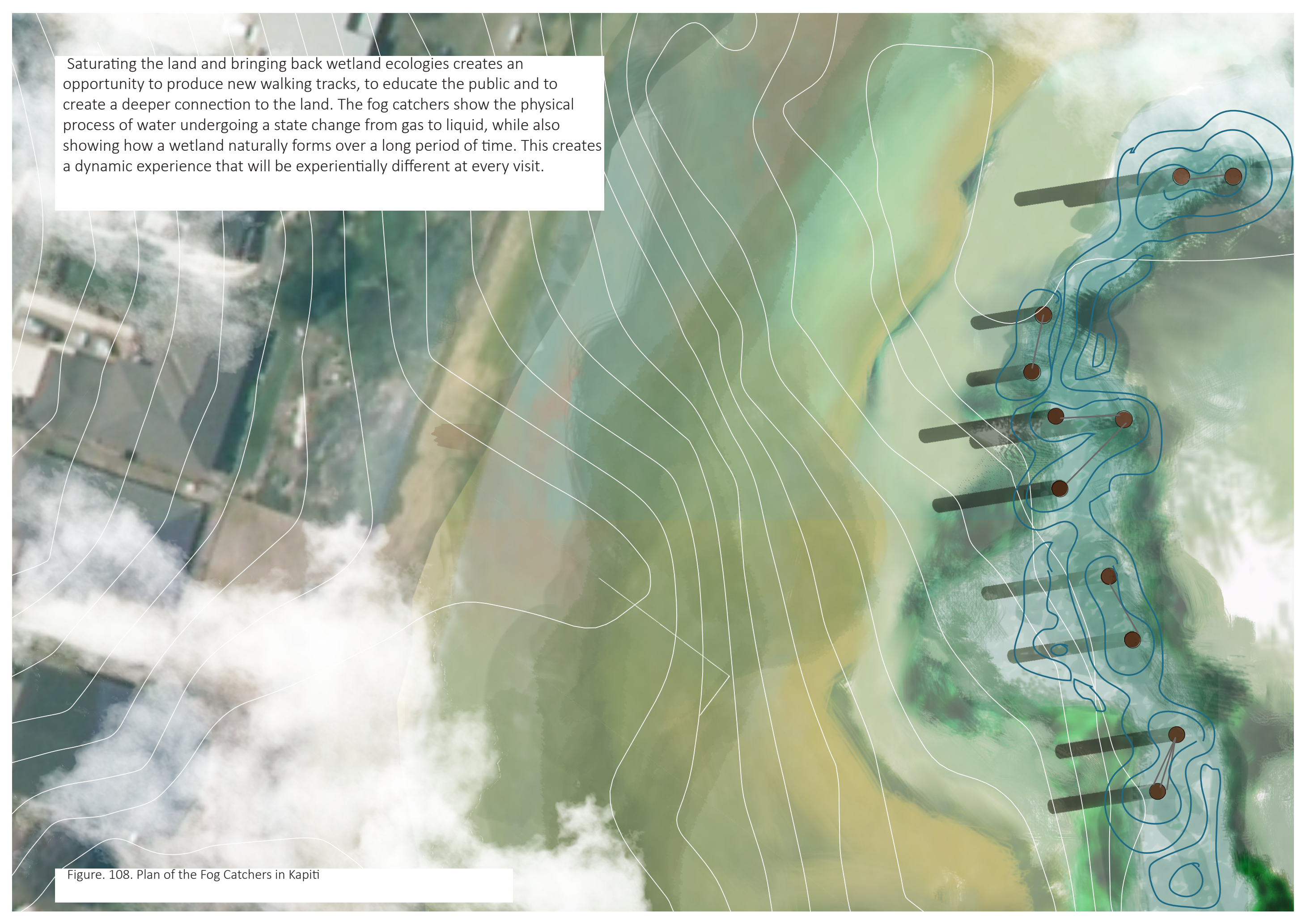




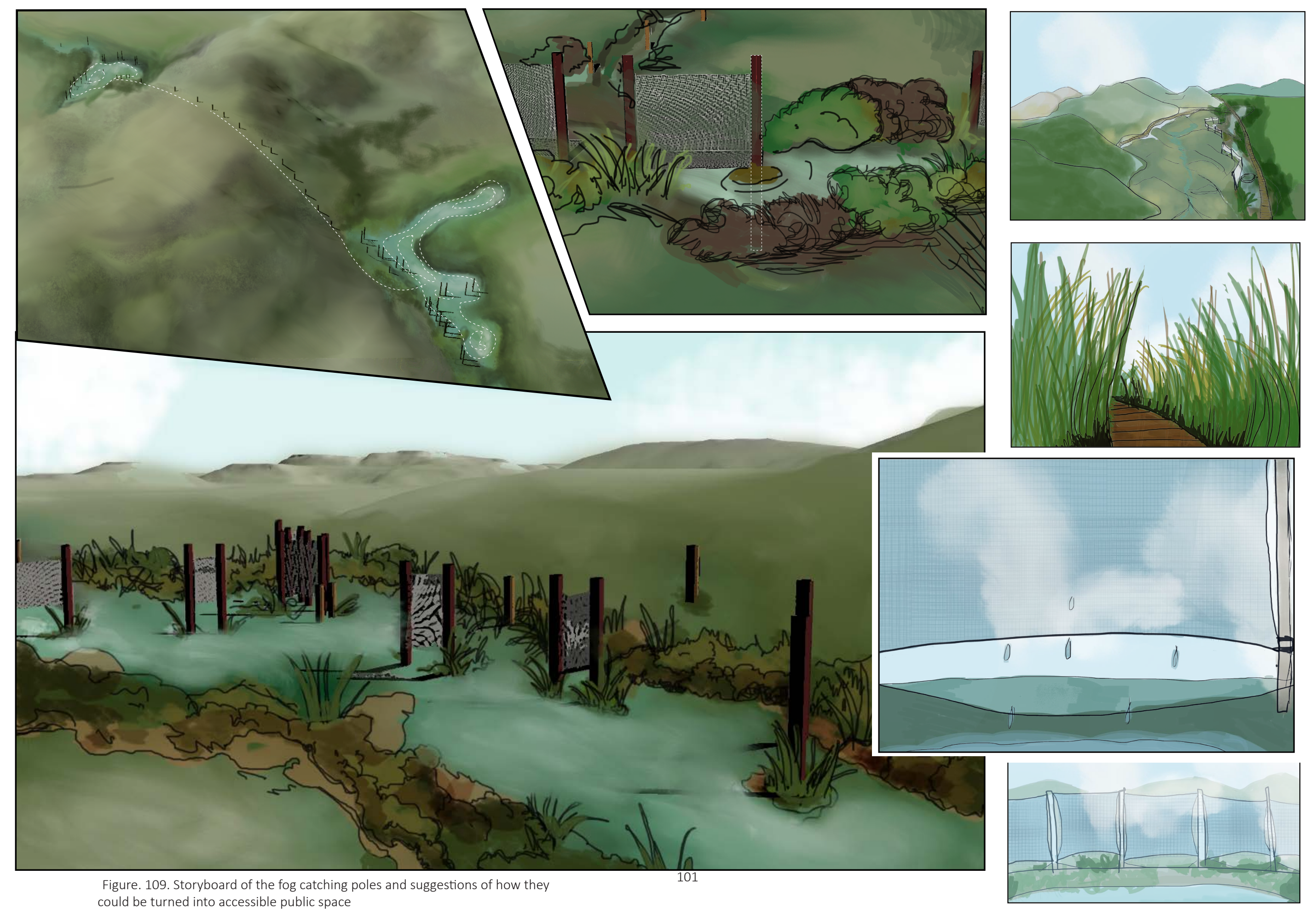




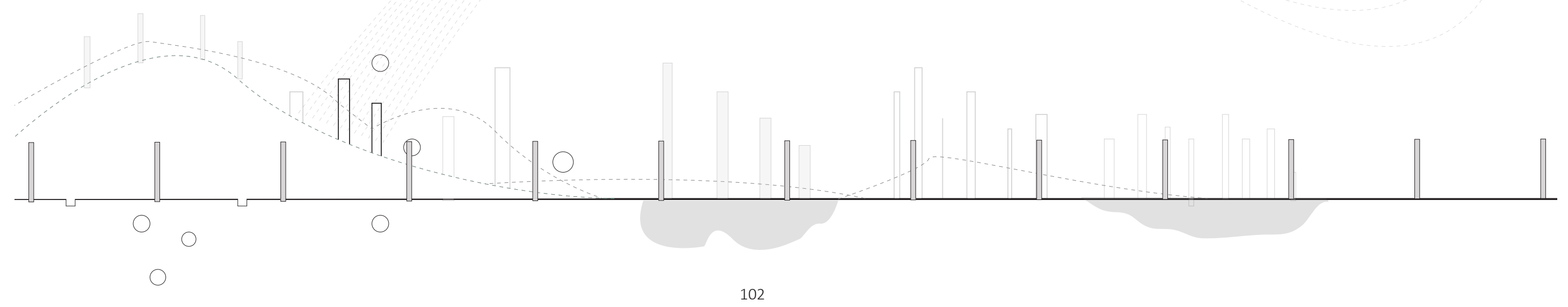




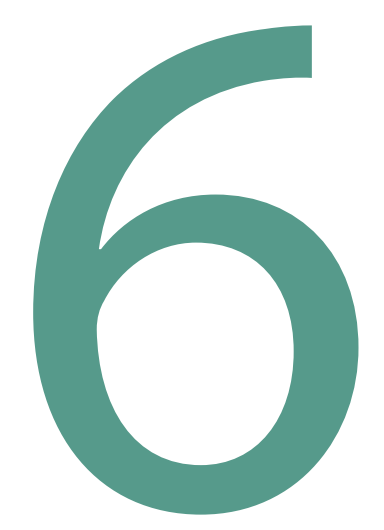

Discussion 


\section{Linking Science and Art}

The theoretical context chapter of this thesis examines how one is able to link science and art. From the early stages of this design research there was a lot of focus on interventions and exploring the concept of Poiesis, but it took a lot of time for these ideas to take root in the realm of design. Until the scientific data behind the different systems became apparent and I was able to translate the data into visual qualities, it was difficult to solidify the design concepts. The strategies behind the sand dune interventions only became realised as more information about the sediment migration from the Manawatu and how it affected the coastal edge of Kapiti, came to light.
The more data I uncovered the more complex the systems appeared, but at the same time, this complexity of knowledge allowed me to pare back the design concepts more precisely, as the connection between science and art began painting a picture of where the systems are currently failing. Grounding poetic ideas in science became the necessary link between the theoretical side of this thesis and the physical constraints of applying these ideas to a real site. This research has become an exploration into finding the balance between uncovering the complexities brought out by layering scientific evidence into an artistic form and producing simple strategies for revealing the complexities at a human scale.
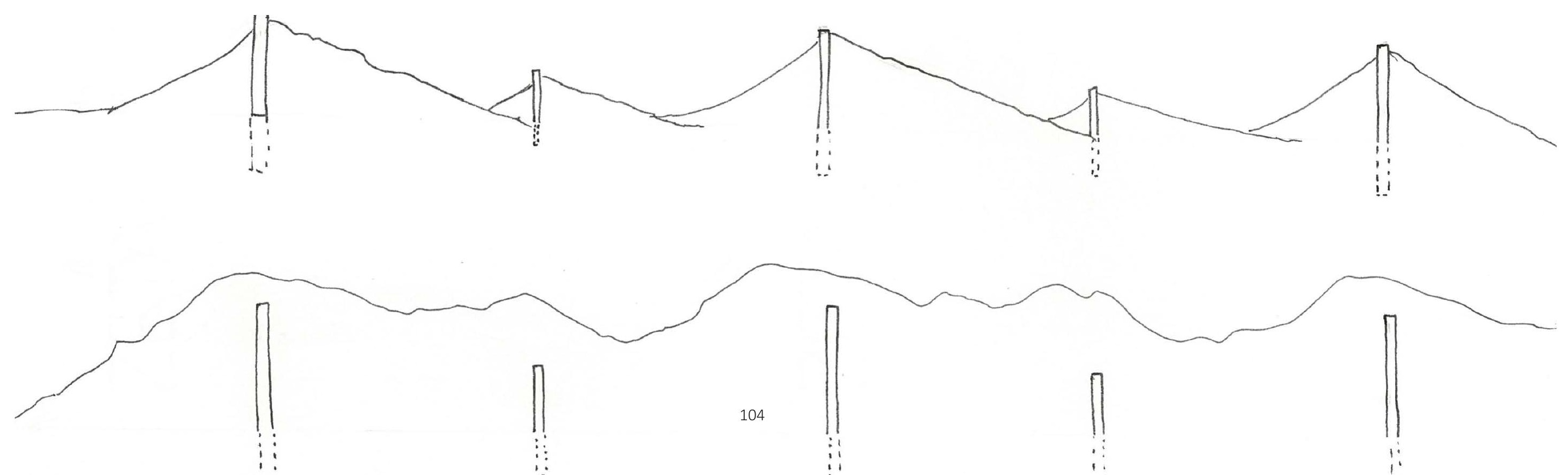


\section{The notion of Site}

The parameters of the site for this research have changed and developed numerous times throughout this thesis. This has been the result of learning more about the ecological systems being examined. Systems aren't simply closed loops that you can draw and box around, they are interconnected and weave into other systems. Because of this, the site parameters kept shifting to include other elements. For example, the early site scope focussed on the sand dunes of Queen Elizabeth Park and Raumati South, but the more my understanding on how dunes function in the landscape expanded the more began to understand their links to swamp and wetland, and how one affects the other due to ground water absorption and tidal change.
The first aim of this research was to engage with design techniques to reveal the large-scale systems operating in coastal landscapes so they were legible at the human scale. As I began to explore these patterns in detail it became clear that having a defined parameter from the beginning of the design limits what systems you can engage with in any meaningful manner. The approach to defining site explored in this thesis also has its limitations. Designing on behalf of a client usually involves dealing with defined site boundaries. One way to deal with this circumstance is to ensure your design won't interfere negatively with systems beyond those boundaries while at the same time encouraging an outreaching design that over time will extend your defined parameters.
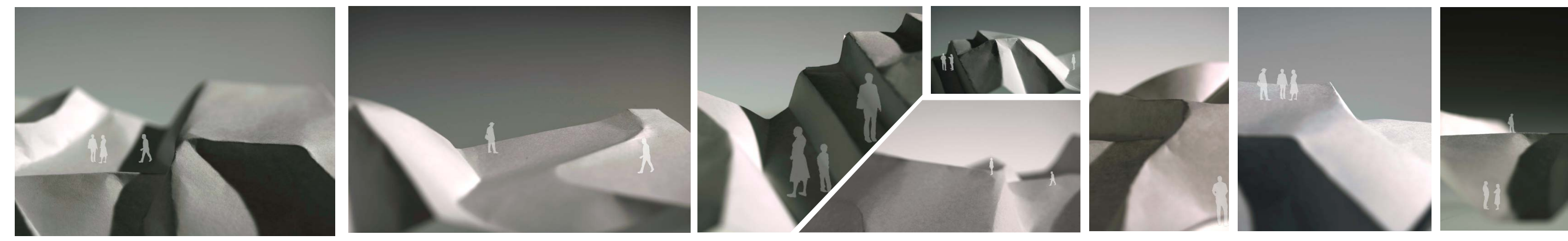


\section{Reading the Landscape}

This thesis has taught me that without fully understanding how ecological systems function and perform you cannot design anything that will enhance or sustain those ecosystems. In order to design spaces that evolve in the future it is important to look back in time at how the systems have already evolved. This was difficult in Kapiti as there are very few precolonial records of the landform. What information I could find, namely about the migration of the dunes, has afforded me the ability to estimate how the dunes will continue to transform if I intervene with a design. The first aim explored in this document was to engage with design techniques to reveal the large scale systems operating in coastal landscapes so they are legible at the human scale.
Through exploring these systems, I was able to minimise the size and intensity of the proposed interventions and still potentially produce a large reaction. Manipulating the land drastically with small moves meant that I could generate complexity that was still legible. Reducing the structures down to different variations of poles meant the movement and change in ecological systems would become more visible, the second objective in this thesis.

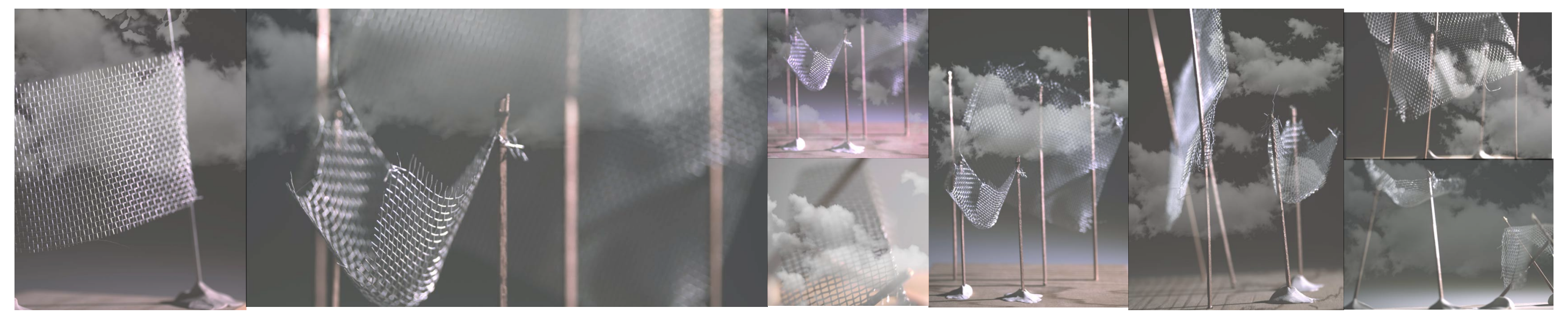




\section{Design Techniques}

This research has produced a set of techniques that facilitate reading and working with large scale landscape systems. Layering offers the ability to represent a multitude of natural landscape occurrences in the same image, while also generating design concepts.

This was achieved through a study of the work of Halprin and Wolesley and then applied in a more design led approach.
The limitation of this technique is that sometimes it needs some sort of legend to ensure it can be interpreted by the reader,. but the technique was useful because it helped reduce the enormity of a design into a more legible notation without taking away the sense of complexity.

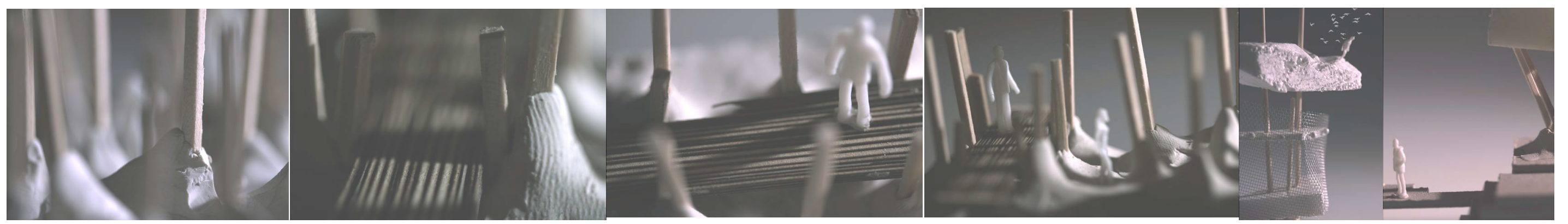




\section{Further Research}

If this research was able to extend further beyond the scope explored in this document, it would be interesting to view how these techniques could work in different regions with different ecologies. Applying these techniques to a more urban environment, such as Wellington CBD could allow one to evaluate how these interventional techniques work in an urban environment with a denser population. Wellington City is coastal, with architectural values that dictate facing into the harbour and design right up the water's edge. Like Kapiti,

Wellington was once wet and marsh land, but much of this has been reclaimed for urban development.
Kapiti and Wellington City share many topographical similarities, they are communities situated between mountains and ocean and share the same culture and industry. Applying technology such as fog catchers or the bird perches (between the mainland and Matu Somes Island sanctuary in the harbour) to Wellington City could have similar effects on the robustness of the landscape and public spaces.

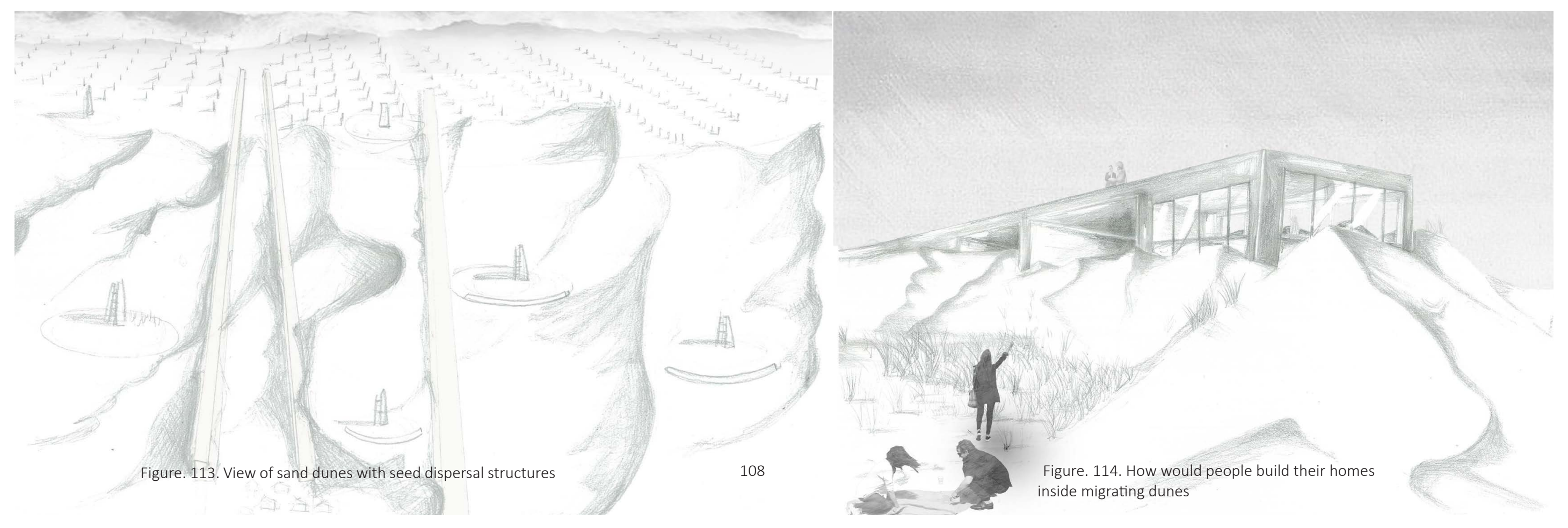





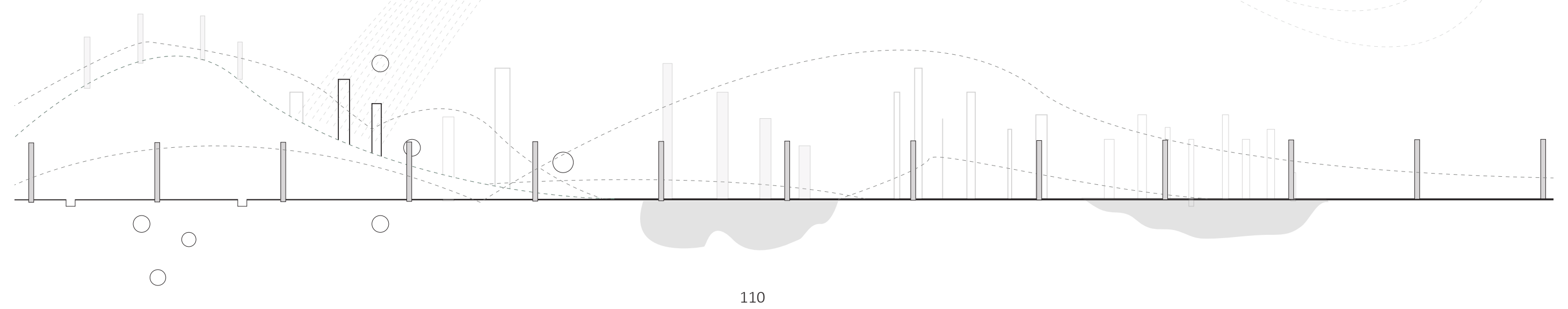



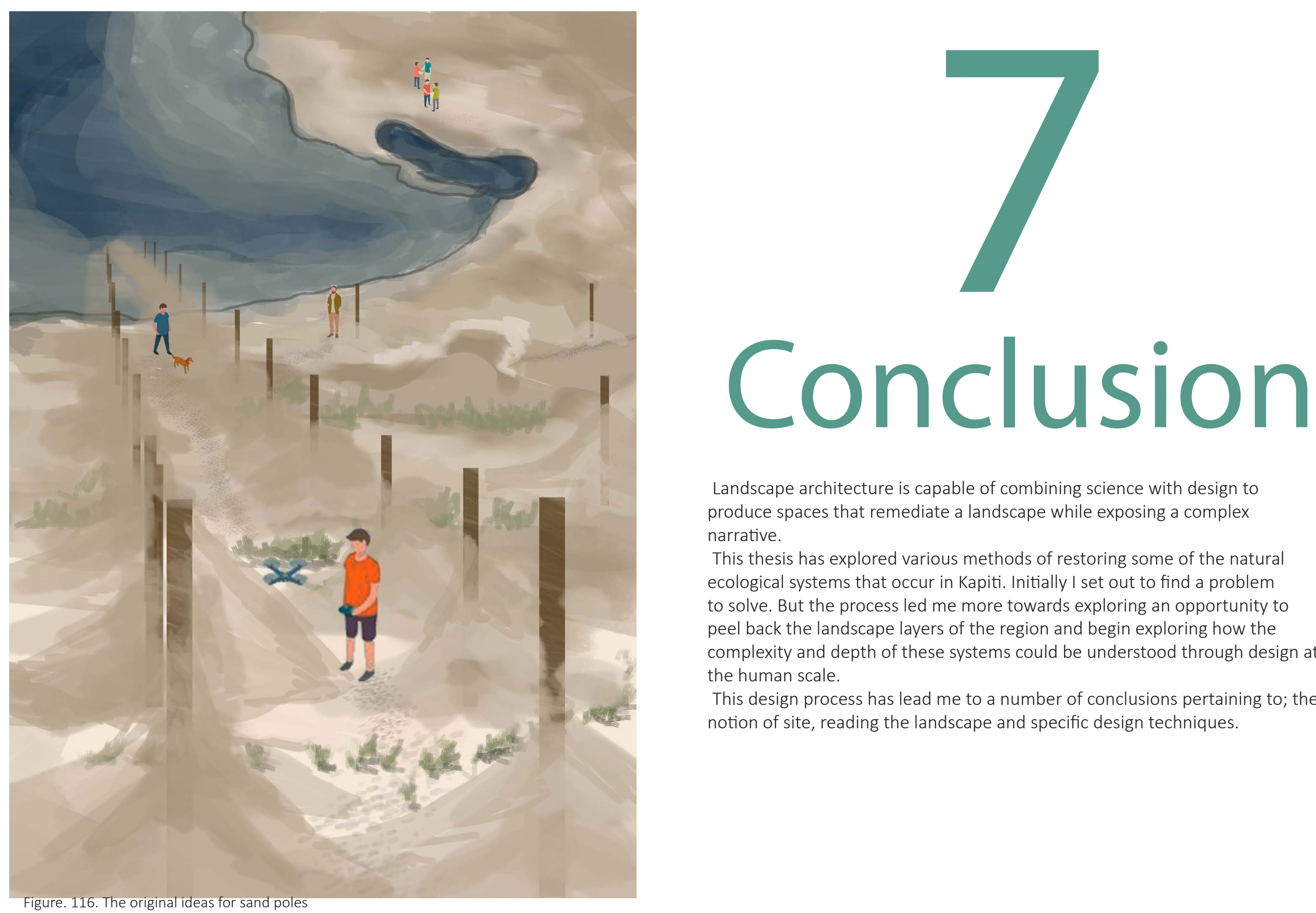

Landscape architecture is capable of combining science with design to produce spaces that remediate a landscape while exposing a complex narrative.

This thesis has explored various methods of restoring some of the natural ecological systems that occur in Kapiti. Initially I set out to find a problem to solve. But the process led me more towards exploring an opportunity to peel back the landscape layers of the region and begin exploring how the complexity and depth of these systems could be understood through design at the human scale.

This design process has lead me to a number of conclusions pertaining to; the notion of site, reading the landscape and specific design techniques. 


\section{References}

Alicia Quezada, Jeremy Haggar, Juan Torres, Rebecca Clements. Fog Harvesting. 18112016. <http://www.climatetechwiki.org/content/fog-harvesting>.

Architects, LOLA Landscape. Lost Landscapes. Rotterdam: nai10 publishers, 2013.

Archives, National. A National Archives. 1 January 2011. Web Page. 29 July 2015.

BALABAN, ODED. "Praxis and Poesis in Aristotle's practical philosophy." The Journal of Value Inquiry (1990): 185- 188

Bruno, Giuliana. Public Intimacy: Architecture and the Visual Arts. Massachusetts: MIT press, 2007. Book.

Cavalier, Robert,. The Nature of Eros. Pittsburgh: Carnegie Mellon University, n.d.

Cockayne, Leonard. Report on the Dunes areas of new zealand: The Geology and Botany with their economic bearing. Wellington : Department of Lands, 1909. Document.

Coren, Michael J. "This Dutch "Sand Engine" Uses Nature's Destructive Power To Protect From Flooding." Fastcoexist (2013).

Corner, James. "Drawings and Making in the Landscape Medium." Word and Image (1992): 161 192. Document.

Council, Wellington City. Plans policies and bylaws. n.d. 17122015.

Dee, Catherine. I argue that although cemeteries do have the tendency to evoke a sense of envelopment and aimlessness it is done so through having an external sole purpose which drives people to these sensations, and that is reflection upon death. To me the sense of aiml. Sheffield: Taylor \& Francis, 2004

Dewhurst, Winston. How can existing geomorphological processes form a symbiotic relationship with urban development? Wellington: Victoria University of Wellington, 2015. Thesis.

Frits Palmboom, Jaap van den Bout, Jeroen Ruitenbeek, Aaron Betsky,. Drawing the Ground Landscape Urbanism Today. Basel: Birkhauser GmbH, 2010.
Grishin, Sasha. John Wolseley Landmarks III. Melbourne: Thames \& Hudson Australia Pty Ltd 2015.

Hall, Michelle. Field of Intimacy: Explorations of interiority within the landscape. Thesis. Wellington: Victoria University of Wellington, 2014. Electronic.

Halprin, Lawrence. Lawrence Halprin Notebooks 1959- 1971. Camebridge,

Massachusettes, and London, England: The MIT Press, 1972.

Hill, Kristina. "The New Age of Coasts : A design Typology." TOPOS : Coastal Strategies 2014: 16 $-21$

Holland, I.D. "Processes of Coastal Change Manawatu- Horowhenua." 1985.

Jandirk Hoekstra, Inge Kersten. "The Future of the Dutch Coast." Topos 10 July 2014: 22- 23.

Kearton, Nicola. "Travels in the Contemporary Mindscape." Art \& The Garden Jan 1997.

Keith Ansell Pearson, John Ó Maoilearca. Henri Bergson: Key Writings. London, 2002

Kuma, Kengo. Anti-Object. Belgium: AA Publications, 2010

Lange, Willem de. Kapiti Coast Coastal Hazard Assessment. Waikato: The University of Waikato 2012.

Marcel Stive, Matthieu de Schipper, Arjen Luijendijk, Roshanka Ranasinghe, Jaap van Thiel de Vries. The Sand Engine : A solution for vulnerable Deltas in the 21st Century? Delft: Delft University of Technology, 2013

MoCA, Mass. Badlands: New Horizons in Landscape. massachusetts: MIT Press, 2008. book.

O'Connell, Jim. Coastal Dune Protection \& Restoration. Barnstable Massachusetts: Woods Hole Sea Grant \& Cape Cod Cooperative Extension, 2008 
Obrist, Hans Ulrich. Ways of Curating. England: Penguin Group, 2014.

Office, LOLA Landscape Architects. Lost Landscapes. Rotterdam: nai010 Publishers, 2013.

Peter Johnson, Philippe Gerbeaux. Wetland Types in New Zealand. Wellington: Department of Conservation, Te Papa Atawhai, 2004. Document.

Potteiger, Matthew and Jamie Purinton. "Landscape Narratives." Swaffield, Simon. Theory in Landscape Architecture. University of Pennsylvania, 2002. 136- 144.

Prudence, Paul. DatalsNature. 12 July 2012. Blog. 30 August 2016.

Pruszak, Zbigniew. Groynes. 1811 2016. < http://www.coastalwiki.org/wiki/Groynes>.

Schmidt, Rainer. Living with water. Rainer Schmidt Landscape Architects and City Planners. RAINER SCHMIDT LANDSCHAFTSARCHITEKTEN. Guangzhou, n.d.

Souza, Eduardo. AD Classics: Igualada Cemetery / Enric Miralles + Carme Pinos. 19 May 2013.

<http://www.archdaily.com/375034/ad-classics-igualada-cemetery-enric-miralles-carme-pinos>

Steven Adams, Anna Gruetzner Robins. Gendering Landscape Art. New Jersey: Rutgers University Press, 2001. book.

Valkenburgh, Michael Van. Emotional Landscapes: Interview with Landscape Architect Michael Van Valkenburgh Gideon Fink Shapiro. 31 January 2012. Video.

Wilson, Penny. The Internationale. 2009. web page. 1 august 2015.

Wolsley, John. John Wolsley. 2016. 30 August 2016.

Wong, Bill. Fog Catchers Harvest Air's Water in Arid Places. 1504 2011. <http://poleshift.ning. $\mathrm{com} /$ profiles/blogs/photos-fog-catchers-harvest>.

Yukhnevich, Melanya. Ephemeral Dune Slacks; How do their Environmental Relations Structure their Patterning. Thesis. Palmaston North: Massey University, 2015. Document.
Zumthor, Peter. Atmospheres. Basel: Birkhauser, 2006

-. Peter Zumthor, 1985-2013: Buildings and Projects. 1998-2001, Volume 3. Zürich: Scheidegger \& Spiess, 2014

—. Thinking Architecture. Baden: Birkhauser, 2006. book. 


\section{Image Index}

All figures not attributed are author's own

Figure 23. Zumthor, Peter. Poetic Landscapes.Buildings and Projects. 1998-2001, Volume 3. Zürich: Scheidegger \& Spiess, 2014.

Figure 30. Photographer unknown. Raumati South Dune Formations. 2012.Lange, Willem de. Kapiti Coast Coastal Hazard Assessment. Waikato: The University of Waikato. Pg. 7. Print

Figure 31. (base image). - Gibb. Proposed Sediment Transport Pathways for the Southern Section of the Kapiti Coast.2012. Lange, Willem de. Kapiti Coast Coastal Hazard Assessment. Waikato: The University of Waikato. Pg. 7. Print

Figure 33. Marcel Stive. The movement of sand from when Zandmotor was implemented to the following year. 2013. Delft: Delft University of Technology. The Sand Engine : A solution for vulnerable Deltas in the 21st Century?. Marcel Stive, Matthieu de Schipper, Arjen Luijendijk, Roshanka Ranasinghe, Jaap van Thiel de Vries. 2013. Print

Figure 38. Alicia Quezada, Jeremy Haggar, Juan Torres, Rebecca Clements. Fog Catcher. Fog Harvesting. 1811 2016. <http://www.climatetechwiki.org/content/fog-harvesting>.

Figure 39. Motation Drawing. Halprin, Lawrence. Prudence, Paul. DatalsNature. 12 July 2012. Blog. 30 August 2016. <http://www. dataisnature.com/?p=1583>

Figure 40. Halprin, Lawrence. Motation Drawings. Lawrence Halprin Notebooks 1959- 1971. Camebridge, Massachusettes, and London, England: The MIT Press, 1972.

Figure 41. Woleseley, John. Cycles of Fire and Water- Lake Tyrrell, Victoria. 2011-2012. John Wolsley. 2016. 30 August 2016. Print

Figure 44. Pruszak, Zbigniew. Various Groyne Shapes. 'Groynes'. 1811 2016. <http://www. coastalwiki.org/wiki/Groynes>.
Figure 99. Images of Birds and Plants

Birds

Castro, I. 2013. Stitchbird. In Miskelly, C.M. (ed.) New Zealand Birds Online. www.nzbirdsonline. org.nz

Robertson, H.A. 2013. Tui. In Miskelly, C.M. (ed.) New Zealand Birds Online. www.nzbirdsonline. org.nz

Powlesland, R.G. 2013. New Zealand tomtit. In Miskelly, C.M. (ed.) New Zealand Birds Online. www.nzbirdsonline.org.nz

Powlesland, R.G. 2013. North Island robin. In Miskelly, C.M. (ed.) New Zealand Birds Online. www.nzbirdsonline.org.nz

Powlesland, R.G. 2013. New Zealand pigeon. In Miskelly, C.M. (ed.) New Zealand Birds Online. www.nzbirdsonline.org.nz

Moorhouse, R.J. 2013. Kaka. In Miskelly, C.M. (ed.) New Zealand Birds Online. www. nzbirdsonline.org.nz

Horowhenua Historical Society Inc, 2007. Viewed from Coastlands carpark. Council Office / Library (left). created H.E.P.B. Office at Paraparaumu. http://horowhenua.kete.net.nz 
Plants

Nancy Swarbrick, 'Flax and flax working- New Zealand flax', Te Ara- the Encyclopedia of New Zealand, http://www.TeAra.govt.nz/en/photograph/10377/new-zealand-flax-species (accessed 23 November 2016

Joanna Orwin, 'Shrubs and small trees of the forest- Kowhai and kaka beak', Te Ara- the Encyclopedia of New Zealand, http://www.TeAra.govt.nz/en/shrubs-and-small-trees-of-theforest/page-9 (accessed 23 November 2016)

Peter Johnson, 'Wetlands- Wetland forests and shrubs', Te Ara- the Encyclopedia of New Zealand, http://www.TeAra.govt.nz/en/photograph/14342/mingimingi-berries (accessed 23 November 2016)

Maggy Wassilieff, 'Tall broadleaf trees- Trees of fertile lowlands', Te Ara- the Encyclopedia of New Zealand, http://www.TeAra.govt.nz/en/tall-broadleaf-trees/page-4 (accessed 23 November 2016

Joanna Orwin, 'Shrubs and small trees of the forest- Broadleaf colonisers', Te Ara- the Encyclopedia of New Zealand, http://www.TeAra.govt.nz/en/photograph/13807/kotukutukutree-fuchsia (accessed 23 November 2016 )

Maggy Wassilieff, 'Tall broadleaf trees- Tree rata', Te Ara- the Encyclopedia of New Zealand, http://www.TeAra.govt.nz/en/photograph/13711/northern-rata-recovery (accessed 23 November 2016)

Maggy Wassilieff, 'Coastal shoreline- Sand dunes', Te Ara- the Encyclopedia of New Zealand, http://www.TeAra.govt.nz/en/coastal-shoreline/page-5 (accessed 23 November 2016)

Peter Johnson, 'Wetlands- Reeds, rushes, sedges and low growers', Te Ara- the Encyclopedia of New Zealand, http://www.TeAra.govt.nz/en/wetlands/page-4 (accessed 23 November 2016) 